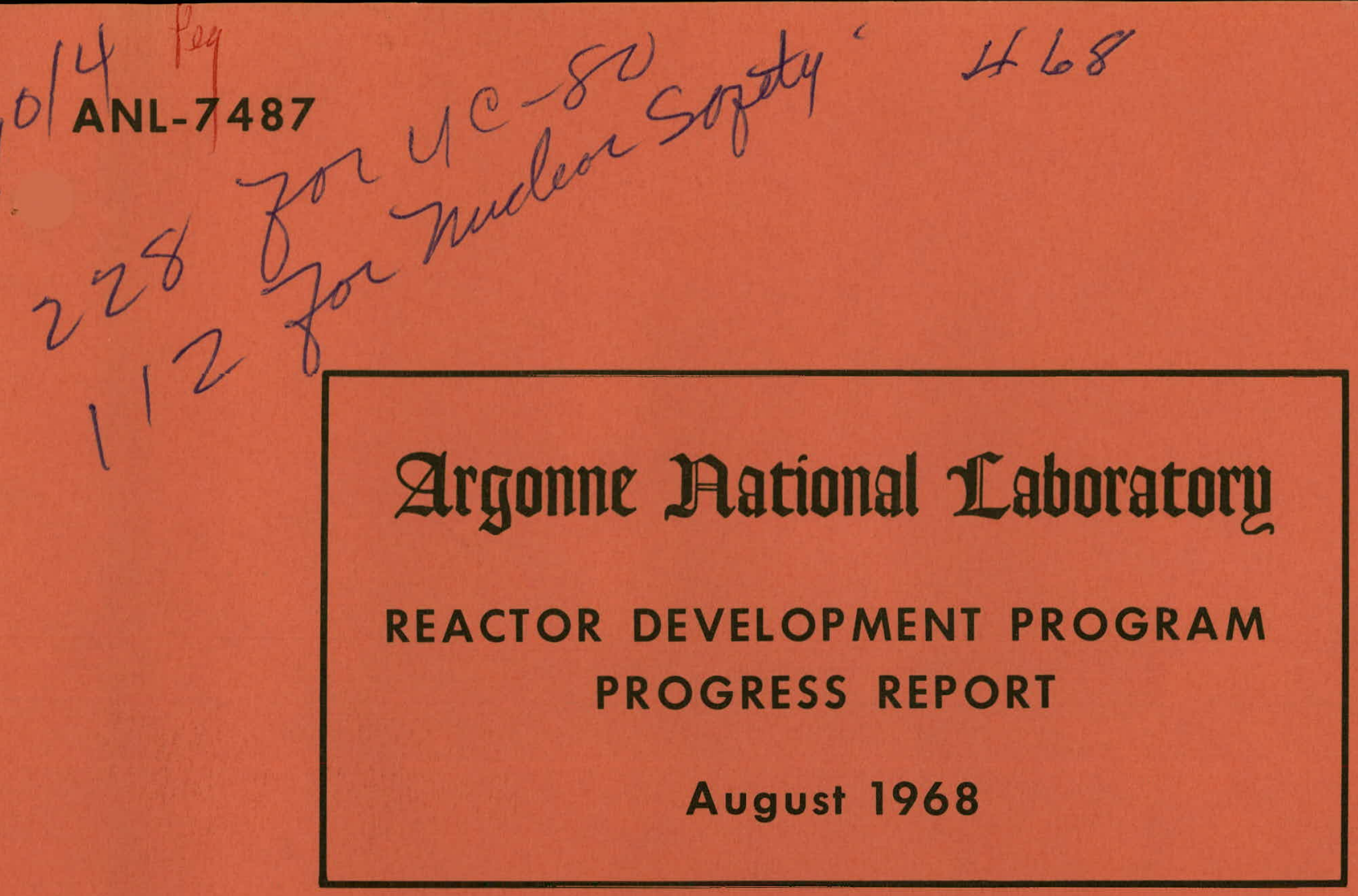

ANL-7487 


\section{DISCLAIMER}

This report was prepared as an account of work sponsored by an agency of the United States Government. Neither the United States Government nor any agency Thereof, nor any of their employees, makes any warranty, express or implied, or assumes any legal liability or responsibility for the accuracy, completeness, or usefulness of any information, apparatus, product, or process disclosed, or represents that its use would not infringe privately owned rights. Reference herein to any specific commercial product, process, or service by trade name, trademark, manufacturer, or otherwise does not necessarily constitute or imply its endorsement, recommendation, or favoring by the United States Government or any agency thereof. The views and opinions of authors expressed herein do not necessarily state or reflect those of the United States Government or any agency thereof. 


\section{DISCLAIMER}

Portions of this document may be illegible in electronic image products. Images are produced from the best available original document. 
The facilities of Argonne National Laboratory are owned by the United States Government. Under the terms of a contract (W-31-109-Eng-38) between the U. S. Atomic Energy Commission, Argonne Universities Association and The University of Chicago, the University employs the staff and operates the Laboratory in accordance with policies and programs formulated, approved and reviewed by the Association.

\section{MEMBERS OF ARGONNE UNIVERSITIES ASSOCIATION}

The University of Arizona

Carnegie-Mellon Univer sity

Case Western Reserve University

The University of Chicago

University of Cincinnati

Illinois Institute of Technology

University of Illinois

Indiana University

Iowa State University

The University of Iowa
Kansas State University

The University of Kansas

Loyola University

Marquette University

Michigan State University

The University of Michigan

University of Minnesota

University of Missouri

Northwestern University

University of Notre Dame
The Ohio State University

Ohio University

The Pennsylvania State University

Purdue University

Saint Louis University

Southern Illinois University

University of Texas

Washington University

Wayne State University

The University of Wisconsin

\section{LEGAL NOTICE}

This report was prepared as an account of Government sponsored work. Neither the United States, nor the Commission, nor any person acting on behalf of the Commission:

A. Makes any warranty or representation, expressed or implied, with respect to the accuracy, completeness, or usefulness of the information contained in this report, or that the use of any information, apparatus, method, or process disclosed in this report may not infringe privately owned rights; or

B. Assumes any liabilities with respect to the use of, or for damages resulting from the use of any information, apparatus, method, or process disclosed in this report.

As used in the above, "person acting on behalf of the Commission" includes any employee or contractor of the Commission, or employee of such contractor, to the extent that such employee or contractor of the Commission, or employee of such contractor prepares, disseminates, or provides access to, any information pursuant to his employment or contract with the Commission, or his employment with such contractor.

Printed in the United States of America Available from

Clearinghouse for Federal Scientific and Technical Information National Bureau of Standards, U. S. Department of Commerce Springfield, Virginia 22151

Price: Printed Copy $\$ 3.00 ;$ Microfiche $\$ 0.65$ 


\section{LEGAL NUIICL}

This report was,prepared as an account of Government sponsored work. Neither the United the Commission:

A. Makes any warranty or representation, expressed or implied, with respect to the accuA. Mmpleteness, or usefulness of the information contained in this report, or that the use racy. privately ouned rights: or

a do or or famages resulting from the B. Assumes any liabilitles with respect to the use ol, or for dased in this report.

use of any information, apparatus, method, or process dise commission" includes any emAs used in the above. "person acting on behalf of the Commissactor, to the extent that ployee or contractor of the Commission, or employe of ployee of such contractor prepares, such employee or contractor of the Commisslon, of enploct disseminates, or provides access to, any information pursuant

with the Commission, or his employment with such contractor.

AN L- 7487

Reactor Technology

(TID-4500)

AEC Research and

Development Report

\section{ARGONNE NATIONAL LABORATORY 9700 South Cass Avenue}

Argonne, Illinois 60439

\section{REACTOR DEVELOPMENT PROGRAM PROGRESS REPORT}

August 1968

Robert B. Duffield, Laboratory Director Stephen Lawroski, Associate Laboratory Director

Division

\section{Chemical Engineering}

Idaho

Metallurgy

Reactor Engineering

Reactor Physics

Remote Control
Director

R. C. Vogel

M. Novick:

M. V. Nevitt

L. J . Ko.ch

$R$. Avery

D. P. Mingesz (Acting)

Report Coordinated by

L. B. Fosdick and A. Glassner

Is sued September 26, 1968 


\section{FOREWORD}

The Reactor Development Program Progress Report, issued monthly, is intended to be a means of reporting those items of significant technical progress. which have occurred in both the specific reactor projects and the general engineering research and development programs. The report is organized in accordance with budget activities in a way which, it is hoped, gives the clearest, most logical overall view of progress. Since the intent is to report only items of significant progress, not all activities are reported each month. In order to is sue this report as soon as possible after the end of the month editorial work must necessarily be limited. Also, since this is an: informal progress report, the results and data presented should be understood to be preliminary and subject to change unless otherwise stated.

The issuance of these reports is not intended to constitute publication in any sense of the word. Final results either will be submitted for publication in regular professional journals or will be published in the form of ANL topical reports.

The last six reports is sued in this series are:

February 1968

March 1968

April 1968

May 1968

June 1968

July 1.968
AN L- 7427

ANL- 7438

ANL- 7445

ANL- 7457

ANL- 7460

ANL- 7478 


\title{
REACTOR DEVELOPMENT PROGRAM
}

\author{
Highlights of Project Activities for August 1968
}

$\underline{\text { EBR-II }}$

The reactor was operated. for $940 \mathrm{MWdt}$ in Runs $29 \mathrm{D}$ and $30 \mathrm{~A}$ in August. Loading changes for Run 30A included the installation of two 91-element subassemblies of 70\% enriched fuel. After the start of Run 30A, approval was received from the AEC for 50-MWt operation, and reactor power was raised to that level on August 26. Operation continues at $50 \mathrm{MWt}$ with all systems functioning satisfactorily. The cumulated total of EBR-II operation is $19,528 \mathrm{MWdt}$.

In the FCF hot line, the cause of high silicon concentrations in injection-casting batches in July has not been defined, but temporary procedural changes have been made. Recent batches have not shown high silicon levels.

The following surveillance results were obtained: (a) $70 \%$ enriched fuel elements which had received maximum burnups of 0.55 to $0.58 \mathrm{a} / \mathrm{o}$ were found to have swelled slightly more than the past average for $52 \%$ enriched fuel with similar burnups but lower centerline temperatures; (b) an "extended burnup" subassembly of Mark-IA fuel showed an encouragingly small amount of swelling--5.2\% average and $6.3 \%$ maximum--after a calculated burnup of $1.31 \mathrm{a} / \mathrm{o}$.

ZPR-3

Experiments were concluded with Assembly 52, the second core of the FTR Phase-B critical program. The reactor was then reloaded for basic physics studies with Assembly 53. This assembly is a plutonium-graphite system with a U-Pu ratio of 1.6 and a depleted-uranium blanket.

ZPPR

The filtration efficiency of the gravel-sand roof of ZPPR was tested satisfactorily. The minimum attenuation factor at the test velocity of $1 \mathrm{ft} / \mathrm{min}$ was $1.4 \times 10^{6}$, compared to a design attenuation factor of $5 \times 10^{4}$.

The loading of ZPPR Assembly I was initiated with loading of nonfuel materials and depleted uranium; loading of fuel must await AEC approval. Assembly I has a calculated core volume of 1400 liters. (which corresponds to a critical mass of $850 \mathrm{~kg}$ of ${ }^{239} \mathrm{Pu}$ plus ${ }^{241} \mathrm{Pu}$ ) and is thus of approximately Demonstration Plant size. 


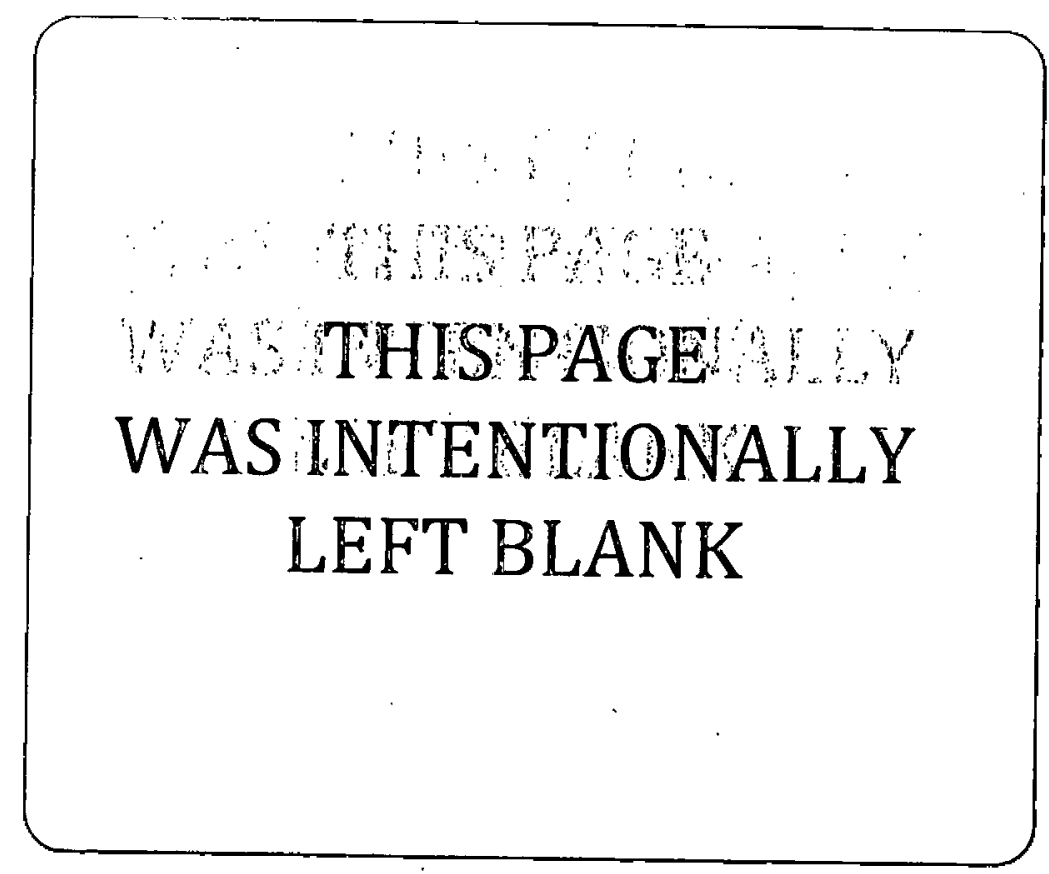


TABLE OF CONTENTS

Page

I. LIQUID METAL FAST BREEDER REACTORS--CIVILIAN I

A. Fuel Development--LMFBR । . . . . 1

1. Metallic 1

2. Oxide $\quad \therefore \quad \cdot 1$

3. Carbide 3

B. Physics Development--LMFBR 4

1. Theoretical Reactor Physics 4

2. Experimental Reactor Physics : 6

3. ZPR-3 Operations and Analysis 13

4. ZPPR Operations and Analysis . . . 26

5. ZPPR Construction 28

C. Component Development--LMFBR 30

1. Sodium Technology Development 30

2. Reactor Mechanism and Instrumentation 31

3. Fuel Handling, Vessels, and Internals--Core
Component. Test Loop

D. Systems and Plant--LMFBR . 35

1. 1000-MWe Plant " . 35

E. EBR-II 38

1. Research and Development 38

a.. EBR-II System Design Descriptions $\quad 38$

b. Reactor Experimental Support--Reactor Analysis. and Testing 38

c. Nuclear Analysis Methods Development $\quad 40$

d. Fuel Performance Studies--Mark I Series 43

e. Mark II Driver Fuel Element Development 44

f. Equipment--Fuel Related ' 46

g. New Subassemblies Design and Experimental Support $\quad 50$

h. Instrumented Subassembly 51

i. Process Chemistry $\quad 52$

j. Experimental Irradiation and Testing - 53

k. FCF Process Analysis and Testing 57

1. FCF Equipment Improvement : 57

m. Hot Fuel Examination Equipment 58

n. Superheater and EM Pump Study and Test. 61 
TABLE OF CONTENTS

$\underline{P a g e}$

o. Feaśibility Study of Fuel Failure Detection-Chemical and Mechanical Methods.

p. Materials-Coolant Compatibility

q. Driver Fuel Transient Performance Studies-TREAT Experiments

r. Systems Engineering

2. Operations

a. Reactor Plant

68

b. Fuel Cycle Facility

A. Applied and Reactor Physics Development

1. Theoretical Reactor Physics--Research and Development

2. Nuclear Data--Research and Development . 79

B. Reactor Fuels and Materials Development : : $\quad 79$

1. Fuels and Cladding

2. Engineering Properties of Reactor Materials--Research and Development--High Temperature Mechanical Properties of Ceramic Fuels

C. Engineering Development

1. Research and Development 91

a. Development of Master-Slave Manipulator Systems 91

b. Heat Transfer and Fluid Flow 91

c. Engineering Mechanics: 93

D, Chemistry and Chemical Separations 95

1. Aqueous and Volatility Processes--Research and Development--Fluoride Volatility Process

2. Closed Cycle Processes--Research and Development-Compact Pyrochemical Processes

3. General Chemistry and Chemical Engineering-Research and Development 
A. Reactor Kinetics--Other Reactor Kinetics--Research and Development

1. Coolant Dynamics

1.04

2. Core Structural Safety

105

3. Fuel Meltdown Studies with TREAT

106

4. Materials Behavior and Energy Transfer

108

5. 1000-MWe Safety Studies

109

B. TREAT Operations 109

1. Reactor Operations 109

2. Development of Automatic Power Level Control System 110

C. Chemical Reaction--Research and Development--Chemical and Associated Energy Problems (Thermal)

1. Analysis of Excursion Accidents 


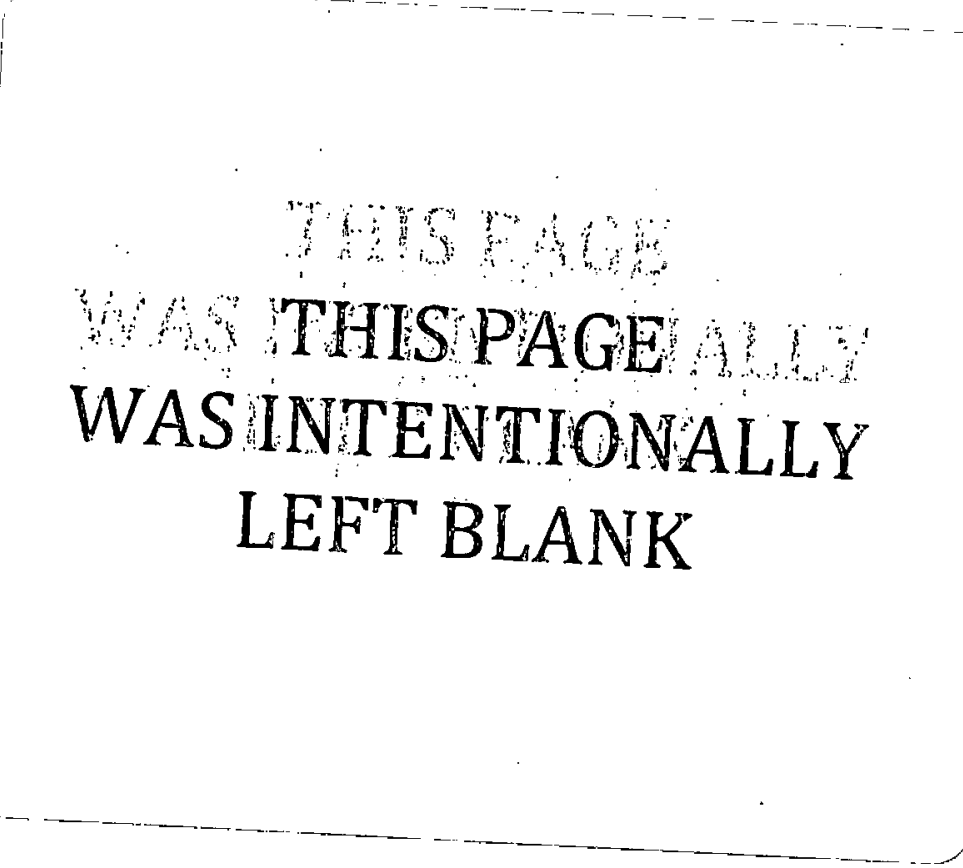

viii 


\section{LIQUIID METAL FAST BREEDER REACTORS--CIVILIAN}

A. Fuel Development--LMFBR

1. Metallic

a. Physical Metallurgy of Metallic Fuel Alloys (D. R. O'Boyle)

Last Reported: ANL-745.7, pp.. 4-5 (May 1968).

Four additional injection-cast melts of high-purity alloys have been made to investigate the effects of temperature, pressure, and impurities on the swelling behavior of U-Pu-base metal fuels: U-l w/o: Pu, $\mathrm{U}-2 \mathrm{w} / \mathrm{oPu}, \mathrm{U}-10 \mathrm{w} / \mathrm{oPu}$, and U-14 w/o Pu-6 w/o Zr. Chemical and spectrographic analyses have been completed on these melts, as well as on the previous four melts of this series (U, U- $5 \mathrm{w} / \mathrm{oPu}, \mathrm{U}-14 \mathrm{w} / \mathrm{o} \mathrm{Pu}$, $\mathrm{U}-14 \cdot \mathrm{w} / \mathrm{o} \mathrm{Pu}-12 \cdot \mathrm{w} / \mathrm{o} \mathrm{Zr}$ ). The principal impurities detected in most of the melts were $\mathrm{C}(85$ to $220 \mathrm{ppm}), \mathrm{O}(8$ to $87 \mathrm{ppm}), \mathrm{N}$ (8 to $125 \mathrm{ppm})$, and $\mathrm{Si}(<200 \mathrm{ppm}$ ). Since higher levels of oxygen and silicon (up to $680 \mathrm{ppm} \mathrm{Si}$ and $1300 \mathrm{ppm} \mathrm{O}$ ) were found in the two U-Pu- $\mathrm{Zr}$ alloys and the $\mathrm{U}-14 \mathrm{w} / \mathrm{o}$ $\mathrm{Pu}$ alloy, these three melts may be used as part of the 'study to determine the effects of silicon on the irradiation performance of these particular alloys. The higher levels of impurity were probably caused by dissolution of silica that was chipped from the quartz molds used in the injectioncasting process:

Specimens from the U, U-5 w/o Pu, and U-14 w/o Pu- $12 \mathrm{w} / \mathrm{o}$ $\mathrm{Zr}$ alloys have been encapsulated in a constant-pressure capsule (1000 psi) and will be irradiated at $450^{\circ} \mathrm{C}$. Loading of the capsule into the reactor is scheduled for later this month.

2. Oxide

a. Fuel Element Performance (L. A. Neimark, F. L. Brown, and B. J. Koprowski)

Last Reported: ANL-7460, pp. 1-2 (June 1968)。

The examination of the fuel elements in Capsules SOV-3, SOV-7, and HOV-15 from EBR-II Subassembly XOl1 continued. These elements had achieved an estimated burnup of 3.5 to $3.7 \mathrm{a} / \mathrm{o}$ at a linear power rating of $\sim 21.4 \mathrm{~kW} / \mathrm{ft}$. The elements in the capsules designated SOV are clad with Type 304 stainless steel, and the HOV capsules contain elements clad with Hastelloy-X. The capsules were measured for diametral expansion, punctured to assay gases in the plenums, and disassembled to remove the fuel elements. Gamma scans of the three capsules have been completed. 
The diametral measurements of the capsules indicated irregular expansions of $\sim 0.5 \%$ (maximum:0.002 in. in a $0.375-$ in. diameter) in the fueled zone, which may indicate swelling of the Type 304 stainless steel capsule material.

Fission gas found in the plenum of Capsule HOV-15 indicates a cladding failure that was not evident by neutron radiøgraphy nor readily apparent on cursory examination of the fuel element after removal from the capsule. Two other Hastelloy-X-clad elements (HOV-4 and - 10) in this subassembly also failed but in a considerably more drastic manner (see Progress Report for February 1968, ANL-7427, p.2).

The gamma scan of SOV-7 showed small peaks at the top and bottom of the element that may be ruthenium concentrations. The scan of HOV-15 also showed irregularities in the ruthenium energy range in the bottom third of the element. The scan of SOV-3 showed only a regular profile.

Dimensional measurements on the elements are currently being made.

b. Compatibility between Uranium-Plutonium Oxide and Cladding

Not reported previousiy.

Preliminary screening tests were made at $800^{\circ} \mathrm{C}$ for $1000 \mathrm{hr}$ with six vanadium-base alloys to evaluate their relative compatibilities with uranium-plutonium oxide. Three of the alloys tested were developed at ANL: V-20 w/o Ti, V-15 w/o Cr-5 w/o Ti, and V-10 w/o Cr. The compositions of the other three alloys, developed at WARD, are given in Table I.A.l. The oxide pellets, which had an oxygen-to-metal atomic ratio of 1.97 , were prepared from physically mixed $\mathrm{UO}_{2}-\mathrm{PuO}_{2}$ powders and fired in helium- $6 \%$ hydrogen.

TABLE I.A.1. Nominal Composition of Westinghouse Vanadium Alloys

\begin{tabular}{lccc}
\hline Element $:$ & VANSTAR-7 & VANSTAR-8 & VANSTAR-9 \\
\hline $\mathrm{V}$ & 86 & 80 & 87 \\
$\mathrm{Cr}$ & 9 & 8 & - \\
$\mathrm{Fe}$ & 3 & - & 6 \\
$\mathrm{Ta}$ & - & 10 & - \\
$\mathrm{Nb}$ & - & - & 5 \\
$\mathrm{Zr}$ & 1.3 & 1.3 & 1.3 \\
$\mathrm{C}$ & 0.05 & 0.05 & 0.05 \\
\hline
\end{tabular}


Metallographic examination of the compatibility couples indicated no interaction between the $\left(\mathrm{U}_{0.8} \mathrm{Pu}_{0.2}\right) \mathrm{O}_{1.97}$ pellets and the four alloys that do not contain titanium. Both alloys that contained titanium ( $\mathrm{V}-20 \mathrm{w} / \mathrm{O}$ Ti and $\mathrm{V}-15 \mathrm{w} / \mathrm{o} \mathrm{Cr}-5 \mathrm{w} / \mathrm{o} \mathrm{Ti}$ ) exhibited a hardened layer adjacent to the oxide pellets. These layers were first observed in the as-polished condition, and averaged $320 . \mu$ in the $\mathrm{V}-20 \mathrm{w} / \mathrm{o} \mathrm{Ti}$ specimen and $550 \mu$ in the $\mathrm{V}-15 \mathrm{w} / \mathrm{o} \mathrm{Cr}-$ $5 \mathrm{w} / \mathrm{o}$ Ti specimen. Etching revealed that the matrix of the $\mathrm{V}-20 \mathrm{w} / \mathrm{o}$ $\mathrm{Ti}$ alloy was affected beyond the hardened layer to an average depth of $480 \mu$. These results are similar to the behavior of vanadium-base alloys tested in sodium of low-oxygen content $(<10 \mathrm{ppm})$.*

Variations within the hardened layers of both alloys are indicated by the etching characteristics. The variations will be studied by means of microhardness measurements and electron probe microanalyses. The alloys that appeared unaffected by etching will also be checked for microhardness differences.

\section{Carbide}

\section{a. Eabrication and Evaluation}

(i) Euel Element Performance (L. A. Neimark, F. L. Brown, and B. J. Koprowski)

Last Reported: ANL-7478, p. 1 (July 1968).

The irradiation of 12 fuel elements in Subassemblies XA08 and XO15 continued in EBR-II. As of August 9, the burnup increment in addition to that previously reported (see ANL-7478, p. 1) was 0.5 to $0.6 \mathrm{a} / \mathrm{o}$, which raises the estimated maximum burnup in Subassembly XA0 8 to 7.8 a/o and in XO15 to $4.1 \mathrm{a} \%$. Target burnups for these subassemblies are 10 and $5 \mathrm{a} / \mathrm{o}$, respectively.

(ii) Compatibility between Uranium-Plutonium Carbide and Cladding Alloys (T.W: Latimer)

Last Reported: ANL-7457, p. 8 (May 1968).

No interaction between hyperstoichiometric $\left(\mathrm{U}_{0.8} \mathrm{Pu}_{0.2}\right) \mathrm{C}$ [containing $20 \mathrm{v} / \mathrm{o}(\mathrm{U}, \mathrm{Pu})_{2} \mathrm{C}_{3}$ ] and VANSTAR-9, a vanadium-base alloy developed at Westinghouse, was observed after contact for $1000 \mathrm{hr}$ at $800^{\circ} \mathrm{C}$. The nominal composition of this alloy was V-6w/o Fe-5 w/o Nb-1.3 w/o $\mathrm{Zr}-0.05 \mathrm{w} / \mathrm{o} \mathrm{C}$ (see Table I.A.1). The specimens were in the form of disks cut from $60-\mathrm{mil}$ sheet. The results of a similar test of two other WARD vanadium-base alloys were reported previously (see Progress Report for November 1967, ANL-7399, p. 7).

\footnotetext{
*Annual Progress Report for 1966, Metaliurgy Division, ANL-7299, pp. $72-74$.
} 
B. Physics Development--LMFBR

1. Theoretical Reactor Physics

a. General Fast Reactor Physics

(i) Dynamics Studies (H. H. Hummel)

Last Reported: ANL-7460, p. 7 (June 1968).

The QXl spatial kinetics program is being modified to enable treatment of transients in an initially subcritical system. The basic equation set has been previously described. ${ }^{\dagger}$ The total flux and delayed-precursor equations may be written as

$$
v^{-i} \frac{\partial \Phi}{\partial t}=\left(M+\chi_{p} F_{p}\right) \Phi+\chi_{d} \lambda C+\chi_{e} S_{e}
$$

and

$$
\frac{\partial c}{\partial t}=\chi_{c} F_{c} \Phi-\lambda C
$$

where $\Phi$ is the space-energy-time-dependent flux, $v$ is the velocity, $M$ the diffusion, removal, and transfer operator, $\ddot{\chi}_{\mathrm{p}} F_{\mathrm{p}}$ the prompt-neutron source, $\chi_{\mathrm{d}} \lambda \mathrm{C}$ the delayed-neutron source, and $\chi_{\mathrm{e}} \mathrm{S}_{\mathrm{e}}$ the external source. In Eq. (2), $\chi_{c} F_{c}$ is the delayed family-dependent precursor-source operator, $\lambda$ the precursor decay constant, and. $C$ is the space-family-time-dependent precursor density. The convention is used that operators are those for time $t=t$ unless otherwise noted. In the usual way, define the factorization into shape and amplitude functions by

$$
\Phi=\psi \phi ; \quad \phi(0)=1.0 ; \quad \frac{\partial}{\partial t} \int \psi^{*} v^{-1} \psi \mathrm{d} \mathrm{Ed} \overrightarrow{\mathrm{r}}=0
$$

where $\psi^{*}$ is the source-free adjoint solution for the initial steady state, found from the equation

$$
\left[M+\frac{1}{k_{0}}\left(\chi_{p} F_{p}+\chi_{d} \chi_{c} F_{c}\right)\right]_{t=0}^{T} \psi^{*}=0 .
$$

Where $T$ denotes the transpose, $t=0$ identifies the initial steady state, $\chi_{\mathrm{d}} \chi_{\mathrm{C}} F_{\mathrm{c}}$ is the delayed-neutron source operator (identical to $\chi_{\mathrm{d}} \lambda \mathrm{C} / \Phi$ for the initial conditions), and $k_{0}$ is the largest eigenvalue of Eq. (4).

†eactor Physics Division Annual Report, ANL-7310, p. 471 (Jan 1968), 
The shape-function equation ${ }^{\dagger}$ is modified by addition of the term $\chi_{e} S_{e} / \Phi$. The amplitude equation is obtained from Eq. (1) as follows. First, add and subtract terms to obtain

$$
\begin{aligned}
\mathrm{v}^{-1} \frac{\partial \Phi}{\partial \mathrm{t}}= & \mathrm{M}+\frac{1}{\mathrm{k}_{0}}\left(\chi_{\mathrm{p}} \mathrm{F}_{\mathrm{p}}+\chi_{\mathrm{d}} \chi_{\mathrm{c}} \mathrm{F}_{\mathrm{c}}\right) \Phi+\left(1-\frac{1}{\mathrm{k}_{0}}\right)\left(\chi_{\mathrm{p}} \mathrm{F}_{\mathrm{p}}+\chi_{\mathrm{d}} \chi_{\mathrm{c}} \mathrm{F}_{\mathrm{c}}\right) \Phi \\
& -\dot{\chi}_{\mathrm{d}} \chi_{\mathrm{c}} \mathrm{F}_{\mathrm{c}} \Phi+\chi_{\mathrm{d}} \lambda \mathrm{C}+\chi_{\mathrm{e}} \mathrm{S}_{\mathrm{e}}
\end{aligned}
$$

Now multiply Eq. (5) by $\psi^{*}$ and Eq. (4) by $\psi$, integrate over space and energy (denoted by $<$,$\rangle ), and subtract the resultant equations. In addition,$ define

$\delta \dot{M}=M(t)-M(0) ; \quad \delta F=\left.\left(\chi_{p} F_{p}+\chi_{d} \chi_{c} F_{c}\right)\right|_{t=t}-\left.\left(\chi_{p} F_{p}+\chi_{d} \chi_{c} F_{c}\right)\right|_{t=0}$.

operators).

The result is (after cancellation of the initial condition

$$
\begin{aligned}
\left\langle\psi^{*}, \mathrm{v}^{-1} \frac{\partial}{\partial \mathrm{t}} \Phi\right\rangle= & \frac{\left(\mathrm{k}_{0}-1\right)}{\mathrm{k}_{0}}\left\langle\psi^{*}\left(\chi_{\mathrm{p}} F_{\mathrm{p}}+\chi_{\mathrm{d}} \chi_{\mathrm{c}} \mathrm{F}_{\mathrm{c}}\right) \Phi\right\rangle \\
& +\left\langle\psi_{,}^{*}\left(\delta \mathrm{M}+\frac{1}{\mathrm{k}_{0}} \delta \mathrm{F}^{\prime} \Phi\right\rangle-\left\langle\psi_{,}^{*} \chi_{\mathrm{d}} \chi_{\mathrm{c}} \mathrm{F}_{\mathrm{c}} \Phi\right\rangle\right. \\
& +\left\langle\psi^{*}, \chi_{\mathrm{d}} \lambda \mathrm{C}\right\rangle+\left\langle\psi_{,}^{*} \chi_{\mathrm{e}} \mathrm{S}_{\mathrm{e}}\right\rangle
\end{aligned}
$$

In order to obtain an amplitude equation which is formally identical to the point kinetics equation, define $F=\left\langle\psi_{*}^{*}\left(\chi_{\mathrm{p}} \mathrm{F}_{\mathrm{p}}+\chi_{\mathrm{d}} \chi_{\mathrm{c}} \mathrm{F}_{\mathrm{c}}\right) \psi\right\rangle$ and adopt the simplified notation given in Eqs. (6) and (7) of ANL-7310. Equation (7) above then may be written as

$$
\frac{\mathrm{d} \phi}{\mathrm{d} t}=\frac{\left(\mathrm{k}_{0}-1\right)}{\mathrm{k}_{0} \Lambda} \phi+\frac{(\rho-\beta)}{\Lambda} \phi+\sum_{\mathbf{f}} \lambda_{\mathrm{f}} \eta_{\mathrm{f}}+\zeta_{\mathrm{e}}
$$

The factorization into $\psi$ and $\phi$ from Eq. (3) has been applied in going from Eq. (7) to Eq. (8): Also,

$$
\zeta_{\mathrm{e}}=\frac{\left\langle\psi * \chi_{\mathrm{e}} \mathrm{s}_{\mathrm{e}}\right\rangle}{\mathrm{F} \Lambda}
$$

The magnitude of $\psi$ at $t=0$ is found by solution of Eq. (8) for the initial steady state (recalling that $\phi=1.0$ at $t=0$ ):

\footnotetext{
$\bar{\dagger}$ See Eq. (9) of ANL-7310, p. 471.
} 


$$
F \equiv\left\langle\left.\psi^{*}\left(\chi_{\mathrm{p}} \mathrm{F}_{\mathrm{p}}+\chi_{\mathrm{d}} \chi_{\mathrm{c}} \mathrm{F}_{\mathrm{c}}\right)\right|_{\mathrm{t}=0} \psi\right\rangle=\frac{\mathrm{k}_{0}}{\left(1-\mathrm{k}_{0}\right)}\left\langle\left.\psi^{*} \chi_{\mathrm{e}} \mathrm{s}_{\mathrm{e}}\right|_{\mathrm{t}=0}\right\rangle .
$$

This same magnitude of $\psi$ is obtained, of course, by solution of Eq. (1) at $\mathrm{t}=0$ :

Modifications of QXl thus consist of addition of the first and last terms of Eq. (8) to the amplitude equation, insertion of the external source term in the shape equation, and initial normalization of $\psi$ according to Eq. (10) in place of the power normalization used in homogeneous cases.

2. Experimental Reactor Physics

a. : Fast Critical Experiments--Experimental Support (Idaho)

(W. G. Davey)

Last Reported: ANL-7478, pp. 5-6 (July 1968).

(i) Neutron Spectrometry

(a) High-count-rate Electronics. New amplifiers have been completed and incorporated in the electronic system for trial in ZPR-3 Assembly 53.

A fast paper-tape reader and punch has been acquired and incorporated in the system. The new reader reads 30 times faster and the punch is 12 times faster than the original Model 33 teletype. Reliability is also markedly improved.

The proton-recoil software has been rewritten in assembly language. The new program is operational and will be tested with Assembly 53 data.

(ii) On-line Computer Applications. Formulation of on-line ZPPR data-acquisition and-analysis programs continues.

A standard labeling system for plutonium fuel is being established for use at both ZPPR and ZPR-3, based on the system to be used for $Z P P R$ fuel. This should make it convenient to add any fuel procured in the future to the computerized fuel-inventory procedure. A standard.fuel-transfer recording form applicable to both $Z P P R$ and $Z P R-3$ has been incorporated and is in use at both areas. The advantages of a standard form are; (a) personnel at both areas use the same recording procedures and can easily work in either area, and (b) no recording. problems should be encountered if different types of fuel are transferred from one area to the other. 
(iii) Integral Studies of Cross Sections. Standardized prescriptions were is sued last month to members of the Cross-Section Evaluation Working Groups for the Phase-IIB benchmark analyses of ENDF/B. Since that time, comments pertaining to the prescriptions have been received, along with suggestions for further standardization. The items in question are data required by the ENDF/B processing codes, or reactor codes to be used in the analyses of As semblies 48 and 11 , which were not specified in the prescriptions or contained in the ENDF/B. A review of these items is underway so that an addendum letter to the prescriptions can be drawn up with recommended standard values.

\section{(iv) Experimental Techniques}

(a) Pulsed-Source Experiments. The results of the ZPR-3 Assembly-5l pulsed-neutron experiments have revealed several interesting effects which deserve further study. The first of these is the consistently smaller decay constants which were measured in Reflector II as opposed to those measured in the core and in Reflector I. The reasons for this slower decay in the outer reflector are not clear, and further experiments in similar cores would be necessary to explain the phenomenon. A second effect is a definite time delay, after the pulse, in attaining a maximum in the dieaway curve. The time delay is approximately 8 to $10 \mu \mathrm{sec}$ longer in Reflector II than in Reflector I. This suggests a pulse-propagation phenomena which also deserves further study: Similar pulse-propagation effects have been reported for the copper-reflected FR-O reactor in Sweden.

In some cases, the data were fitted to the sum of two exponentials plus a constant. The results were inconsistent in that the decay constants as obtained from data collected in the different detector locations did not agree. In fact, these data indicated that the initial fast decay is a harmonic effect and cannot be attributed to reflector-core coupling. Again, further study is warranted.

b. Fast Critical Experiments--Experimental Support (Argonne)

(i) On-line Computer Applications (R. Gold)

Last Reported: ANL-7445, p. 10 (April 1968).

(a) Reliability Improvements for the DDP-24 Main Frame

(1) Introduction. In the past, the reliability of the DDP-24 computer has not been all that one might desire. Recently, some modifications have been made which, it is hoped, will eliminate the deficiencies and yield near-ideal reliability. These modifications involved changes in the operating currents of the magnetic-core memory and improvements in the cooling of the circuit boards in the main frame. 
(2) Memory-current Adjustments. In a magneticcore memory there are three important operating currents which flow through the wires threading the cores: the write current, which changes the state of a core when a "one" is to be stored in it; the read current, which resets a core from the "one" state and generates an output signal; and the inhibit current, which counteracts the write current and prevents a state change in a core where a "zero" is to be stored. It can be shown* that these three currents should be approximately equal in order to provide the greatest margin against the spread in characteristics of the various cores throughout the memory as well as against system drift.

The DDP-24 core memory has screwdriver adjustments for the read and write currents, but none for the inhibit current. When adjusted for best operation, the read and write currents were 240 to $250 \mathrm{~mA}$, while the inhibit current measured $160 \mathrm{~mA}$. Therefore, the inhibit current was clearly suboptimal.

This deficiency was particularly evident in one of the two 4096-word memory modules where the spread in core characteristics was especially large. In particular, there was one core whose threshold for state change was some $40 \mathrm{~mA}$ lower than all the rest. Possibly because of component aging, it became impossible to find an adjustment for this module at which all cores would function properly. Therefore, to restore proper operation it was imperative to increase the inhibit current.

There are twenty-four circuits which determine the inhibit current, one for each bit, in each module. When a given bit is to be stored as a zero, an inhibit driver transistor conducts and draws a current through the inhibit wire as determined by a resistor network. The resistor networks are contained on two inhibit component boards which are located inside the core-stack enclosure. The currentwasincreasedisimply by adding a resistor to each network.

This modification made it possible to obtain completely satisfactory adjustments in both modules. The modifications were completed in November 1967, and the memory operations since then have been highly satisfactory. Unfortunately, the increased inhibit current caused the failure of five of the inhibit driver transistors--three immediately after the modifications were completed and two subsequently. Since these failures are very readily localized and corrected, they are considered a small price to pay for the improved memory operation obtained. It is believed that they represent a sorting-out of particularly weak transistors, and so will become less likely in the future. Furthermore, it is hoped that the cooling improvement described in the next section will further reduce the likelihood of these failures.

* Womack, C. P., IEEE Trans. Electron. Computers EC-14, 36-44 (1965). 
(3) Main-frame Cooling Improvements. From time to time throughout its life, the DDP-24 has been plagued with intermittent, evanescent main-frame failures which were impossible to localize. Consideration of the causes for these failures pointed to inadequate cooling of the circuit boards from which the main frame is constructed.

Although the manufacturer recommends forcedair cooling for these boards, he did not make adequate provisions for such cooling in the design of the computer. He did install a blower at the bottom of each of the three rack bays which contain the boards. However, he made no provisions to channel the air into the restricted spaces between the boards, where the flow is really needed. As a consequence, most of the air bypassed the board enclosures and was ineffective for cooling.

In addition, it had become the practice to keep frequently used program tapes on top of the computer. It appeared that an increase in the failure rate was correlated with an increase in such storage. This was confirmed by complete freedom from failures for two weeks after all tapes were removed from atop the ventilation openings. Since no more than one-third of the ventilation area had ever been covered, the existing cooling was evidently marginal.

An improved cooling arrangement was installed. The existing rack blowers were removed. In each bay, a standard $7 \times 17 \times$ 3 -in. chassis base was mounted, inverted, snugly under the bottom row of boards. Under each chassis were mounted three 100-cfm axial-flow fans. The chassis serves as a plenum chamber to channel the air between the boards and provide even distribution. The design of the board enclosures provides for air circulation upwards past all the boards in the bay.

Each memory module was already equipped with fans which force air into the core-stack compartment and outwards between some additional boards. These fans were equipped with dust filters which seriously restricted the flow, even when clean. Therefore, these filters were removed. (Dust is not a major problem in this low-voltage; lowimpedance circuitry.)

The boards here include those containing the inhibit-driver transistors. It is expected that the improved air flow will significantly: lower the failure probability of these transistors. It appears that heat transfer is particularly important for these, as internal examination of a failed transistor revealed that they are filled with a putty-like substance ostensibly intended to conduct heat from the semiconductor chip to the case. It is planned to install clip-on heat sinks on the se transistors if a variety can be found that is suitable for their close spacing on the boards. 
These cooling improvements have been in service for a little over three months, during which no main-frame failures at all have occurred. This implies that the hoped-for major improvement in reliability will indeed be realized.

The memory modules possess another stack of boards which is cooled by a 270 - cfm axial-flow fan mounted under them. Here; again, no provision was made for channeling the air between the boards, so that most of the air again bypasses them. Although this area has not been troublesome in the past, it is planned to install a sheet metal shroud over the fan to direct the air properly.

(ii) Fission Process and Cross-section Data Related to Fast Reactors "(R'. Gold)

Last Reported: ANL-7438, p. 11 (March 1968).

(a) Measurements of the Compton-recoil Continuum for In-core Gamma-ray Spectroscopy. The development of high-resolution solid-state detectors for gamma-ray measurements is a significant experimental advance which has been widely applied in nuclear spectroscopy. Work with these detectors has focused on precise definition of nuclear energy levels by accurate measurements of gamma-ray energy (of the photopeak response). In such investigations, only a limited number of transitions can be successfully analyzed because of the dominance of the Compton response in these detectors. Hence, these detectors cannot be used in the same manner (i.e., as photopeak detectors) for measurement of continuous gamma-ray spectra.

Although the dominance of the Compton-recoil continuum in these detectors is regarded as an unwanted and troublesome complication in nuclear (energy-level) spectroscopic studies, it is precisely this response which can be exploited for continuous gamma-ray spectroscopy. Indeed, the Compton distribution and the continuous gammaray spectrum are directly related by a well-defined integral equation. Consequently, the continuous gamma-ray spectrum can be determined from an unfolding problem, * in terms of the measured electron-recoil spectrum.

Some obvious advantages of this method can be cited. The response kernel (or response matrix) can be directly calculated from first principles. This assumption rests upon the dominance of the Compton response, by roughly one-to-two orders of magnitude, in the broad energy region from about $100 \mathrm{keV}$ up to a few $\mathrm{MeV}$. In comparison, all other photon-interaction modes can be regarded as higher-order perturbations and as such are neglected in the present treatment. Consequently, a geometry-independent formulation can be introduced, which is valid as

\footnotetext{
*Gold, R., An Iterative Unfolding Method for Response Matrices, ANL-6984 (1964).
} 
long as effects of finite detector size are small (i.e., up to a few MeV). It follows that the required response function for these detection systems need not be determined experimentally. Only through higher-order. effects can the specific type, geometry, or design of the solid-state detector have an influence.

There are additional advantages that automatically accrue from the use of solid-state detectors, namely, sensitivity, resolution, and compactness, all of which should allow adequate measurements with little perturbation of the environment. In addition, the well-established Compton-scattering kernel should permit absolute measurement of continuous photon-energy spectra. In this regard, the relative error of this method can only be estimated, at present, to lie in the range of 10 to $20 \%$ and is dominated by the neglect of higher-order effects already mentioned.

c. Planning and Evaluation of FFTF Critical Assembly Experiments (D. Meneghetti)

Last Reported: ANL-7478, pp. 7-9 (July 1968).

(i) A Method for Approximating Solutions of Axially Split Cylindrical Cores. In previous Monthly Reports* a method was described by which a finite cylindrical reactor in coordinates $r$ and $z$ may be viewed as a finite. slab reactor in coordinates $x, y$, and $z$.

For the jth group of a multigroup $r$, $z$ diffusion problem,

$$
D_{j}\left(\frac{1}{\phi_{j}} \frac{\partial^{2} \phi_{j}}{\partial r^{2}}+\frac{1}{r \phi_{j}} \frac{\partial \phi_{j}}{\partial r}+\frac{1}{\phi_{j}} \frac{\partial^{2} \phi_{j}}{\partial z^{2}}\right) \phi_{j}-\Sigma_{a j} \phi_{j}+S_{j-}=0 \text { 。 }
$$

From a converged solution of this problem the value of the term

$$
\frac{1}{r \phi_{j}} \frac{\partial \phi}{\partial r} \equiv-B_{y j}^{2}
$$

may be obtained at every mesh interval. This term may be thought of as a group-dependent, region-dependent buckling in

$$
D_{j}\left(\frac{1}{\phi_{j}} \frac{\partial^{2} \phi_{j}}{\partial x^{2}}-B_{y j}^{2}+\frac{1}{\phi_{j}} \frac{\partial^{2} \phi_{j}}{\partial z^{2}}\right) \phi_{j}-\Sigma_{a j} \phi_{j}+S_{j}=0 。
$$

This is a diffusion equation in the rectangular coordinates $\mathrm{x}$ and $\mathrm{z}$, but its solution, $\phi_{j}$, must be the same as that of Eq. (1) when $x$ and $r$ are

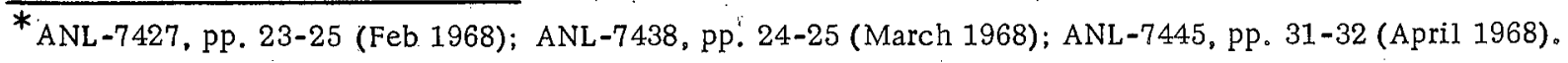


considered to be analogous, because of the definition of $\mathrm{B}_{\mathrm{yj}}^{2}$. In effect, solution of (3) is the same as the solution of (1) except that the converged value of the second term is used starting with the first iteration.

Six-group tests of simulation appear in Table I.B.1, showing the dependence of the result on the number of mesh intervals used in the problem.

TABLE I.B.1. Comparisons in One- and Two-dimensional Calculations

\begin{tabular}{|c|c|c|c|}
\hline $\begin{array}{l}\text { Diffusion } \\
\text { Program }\end{array}$ & $\begin{array}{c}\text { Reflected Cylinder } \\
\left(k_{\text {eff }}\right)\end{array}$ & $\begin{array}{l}\text { Simulation } \\
\left(\mathrm{k}_{\mathrm{eff}}\right)\end{array}$ & $\begin{array}{c}\text { Number of } \\
\text { Mesh } \\
\text { Intervals }\end{array}$ \\
\hline $\mathrm{MACH} 1 \mathrm{D}^{\mathrm{a}}$ & 1.0000 & 0.9999 & 38 \\
\hline $\mathrm{MACH} 1 \mathrm{D}^{\mathrm{a}}$ & 1.0000 & 0.9999 & 148 \\
\hline CANDID $2 D^{b}$ & 1.0095 & 0.9769 & $15 \times 13$ \\
\hline CANDID $2 D^{b}$ & $l_{. .0083}$ & 0.9914 & $19 \times 23$ \\
\hline \multicolumn{4}{|c|}{$\begin{array}{l}{ }^{a} \text { Meneley, D. A., Kvitek, L. C., and O'Shea, D. M., MACH 1, A One- } \\
\text { dimensional Diffusion-theory Package, ANL-7223, (June 1966). } \\
\text { beaf, G. K., Kennedy, A. S., and Jensen, G. C., ANL-CANDID, } \\
\text { A Two-dimensional, Diffusion-theory Code Based on CANDID2D, }\end{array}$} \\
\hline
\end{tabular}

If a slab-like zone of differing material properties splits the cylinder along a plane containing the axis, as in the split-core concept for the Fast Flux Test Facility (FFTF), * the material properties may then be considered to be a function of the distance $x$ from the plane. The set of values of $\mathrm{B}_{\mathrm{yj}}^{2}$ from the cylindrical solution is held constant; the core material is removed from the slab-like zone normal to the $x$ axis, and is replaced by the different composition. A solution $\phi_{j}(x, z)$ is then computed for the split core. The assumption is made here that the effect of the zone of different composition appears almost entirely in the $\mathrm{x}$-dependence of the solution while the $y$-dependence, as represented by the set of values of $B_{y j}^{2}$, is almost constant.

This assumption and the method is tested in the S2 transport approximation on right-circular cylindrical reflected cores in which the axial leakage is handled by the usual $B_{z}^{2}$. The $k_{\text {eff }}$ for unsplit and split cores is computed in $x, y$ representation by the SNARG-2D** code using the $S 2$ transport approximation, giving $\Delta \mathrm{k}=0.1364$. A solution is found for an equivalent one-dimensional cylindrical core, and is simulated by the

\footnotetext{
* Astley, E. R., The Conceptual Evaluation of Fast Flux Test Facility, Presented at the National Topical : Meeting on Fast Reactors, BNWL-SA-978.

**Duffy, G. J., Greenspan, H., Sparck, S. D., Zapatka, J. V., and Butler, M. K., SNARG-1D, A Onedimensional, Discrete-ordinate, Transport-theory Program for the CDC-3600, ANL-7221 (June 1966).
} 
above method in a one-dimensional slab calculation with SNARG-1D. The split core is then simulated with SNARG-1D, giving $\triangle \mathrm{k}=0.1358$.

3. ZPR-3 Operations and Analysis (W. G. Davey and R. L. McVean)

Last Reported: ANL-7478, pp. 9-15 (July 1968).

a. Mockup Studies

(i) Space-dependent Reactivity Traverses in Assembly 51.

In May 1968, space-dependent reactivity traverses of plutonium, ${ }^{238} \mathrm{U}$, and ${ }^{10} \mathrm{~B}$ were made along the axial and radial centerlines of Assembly 51. These traverses were made with most of the same configurations as for the previously reported reaction-rate traverses.* An axial traverse with a locally rotated plate loading was not measured for the ${ }^{238} \mathrm{U}$ sample.

During each traverse the reactor was maintained at constant power by using a calibrated autorod. The sample worth at each position was determined by measuring the autorod position. Throughout a traverse, an arbitrary position within the reactor was repeated frequently as a reference. Changes in autorod position for these reference measurements were interpreted as being due to reactor drift with temperature variation. Measurements were also made for the traverse-mechanism rod without the uranium sample and the traverse-mechanism rod with an empty stainless steel capsule in order to correct the sample traverse data.

An IBM 1620 computer code was written (code name RTC) which (a) converted the autorod-position information to autorod worth, applying up to six constants for the polynomial fit of the rod worth, (b) corrected for reactivity effects of temperature drift by treating changes between reference points linearly and subtracting the interpolated effect from each datum point, (c) changed relative worth to absolute worth by setting the worth with the sample fully withdrawn to zero, and adjusting the other values accordingly, and (d) subtracted background reactivity .effects due to the capsule (for encapsulated samples) and the traverse rod.

Details of the samples are given in Table I.B.2, and results of axial and radial traverses are given in Tables I.B. 3 and I.B.4, respectively. Figures I.B.1 through I.B.6 show graphically the results of the traverses. Most values were determined with the sample positioned on the same side of the reactor centerline or centerplane as the traversing mechanism (labeled as "right side"). The other values were obtained for comparable positions on the opposite side of the reactor. The "left'side" of the reactor corresponds to the negative dimensions in the tables. It should be noted that in the experimental data plotted with triangular symbols (normal and inverted), the measured yalue corresponds to the apex of the triangle.

\footnotetext{
*See Progress Report for May 1968, ANL-7457, pp. 23-26.
} 
TABLE I.B. 2. ZPR-3 Assembly-51 Perturbation Samples

\begin{tabular}{|c|c|c|c|c|c|c|}
\hline \multirow[b]{2}{*}{ Sample } & \multirow[b]{2}{*}{ Type } & \multirow{2}{*}{$\begin{array}{l}\text { Thickness } \\
\text { (in.) }\end{array}$} & \multirow{2}{*}{$\begin{array}{c}\text { OD } \\
\text { (in.) }\end{array}$} & \multirow{2}{*}{$\begin{array}{l}\text { W eight } \\
\quad(\mathrm{g})\end{array}$} & \multicolumn{2}{|c|}{ Stainless Steel Can ${ }^{\mathrm{b}}$} \\
\hline & & & & & OD (in.) & Weight $(\mathrm{g})$ \\
\hline $\mathrm{Pu}\left(4.5 \mathrm{w} / \mathrm{o}^{240} \mathrm{Pu}\right)$ & Annulus & 0.020 & 0.391 & $9.315^{a}$ & 0.42 & 6.498 \\
\hline${ }^{10} \mathrm{~B}$ & Annulus & 0.010 & 0.391 & $0.4484^{c}$ & 0.42 & 10.5647 \\
\hline${ }^{238} \mathrm{U}\left(0.21 \mathrm{w} / \mathrm{o}^{235} \mathrm{U}\right)$ & $\begin{array}{c}\text { Solid } \\
\text { Cylinder } \mathrm{b}\end{array}$ & - & 0.420 & $85.76^{d}$ & - & - \\
\hline
\end{tabular}

${ }^{a}$ Alloy content (w/o): $\mathrm{Pu}, 98.62 ; \mathrm{Al}, 1.22$; other, 0.16. Pu weight--9.186 g. Isotopic composition (w/o): ${ }^{239} \mathrm{Pu}, 95.05 ;{ }^{240} \mathrm{Pu}, 4.50 ;{ }^{241} \mathrm{Pu}, 0.45$.

boverall length of each sample was 2 in.

c $92.8 \mathrm{w} / \mathrm{o}$ of sample was boron; $92.1 \mathrm{w} / \mathrm{o}$ of boron was ${ }^{10} \mathrm{~B} .{ }^{10} \mathrm{~B}$ weight was $0.383 \mathrm{~g}$.

$\mathrm{d}^{238} \mathrm{U}$ weight was $85.58 \mathrm{~g}$. No correction in measurements for ${ }^{235} \mathrm{U}$ content.

TABLE I.B.3. Axial Space-dependent Reactivity Traverses for ZPR-3 Assembly 51

\begin{tabular}{|c|c|c|c|c|c|c|c|c|}
\hline & \multirow{3}{*}{\multicolumn{2}{|c|}{$\begin{array}{c}\text { Sample } \\
\text { Weight }(\mathrm{g}): \\
\text { Fuel-material } \\
\text { Configuration: }\end{array}$}} & \multicolumn{6}{|c|}{ Worth $(\mathrm{Ih} / \mathrm{kg})$} \\
\hline & & & \multicolumn{3}{|c|}{$\begin{array}{l}\mathrm{Pu} \\
9.186\end{array}$} & \multicolumn{2}{|c|}{$\begin{array}{c}{ }^{10} \mathrm{~B} \\
0.383\end{array}$} & $\begin{array}{c}{ }^{238} \mathrm{U}\left(0.21 \mathrm{w} / \mathrm{o}^{235} \mathrm{U}\right. \\
85.58--{ }^{238} \mathrm{U}\end{array}$ \\
\hline & & & Normal & & Rotated $90^{\circ}$ & Normal & Rotated $90^{\circ}$ & Normal \\
\hline \multicolumn{9}{|c|}{$\begin{array}{l}\text { Distance from Reactor } \\
\text { Centerline (in.) })^{\mathrm{a}}\end{array}$} \\
\hline & 0 & & 576.8 & & 590.7 & -9651 & -9707 & -23.72 \\
\hline & 1 & & 580.9 & & 591.6 & -9570 & -9633 & -23.83 \\
\hline & -1 & & 578.3 & & 589.7 & -9546 & -9617 & -23.52 \\
\hline & 2.5 & & 566.3 & & 580.1 & -9177 & -.9408 & -22.69 \\
\hline & -2.5 & & 571.1 & & 583.6 & -9341 & -9389 & -22.90 \\
\hline & 5 & & 524.7 & & 532.1 & -8495 & -8630 & -19.53 \\
\hline & -5 & & 529.7 & & 537.2 & -8552 & -8679 & -20.45 \\
\hline V & 7.5 & & 448.3 & & 456.1 & -7317 & -7359 & -15.32 \\
\hline & 10 & & 361.4 & & 371.3 & -5928 & -5914 & -9.62 \\
\hline & -10 & & 368.7 & & 375.9 & -5825 & -5983 & -10.28 \\
\hline & 12.5 & & 266.7 & & 276.2 & -4590 & -4529 & -3.93 \\
\hline & 1.5 & & 177.8 & & 186.0 & -3535 & -3418 & 0.51 \\
\hline & -15 & . & 177.4 & $\because$. & 188.5 & -3697 & -3672 & -1.02 \\
\hline & 16 & & 141.7 & & 151.8 & -3331 & -3228 & 1.24 \\
\hline & 17 & & 115.6 & . & 121.8 & -3296 & -3195 & 0.15 \\
\hline & 18 & “ & 93.4 & & 103.3 & -3132 & -3031 & 0.11 \\
\hline & 19 & & 78.5 & & 89.0 & -2737 & -2592 & -0.68 \\
\hline & 20 & & 73.6 & & 80.3 & -2101 & -2054 & -0.66 \\
\hline & -20 & & 74.8 & & 87.0 & -2513 & -2515 & - \\
\hline & 22.5 & & 50.5 & & 58.9 & -1023 & -957 & 0.10 \\
\hline & 25 & & 28.3 & . & 36.0 & -440 & -392 & 0.62 \\
\hline & 27.5 & & 9.0 & . & 17.9 & -119 & -189 & 0.33 \\
\hline & 30 & & 0.0 & & 0.0 & 0 & 0 & 0.0 \\
\hline
\end{tabular}

a Negative distance indicates sample was on opposite side of reactor centerline from the traverse mechanism. 
TABLE I.B.4. Radial Space-dependent Reactivity Traverses for ZPR-3 A.ssembly:51

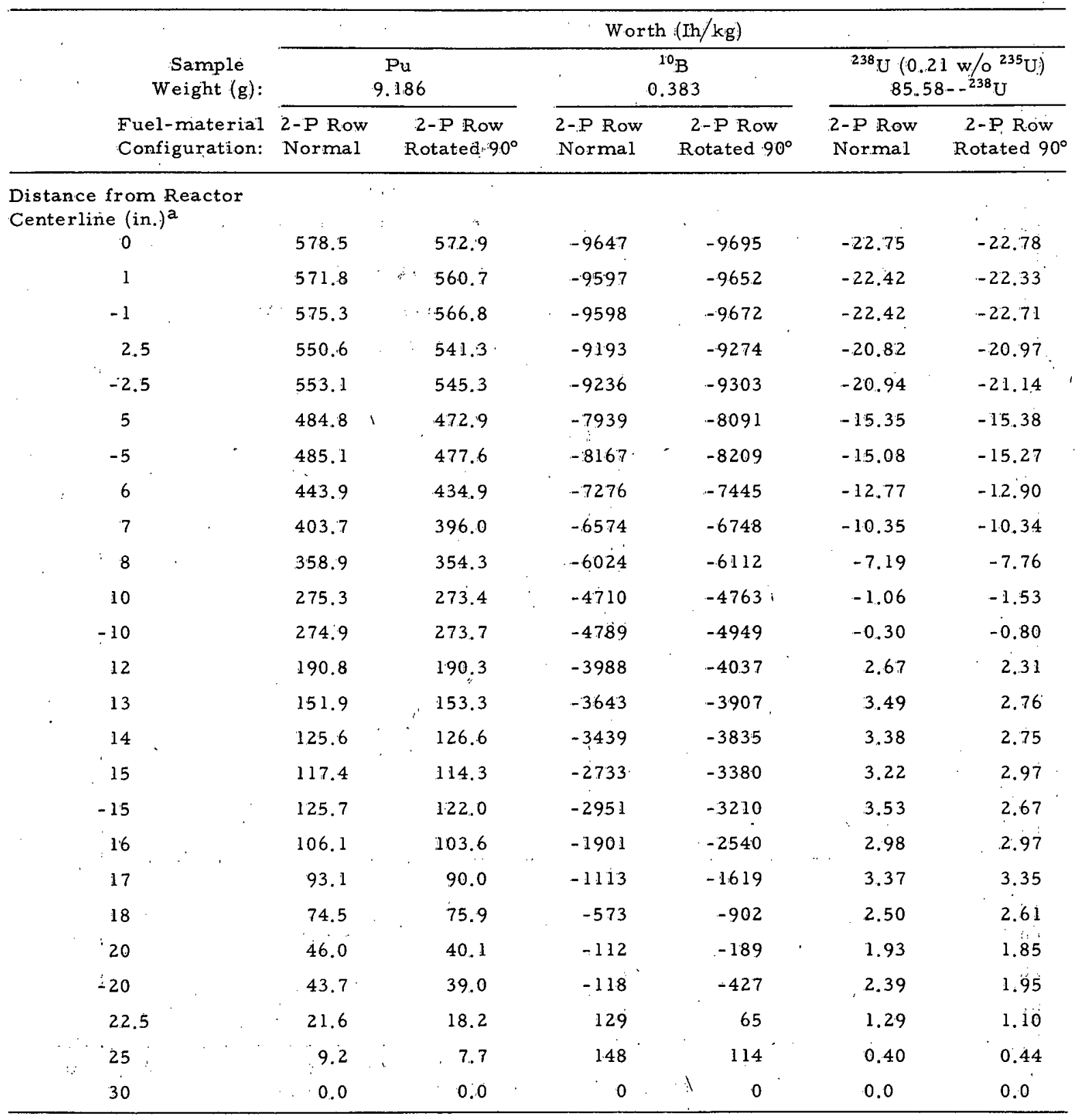

a Negative distance indicates sample was on opposite side of reactor centerline from the traverse mechanism. 


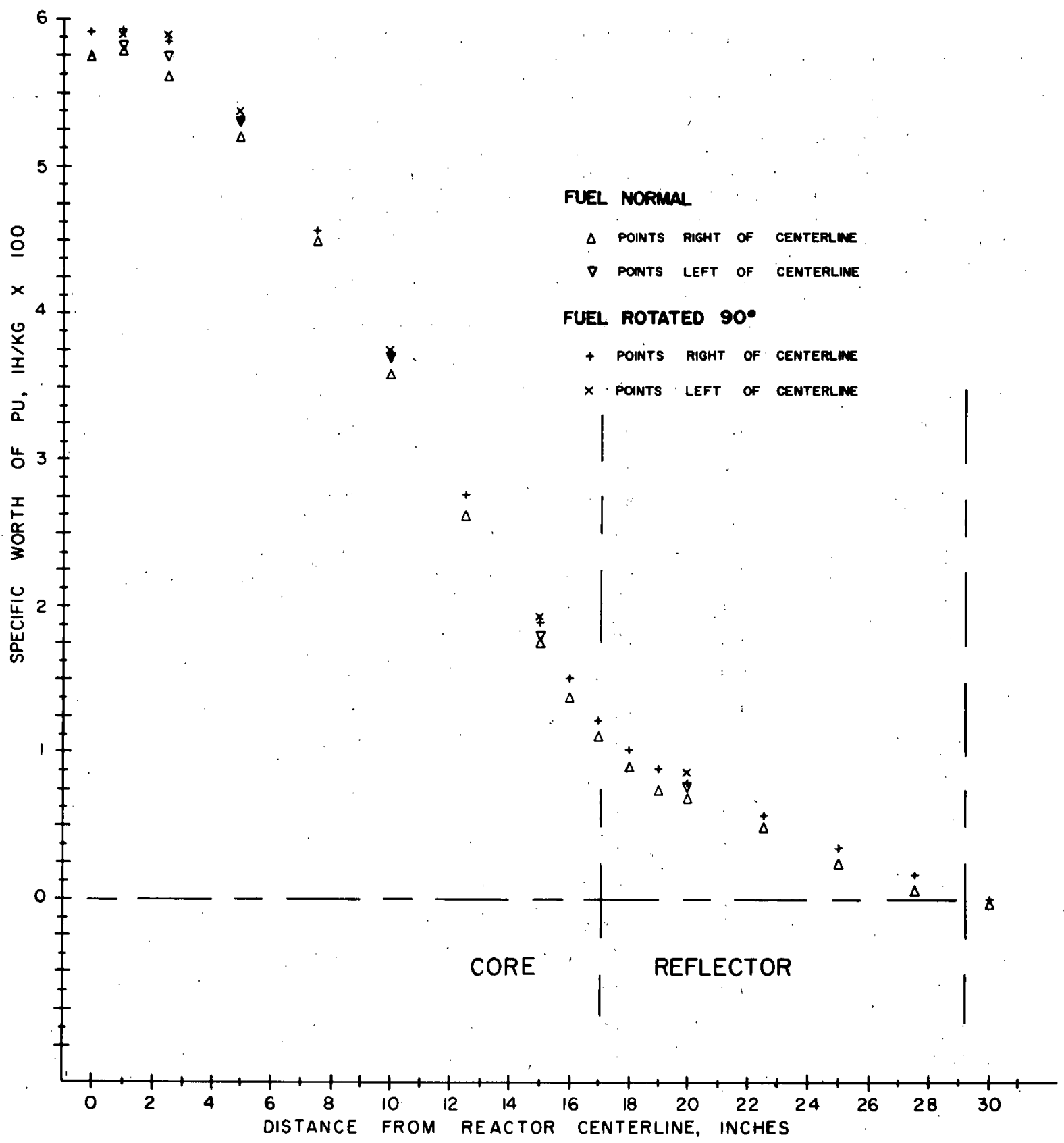

Fig. I.B.1. Space-dependent Axial Reactivity Traverse in ZPR-3 Assembly 51 for Plutonium 


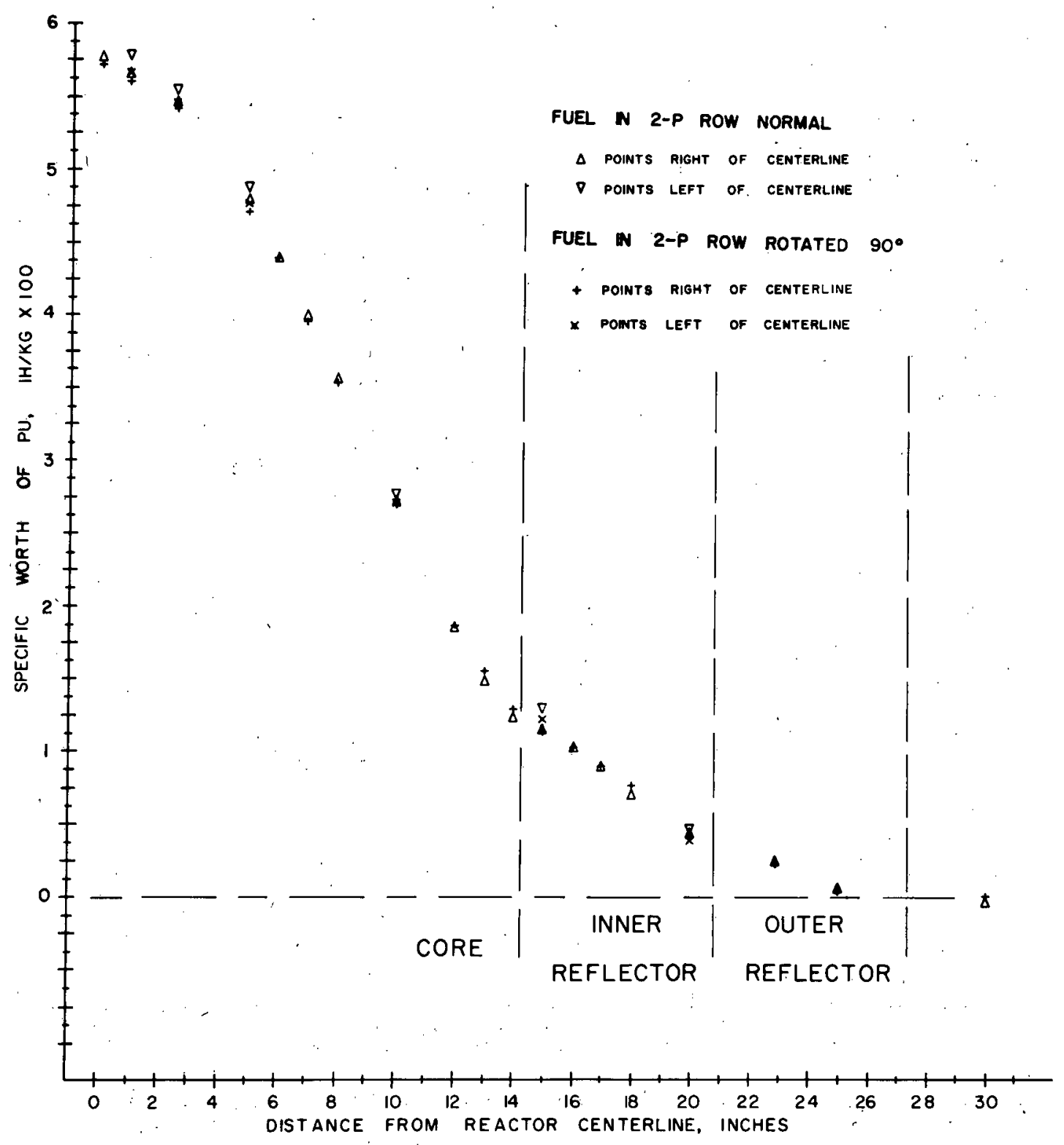

Fig. I.B.2. Space-dependent Radial Reactivity Traverse in ZPR-3 Assembly 51 for Plutonium 


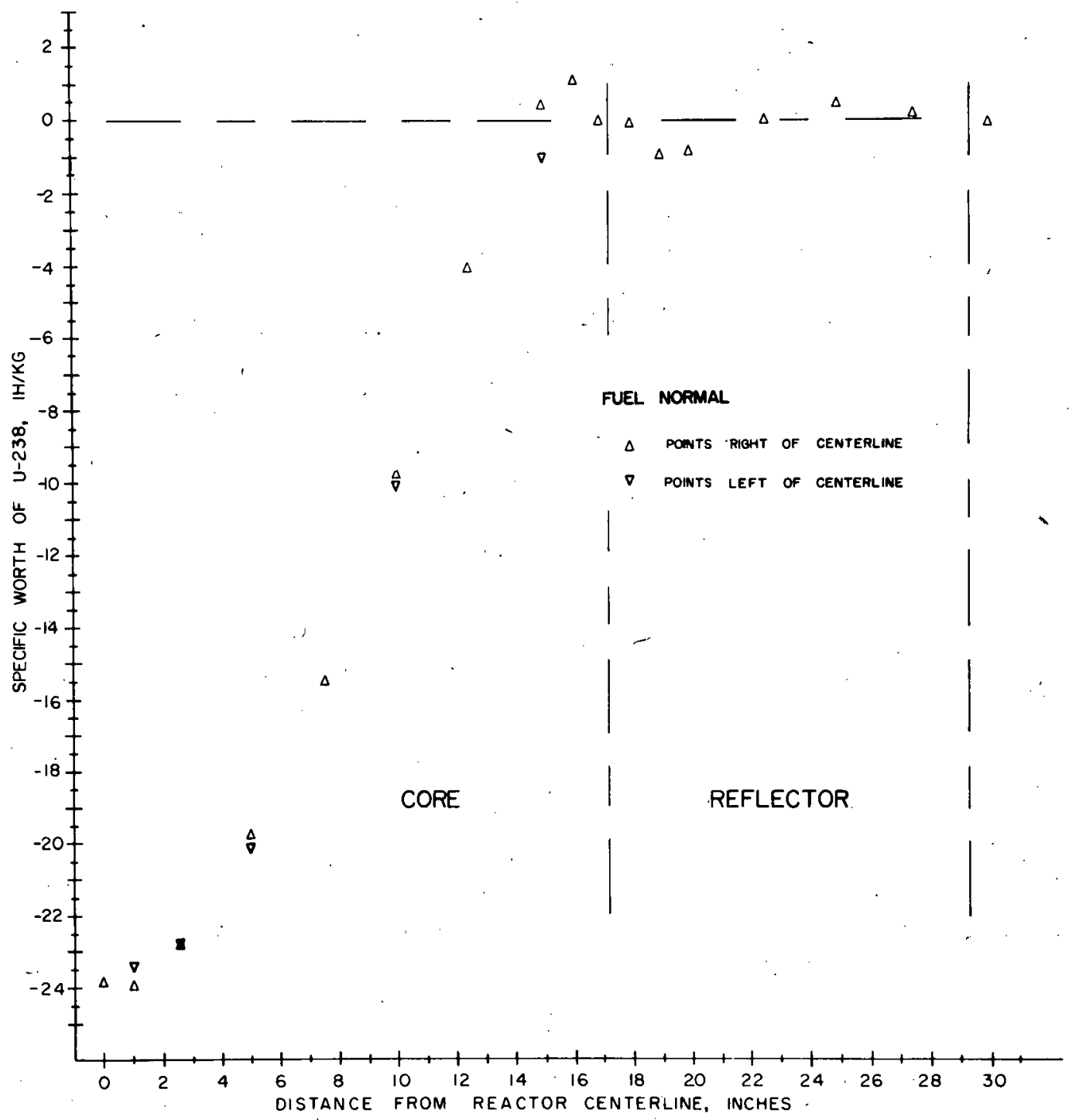

Fig. I.B.3. Space-dependent Axial Reactivity Traverse in ZPR-3 Assembly 51 for ${ }^{238} \mathrm{U}$ 


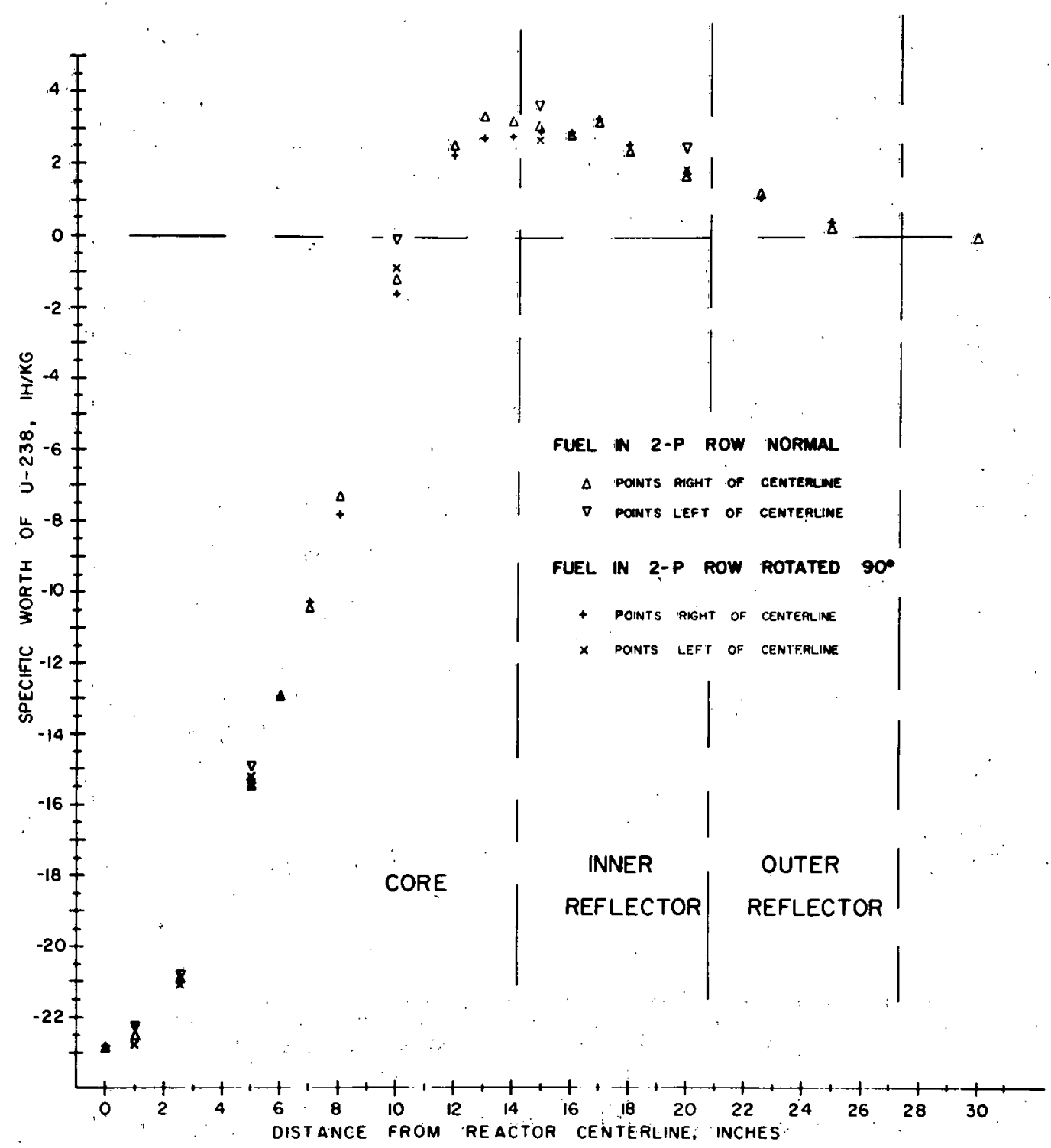

Fig. I.B.4. Space-dependent Radial Reactivity Traverse in ZPR-3 Assembly 51 for ${ }^{238} \mathrm{U}$ 


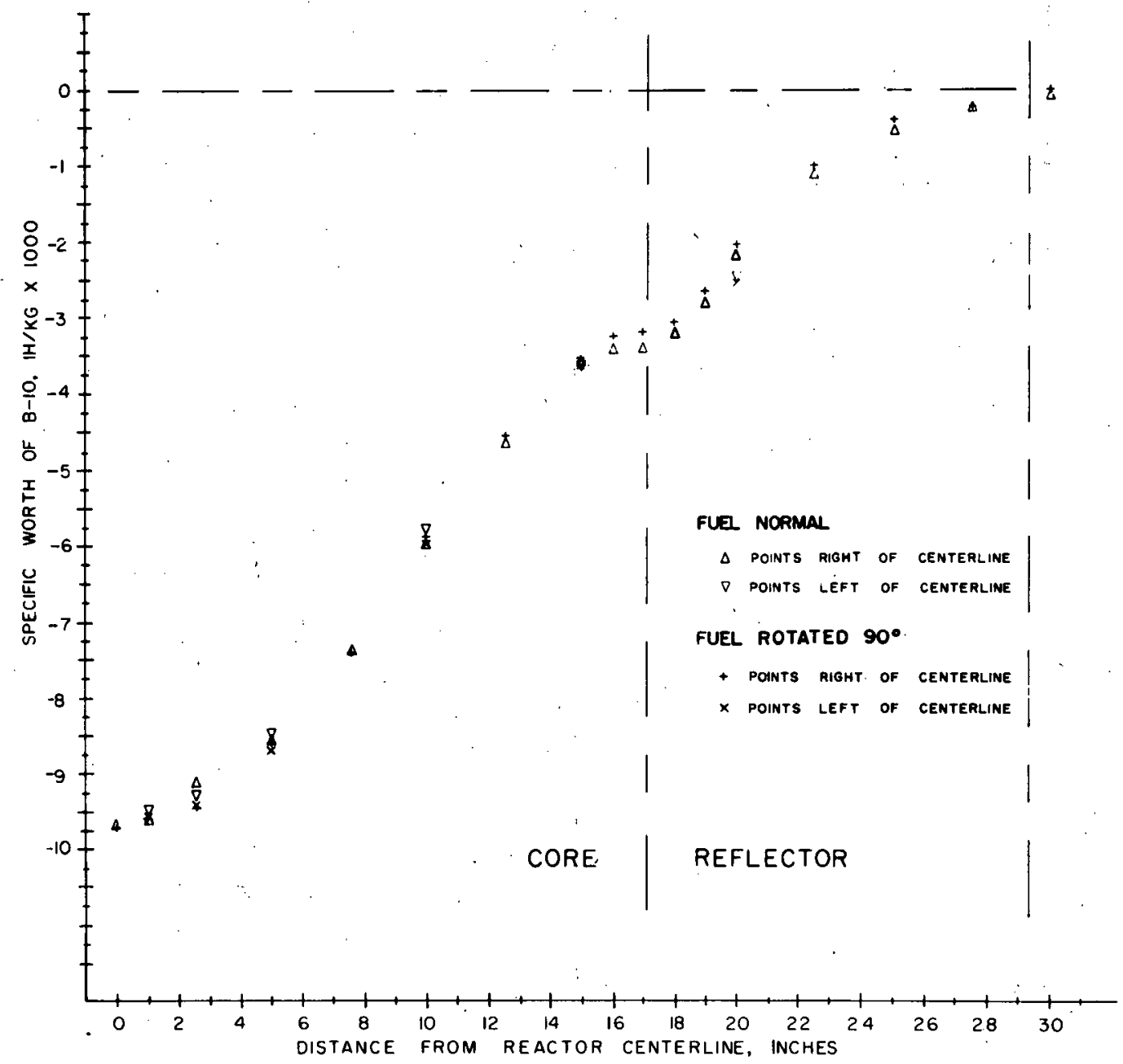

Fig. I.B.5. Space-dependent Axial Reactivity Traverse in ZPR-3 Assembly 51 for ${ }^{10} \mathrm{~B}$ 


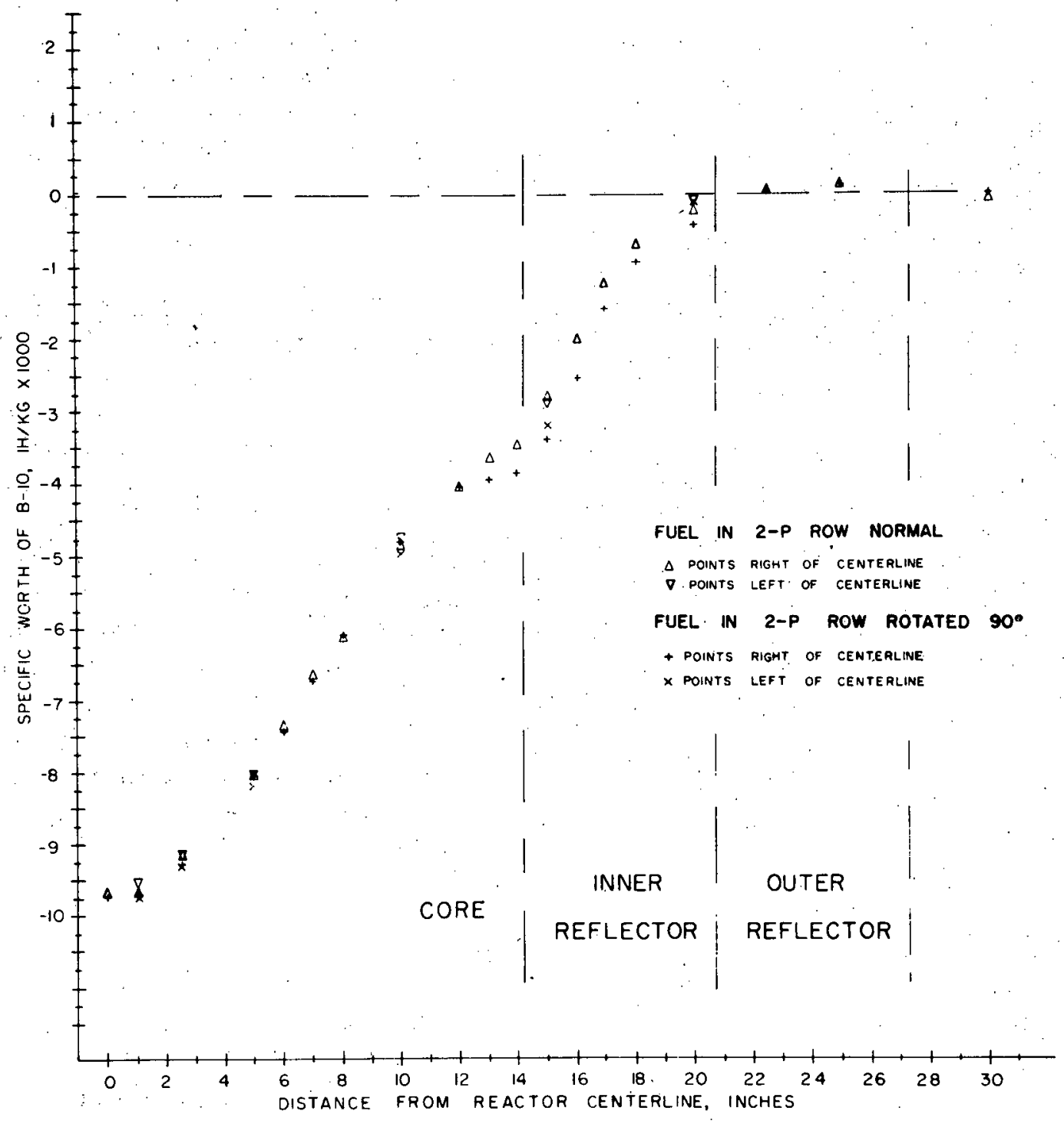

Fig. I.B.6. Space-dependent Radial Reactivity Traverse in ZPR-3 Assembly 51 for ${ }^{10} \mathrm{~B}$ 
A root-mean-square error of \pm 0.025 Ih has been assigned to each value of sample worth. The uncertainties are $\pm 3, \pm 60$, and $\pm 0.3 \mathrm{Ih} / \mathrm{kg}$ for plutonium, ${ }^{10} \mathrm{~B}$, and ${ }^{238} \mathrm{U}$ measurements, respectively.

(ii) Assembly-52 Results. Experiments have been concluded with Assembly 52 , the second core of the FTR Phase-B critical program. The data presented here are the critical mass of Assembly $52 \mathrm{~F}$, the ${ }^{239} \mathrm{Pu}$

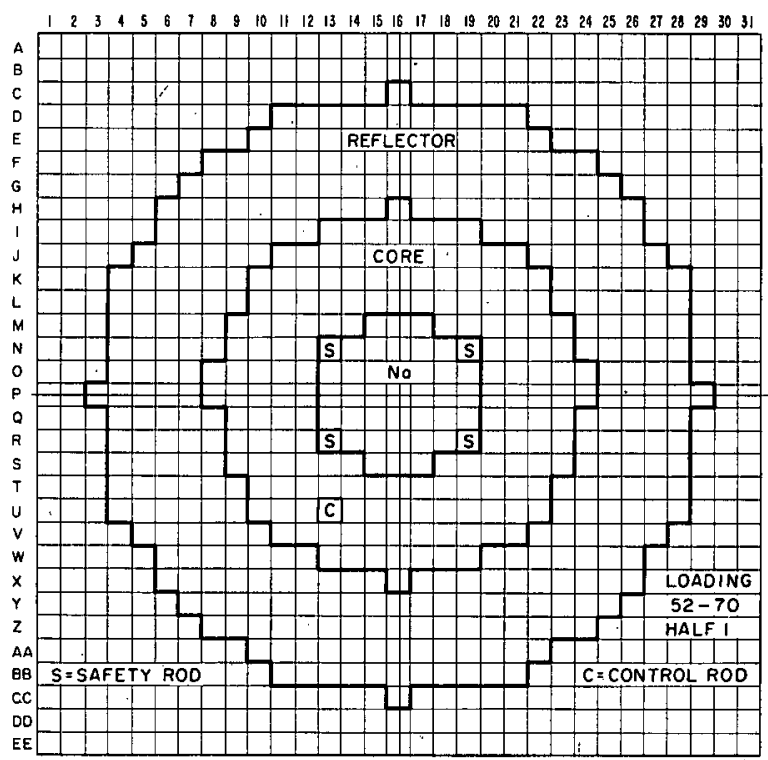

Fig. I.B.7. Reference Loading for Assembly 52F reaction-rate traverses in Assembly $52 \mathrm{~F}$, and a comparison of the spiking worth of the ZPR-3 safety rods in all the Assembly -52 geometries.

(a) Critical Mass of Assembly $52 \mathrm{~F}$. The critical loading of Assembly $52 \mathrm{~F}$ is shown in Fig. I. B.7, and a tabulation of the total fissile inventory is given in Table I.B. 5 . The critical loading was-symmetrical in both halves of ZPR-3, with the exception of the control rods. The central sodium zone consisted of 37 drawers interior to the core material. The sodium zone extended through the upper and lower axial reflectors. The ZPR-3 safety-rod composition was the same as in Assemblies $52 \mathrm{D}$ and $52 \mathrm{E}$ (see ANL-7478, pp. 11-12). The critical mass of Assembly 52F was determined to be $309.2 \pm 0.5 \mathrm{~kg}$ of fissile material.

TABLE I.B.5. Fissile-mass Inventory for ZPR-3 Assembly-52F Reference Core

\begin{tabular}{|c|c|c|}
\hline Type ${ }^{a}$ of Drawer & Number & $\begin{array}{c}52 \mathrm{~F} \text { Loading } 52-70 \\
{ }^{239} \mathrm{Pu}+{ }^{241} \mathrm{Pu}+{ }^{235} \mathrm{U} \\
(\mathrm{kg})^{\mathrm{b}}\end{array}$ \\
\hline A & 163 & 170.34 \\
\hline$A^{*}$ & 151 & 120.50 \\
\hline Control (i-U-13) & 1 & 0.79 \\
\hline Control $(2-K-14)$ & 1 & 1.06 \\
\hline Safety & 8 & 17.23 \\
\hline Total & & 309.92 \\
\hline
\end{tabular}


(b) ${ }^{239} \mathrm{Pu}$ Reaction-rate Traverses in Assembly $52 \mathrm{~F}$.

Reaction-rate traverses were made in Assembly $52 \mathrm{~F}$ with a ${ }^{239}$ Pu fission counter. The counter was a brass, gas-filled assembly.* The axial and radial traverse results are tabulated in Tables I.B.6 and I.B.7, and plotted in Figs. I. B. 8 and I.B.9.

TABLE I.B.6. ${ }^{239} \mathrm{Pu}$ Axial Traverse through P-16 Assembly $52 \mathrm{~F}$ of ZPR-3

Counter: ${ }^{239} \mathrm{Pu} \# \mathrm{Q}\left(5.87 \mathrm{mg}{ }^{239} \mathrm{Pu}\right)$

Power: $\quad 3 \mathrm{~W}$ (controlled by autorod)

Indexer: The indexer indicated 35.43 in. when

the active portion of the counter was

approximately at the core center

\begin{tabular}{|c|c|c|c|c|c|}
\hline Indexer & Position (in.) & Counts $/ 30 \mathrm{sec}$ & Indexer & Position (in.) & Counts $/ 30 \mathrm{sec}$ \\
\hline & 4.43 & 13,566 & & 35.43 & 55,791 \\
\hline & 5.43 & 16,065 & & 36.43 & 55,063 \\
\hline & 6.43 & 19,226 & & 37.43 & 55,380 \\
\hline & 7.43 & 22,688 & & 38.43 & 54,318 \\
\hline & 8.43 & 26,035 & & 39.43 & 53,477 \\
\hline & 9.43 & 29,154 & & 40.43 & 53,161 \\
\hline & 10.43 & 32,464 & & 41.43 & 52,234 \\
\hline & 11.43 & 35,023 & & 42.43 & 51,476 \\
\hline \multirow[t]{13}{*}{. } & 12.43 & 37,331 & & 43.43 & 50,385 \\
\hline & 13.43 & 39,575 & & 44.43 & 49,446 \\
\hline & 14.43 & 40,616 & & 45.43 & 48,693 \\
\hline & 15.43 & 42,551 & & 46.43 & 48,720 \\
\hline & 16.43 & 43,539 & & 47.43 & 47,694 \\
\hline & 17.43 & 44,702 & & 48.43 & 46,468 \\
\hline & 18.43 & 45,339 & & 49.43 & 46,057 \\
\hline & 19.43 & 46,015 & & 50.43 & 45,640 \\
\hline & 20.43 & 46,299 & & 51.43 & 45,437 \\
\hline & 21.43 & 46,466 & & 52.43 & 44,565 \\
\hline & 22.43 & 47,555 & & 53.43 & 44,109 \\
\hline & 23.43 & 47,991 & & 54.43 & 43,446 \\
\hline & 24.43 & 48,608 & & 55.43 & 41,421 \\
\hline & 25.43 & 49,599 & & 56.43 & 40,242 \\
\hline & 26.43 & 50,270 & & 57.43 & 38,981 \\
\hline & 27.43 & 51,408 & & 58.43 & $36,5.96$ \\
\hline & 28.43 & 52,344 & & 59.43 & 34,259 \\
\hline & 29.43 & 53,330 & & 60.43 & 31,471 \\
\hline & 30.43 & 53,970 & & 61.43 & 28,771 \\
\hline & 31.43 & 54,445 & & 62.43 & 25,226 \\
\hline & 32.43 & 54,680 & - & 63.43 & 21,888 \\
\hline & 33.43 & 55,167 & & 64.43 & 18,286 \\
\hline & 34.43 & 55,542 & & 65.43 & 15,712 \\
\hline
\end{tabular}

*See Progress Report for May 1968, ANL-7457, p. 23, Fig. II.B.8. 
TABLE I.B.7. ${ }^{239} \mathrm{Pu}$ Radial Traverse in P-Row in Assembly $52 \mathrm{~F}$ of ZPR-3

Counter: ${ }^{239} \mathrm{Pu}$ \#Q $\left(5.87 \mathrm{mg}{ }^{239} \mathrm{Pu}\right)$

Power: $3 \mathrm{~W}$ (controlled by autorod)

Indexer: The indexer indicated $37.6 \mathrm{in}$. when

the active portion of the counter was

approximately at the core center

\begin{tabular}{cc|cc}
\hline Indexer Position (in.) & Counts/60 sec & Indexer Position (in.) & Counts/60 sec \\
\hline 9.76 & 19,809 & 37.76 & 107,579 \\
10.76 & 28,318 & 38.76 & 107,245 \\
11.76 & 39,708 & 39.76 & 105,274 \\
12.76 & 51,935 & 40.76 & 103,497 \\
13.76 & 62,974 & 41.76 & 101,303 \\
14.76 & 72,828 & 42.76 & 99,275 \\
15.76 & 80,746 & 43.76 & 95,272 \\
16.76 & 82,906 & 44.76 & 91,997 \\
17.76 & 82,254 & 45.76 & 85,564 \\
18.76 & 75,900 & 46.76 & 81,295 \\
19.76 & 61,051 & 47.76 & 77,962 \\
20.76 & 58,560 & 48.76 & 74,410 \\
21.76 & 59,704 & 49.76 & 72,101 \\
22.76 & 61,686 & 50.76 & 69,423 \\
23.76 & 65,240 & 51.76 & 66,197 \\
24.76 & 68,464 & 52.76 & 61,972 \\
25.76 & 72,252 & 53.76 & 60,449 \\
26.76 & 74,757 & 54.76 & 59,631 \\
27.76 & 77,462 & 55.76 & 64,685 \\
28.76 & 81,011 & 56.76 & 76,732 \\
29.76 & 87,085 & 57.76 & 84,382 \\
30.76 & 91.776 & 58.76 & 85,113 \\
31.76 & 95,128 & 59.76 & 81,401 \\
32.76 & 98,905 & 60.76 & 73,401 \\
33.76 & 101,081 & 61.76 & 63,710 \\
34.76 & 103,111 & 62.76 & 51,148 \\
35.76 & 104,677 & 63.76 & 39,113 \\
36.76 & 106,292 & 64.76 & 28,687 \\
\hline
\end{tabular}

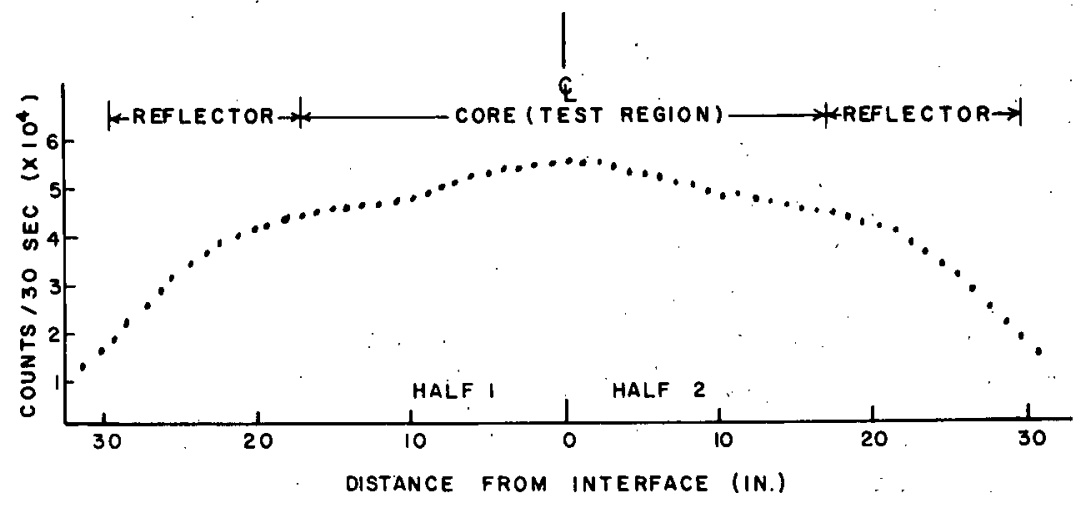

Fig. I.B.8. Reaction-rate Axial Traverse in ZPR-3 Assembly $52 \mathrm{~F}$ for ${ }^{239} \mathrm{Pu}$ 


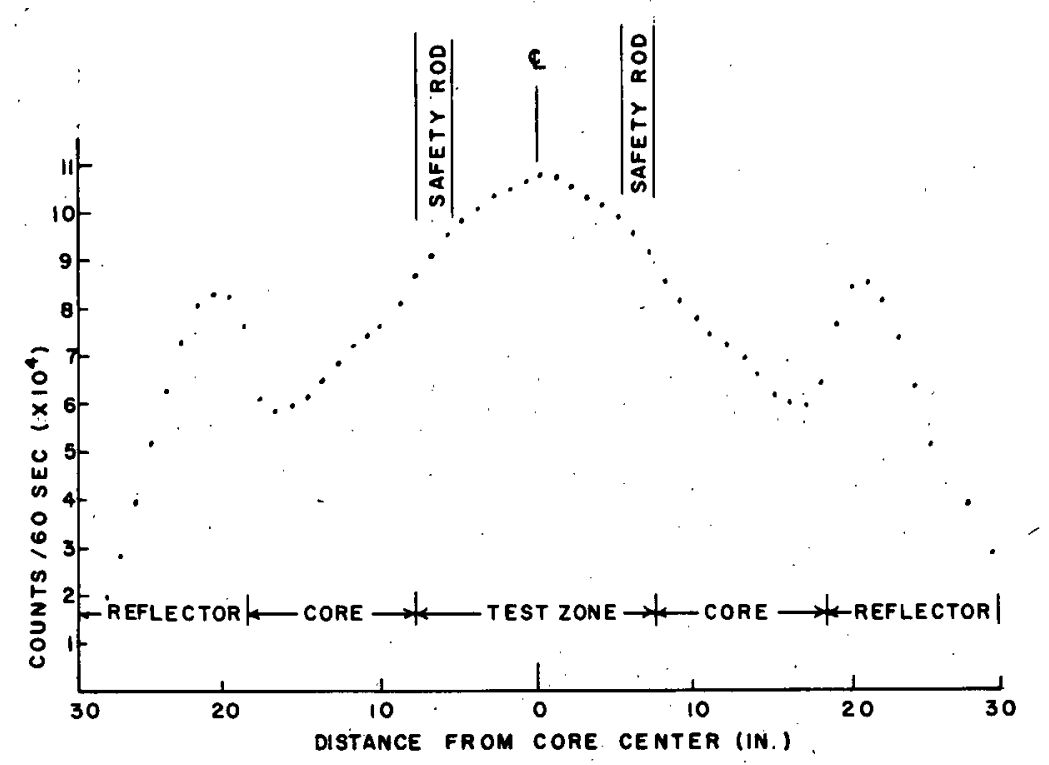

Fig. I.B.9. Reaction-rate Radial Traverse in ZPR-3 Assembly $52 \mathrm{~F}$ for ${ }^{239} \mathrm{Pu}$

(c) Reactivity Correction for Safety-rod Spiking. The reactivity effect of the increased fissile loading, or spiking, of the safety rods has been estimated for each of the Assembly-52 cores by using the worth of Safety Rod No. 1 and the reactivity effects of the spiking in Safety Rods Nos. 2 and 8. The results are given in Table I.B.8. The worth of Safety Rod No. 1 was measured in each core by the inverse kinetics method.

TABLE I.B.8. Corrections for Reactivity Spiking

\begin{tabular}{|c|c|c|c|}
\hline \multirow{2}{*}{$\begin{array}{c}\text { ZPR-3 } \\
\text { Assembly }\end{array}$} & \multirow{2}{*}{$\begin{array}{l}\text { Measured Worth of } \\
\text { Safety Rod No. } 1 \\
\text { (Ih) }( \pm 1 \%)\end{array}$} & \multicolumn{2}{|c|}{ Spiking Correction ${ }^{\mathrm{a}}$ (Ih) } \\
\hline & & To Initial Spiking & To No Spiking \\
\hline $52 \mathrm{~A}$ & 240 & - & 2210 \\
\hline $52 \mathrm{~B}$ & 223 & - & 2050 \\
\hline $52 \mathrm{C}$ & 177 & $\therefore$ & 1630 \\
\hline $52 \mathrm{D}$ & 298 & 1410 & 2750 \\
\hline $52 \mathrm{E}$ & 288 & 1370 & 2650 \\
\hline $52 \mathrm{~F}$ & 223 & $1060^{\circ}$ & 2050 \\
\hline
\end{tabular}

a The uncertainties for the spiking measurements in Assembly $52 \mathrm{E}$ are $\pm 1 \%$. All other values were obtained from these measurements and the Safety Rod No. 1 worths.

The spiking effect was measured in Assembly $52 \mathrm{E}$ (see ANL-7478, p. 12) by determining the degree of subcriticality with three different loadings of Safety Rods Nos. 2 and 8: unspiked, spiked as in Assemblies 52 A, B, and C, and more heavily spiked as in Assemblies $52 \mathrm{D}$, $E$, and $F$. It was assumed that the rods measured were typical of the other 
safety rods. The spiking corrections were estimated for the other Assembly-52 cores by assuming that the ratio of the spiking effect to the worth of the rod was the same.

Measurements were made in Assembly $52 \mathrm{~F}$ to check the assumption of a constant ratio of spiking effect to rod worth. The degree of subcriticality was measured for the three loadings of Safety Rod No. 8 measured in Assembly $52 \mathrm{E}$. The total worth of the safety rods was not large enough to allow the measurement of Safety Rod No. 2 also. The measured effect of removing all the spiking, when multiplied by eight to include all the rods, was $2170 \pm 110 \mathrm{Ih}$; the measured effect of reducing the spiking to its earlier value was $1070 \pm 50 \mathrm{Ih}$. These values agree with those predicted from the Assembly-52E data which are tabulated in Table I.B.8, i.e., 2050 and 1060 Ih. The values obtained from a single rod measurement would be expected to be as much as a few percent higher than those from a double rod measurement.

b. Basic Studies of Plutonium Systems. After completion and unloading of Assembly 52, required maintenance was performed on the reactor and loading of Assembly 53 was begun. Assembly 53 is the fourth of a series of six physics cores, of which Assemblies 48, 49, and 50 were the first three. The assembly is a plutonium-graphite system with a U-Pu ratio of 1.6 and a depleted-uranium blanket.

The approach to critical was inter rupted at approximately $70 \%$ of the calculated critical mass for measurements of the proton-recoil spectrum.

4. ZPPR Operations and Analysis (W. G. Davey and P. I. Amundson)

Last Reported: ANL-7478, pp. 30-33 (July 1968).

a. Basic Studies of Large Plutonium Systems

(i) Program. The loading of the first critical as sembly in ZPPR was initiated this month. As is usual, the initial stage consisted of the insertion of loaded core and reflector drawers in the matrix with depleted uranium in place of the plutonium-uranium-alloy fuel. The approach to criticality then was made by stepwise replacement of depleted uranium by fuel. No fissionable material was inserted into the assembly or will be, however, until final approval for the operation of the facility has been received.

ZPPR Assembly I has a calculated core volume of 1400 liters (which corresponds to a critical mass of $850 \mathrm{~kg}$ of ${ }^{239} \mathrm{Pu}$ plus ${ }^{241} \mathrm{Pu}$ ) and is thus of approximately Demonstration Plant size. The core composition corresponds to a mixed $\mathrm{PuO}_{2}-\mathrm{UO}_{2}$, sodium-cooled reactor. The approximate volume percentages of fuel, sodium, structure, and void (for power-reactor material densities) are 40,34, 17 and 9, respectively. 
The actual, "as-built" compositions will be determined by the final critical size and may be moderately different from the provisional data given here.

The inner axial and radial reflectors correspond to sodiumcooled, depleted uranium dioxide blankets. The outer reflector is depleted uranium metal. The estimated height-to-diameter ratio of the critical core is 0.3 , which is in the range of interest for large power reactors.

b. Doppler Effect

(i) Design. The design of the Doppler drive has been approved for construction. The design of the Doppler rod, that portion of the equipment which carries the Doppler sample in and out of the reactor, is being re-evaluated, because none of the designs for the cooling air system were considered satisfactory.

(ii) Equipment. Remote-control development is in progress

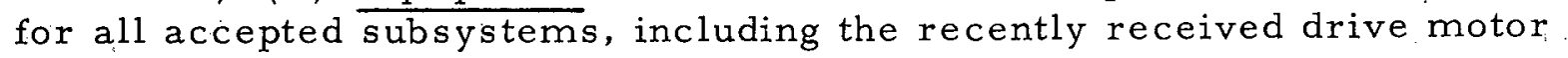
and control.

The only major systems not yet on hand are the ion pump and control, and the cooling air system.

The entire cooling air system is being reconsidered with a view to improving the design.

c. Reactor Equipment Development

(i) Experimental Equipment. The preparation for reactor experiments continues. The status of items of equipment under development is as follows:

(a) Assembly and inspection work of the perturbation sample changer continues. Work on the control system has been deferred because of increased emphasis on reactor startup.

(b) An internal-safety analysis of the axial traverse drive system has been completed. The drive system has been approved for construction. The drawer design is being subjected to further safety studies.

(c) Rod-timing and arc-suppression circuits have been designed and are being incorporated with the safety rods.

(d) The thermocouple system has been as sembled, and all thermocouples have been tested. Thermocouples have been installed in permanent matrix positions. 


\section{(ii) Automation of Data Acquisition}

(a) Digital Position Indicators. Construction is continuing on two digital position indicators.

(b) Buffer Scaler Register. Two buffer scaler registers are under construction. Both units will be incorporated in the dataacquisition and -recording system. One unit will provide data as to the number of records accumulated; the other will interface the digital clock to the data-acquisition and-recording system.

(c) Autorod Control. Bench testing of the autorod control system has been completed. Plans are being formulated for testing further the autorod and autorod control system in AFSR.

(d) Digital Clock. A digital clock has been constructed and is currently under test. The digital clock is part of the data-acquisition and -recording system, and will be used to provide timing for experiments and time of day for recording on the incremental magnetic tape system.

d. Heterogeneity. Computer codes are now nearly complete for the analysis of multichannel pulse-height-analyzer data obtained from fission foils. Some data have been processed with encouraging results. The results will be compared with previous hand calculations.

Two pairs of foils were recently exposed in ZPR-3 Assembly 52 . These foils were placed between the foil plates of back-to-back fission counters. The first pair of foils, of ${ }^{238} \mathrm{U}$ and ${ }^{239} \mathrm{Pu}$, was exposed to a marginally low integrated flux. The second pair of foils, of ${ }^{235} \mathrm{U}$ and ${ }^{238} \mathrm{U}$, was exposed at a considerably higher power. All four foils are being counted and evaluated for relative fission-product activity and count levels. The relative count-rate levels will assist in evaluating power level needs for future irradiations.

\section{ZPPR Construction ' (H. Lawroski)}

Last Reported: ANL-7478, pp. 33-34 (July 1968).

The filtration efficiency of the ZPPR gravel-sand filter was tested on August 8, 1968. The test aerosol, fluorescein, was generated from a solution of $0.5 \mathrm{w} / 0$ fluorescein in ethanol (pure grade). Samples for determining the aerosol characteristics were obtained from the inlet air stream by direct electrostatic precipitation onto electron-microscope grids during the performance of the test. Analyses of the aerosol indicated a count mean diameter of $0.108 \mu$ with a standard deviation of 1.62 . The calculated mass mean diameter was $0.277 \mu$. The test aerosol characteristics agreed very well with those obtained in laboratory tests previously performed. 
The aerosol concentration in the inlet air stream was sampled four times throughout the test. Calculations based on results for these samples indicated a fluorescein concentration of $2.93 \mu \mathrm{g} / \mathrm{ft}^{3}$ of inlet air. The variation in the samples was less than $\pm 13 \%$.

Seven samples were taken from the outlet air stream from the gravel-sand roof: two for a $1-\mathrm{hr}$ period of sampling, two for $2 \mathrm{hr}$, two for $3 \mathrm{hr}$, and one for $4 \mathrm{hr}$. A background sample was taken for a period of $3 \mathrm{hr}$ prior to the insertion of the aerosol. The sampling rate for each sample was $1 \mathrm{cfm}$. The background sample indicated no fluorescent materials which might interfere with the analysis of test samples. A critical review of the analytical technique indicated that $5 \times 10^{-4} \mu \mathrm{g}$ of fluorescein on a sample could be readily determined. Analyses of the seven air samples taken from the exhaust stream of the test indicated that the quantity of fluorescein penetrating the gravel-sand roof during the test was less than this value.

During the test period the air flow to the suspended ceiling of the reactor cell was measured by use of a pitot tube. The indicated flow was $1870 \mathrm{cfm}$ through the main supply duct, and about $100 \mathrm{cfm}$ through the loading tube, for a total of approximately $2000 \mathrm{cfm}$. Air-flow measurements out of the exhaust duct from the gravel-sand roof were made with a velometer, and they agreed quite well (within 10\%) with the supply air measurements.

The pressure drop across the gravel-sand roof for the 2000-cfm flowrate was 1.25 in. $\mathrm{H}_{2} \mathrm{O}$ as measured by a static pressure tap from the cell. The originally estimated pressure drop for this flowrate on the basis of laboratory data was 1.5 in. $\mathrm{H}_{2} \mathrm{O}$.

By considering the minimum acceptable analysis limit of $5 \times 10^{-4} \mu \mathrm{g}$ of fluorescein, the sampling rate, and the inlet aerosol concentration, the minimum attenuation of the test aerosol was determined to be $1.4 \times 10^{6}$. Data obtained from laboratory tests had indicated that a single $30-i n$. bed of 20 - to 50-mesh sand would have an attenuation of $5 \times 10^{4}$, which was the basis for the design of the ZPPR cell roof.

Adverse weather conditions prevented testing the emergency sand filter and the HEPA filters in the backup containment structure. 
C. Component Development---LMFBR

1. Sodium Technology Development

a. Engineering Development

(i) Sampling Development (J. R. Humphreys)

Last Reported: ANL-7460, pp. $31-33$ (June 1968).

(a) Nonradioactive-sodium Distillation Sampling. Additional modifications are being made on the line distillation sampler on the Sodium Analytical Loop (SAL) to improve the guide and alignment system of the sample cup stem. This is necessary to' $r$ educe cup vibration during the transport operation.

(b) Bypass Freeze Sampling. Installation of the vacuum distillation equipment inside the inert atmosphere glovebox has been completed. No major problems were encountered in several distillation runs.

The earlier procedure was to place a sample in the distillation apparatus, seal the apparatus, and remove it from the glovebox. It was then attached to a vacuum system, evacuated, and inductively heated to distill the sodium. The new method eliminates the possibility of sample contamination by room air and moisture when the distillation apparatus is being evacuated.

(ii) Monitoring Development (S. B. Skladzien)

Last Reported: ANL-7478, p. 36 (July 1968).

(a) Monitoring of Sodium Electrical Resistivity. The monitoring of sodium resistance in the Sodium Analytical Loop is continuing. An analysis is being made of the effects of differential sodium temperature between the inlet and outlet of the dc resistance meter. The unit is designed with vacuum insulation and radiation shields to minimize temperature losses; in addition, a line heater is installed to balance such losses. In this analysis, the change of temperature is being adjusted by this line heater power and its effect on total sample-leg resistance is being noted. From this will come operating specifications for the dc resistance meter.

(iii) General-impurity Saturation-temperature Monitoring. The next-run series in the Sodium Analytical Loop will be a general calibration of the on-line monitoring systems to impurity levels as controlled by coldtrap temperature. These systems include a dc electrical-resistivity device, two UNC electrochemical oxygen cells, a plugging meter, and two distillation samplers: dip-cup and line types. The modified cold trap with the new cooling coils has been reinstalled in the system, and temperature 
scans have been completed to locate the coldest point in the crystallizer vessel at a series of nominal operating temperatures up to $500^{\circ} \mathrm{F}$.

The recently developed cyclic mode of plugging-meter operation (at LASL) appears to have great potential as an information source on the impurity levels in sodium systems, giving both plugging and deplugging temperatures for greater reliability in establishing a saturation temperature. The partially plugged state of the orifice tends to minimize the temperature overshoot by "seeding" precipitation processes. An attempt was made to run the existing plugging loop in the partially plugged cyclic mode. Tests were made using a regular 12 -fluted, early EBR-II design and a single-hole orifice with the system containing about $30 \mathrm{ppm}$ oxygen. In both cases, the flowrates were remarkably insensitive to plugging-valve temperatures. It was possible to control the flowrate at $50 \%$ plugged flow to within $5 \%$ while the temperature oscillated in a cyclic but irregular fashion in as high as a $100^{\circ} \mathrm{F}$ span. The design of the plugging system allows precipitation upstream from the plugging orifice in a length of nearisothermal tubing. Such deposition and dissolution could lead to the same instabilities as those observed in this system. The plugging unit is being redesigned to eliminate this isothermal section upstream from the plugging valve.

2. Reactor Mechanism and Instrumentation

a. Instrumentation Development

(i) Fission-Gas Pressure Transducer Evaluation and Development (J.R. Folkrod)

Last Reported: ANL-7478, p. 42 (July 1968).

(a) Null-balance System. The ANL null-balance pressure transducer has successfully passed 250 thermal shock cycles without any performance deterioration. Each cycle raised the transducer temperature from 400 to $900^{\circ} \mathrm{F}$ in one hour, then dropped it back to $400^{\circ} \mathrm{F}$ in $2.5 \mathrm{~min}$.

Concurrently, a test was run to determine the relationship of temperature and the pressure differential between the reference gas and process gas. This differential pressure decreased slightly with decreasing temperature. The data obtained were so scattered that no reasonable fitting or correlation with temperature could be accomplished; nevertheless, this effect is within the accuracy of the readout device. Another method is being investigated to correlate the temperature effect upon pressures. 
b. FFTF Instrumentation
(i) In-core Flowmeter Development
(G. F. Popper)

Last Reported: ANL-7478, pp. $42-44$ (July 1968).

(a) Magnet Thermal and Mechanical Tests. The magnetometer furnace test apparatus has been used to determine the reversible temperature effects up to $1200^{\circ} \mathrm{F}$ of Alnico-5, -6 , and -8 rod magnets having an L/D (length-to-diameter ratio) of 2. The results are shown in Fig. I.C.l. The changes reported are in terms of $B_{i}$, the intrinsic induction, rather than the more conventional $\mathrm{B}_{\mathrm{d}}$, the residual induction of the magnet. Before the measurements, the magnet samples were temperature-stabilized to $1200^{\circ} \mathrm{F} *^{*}$

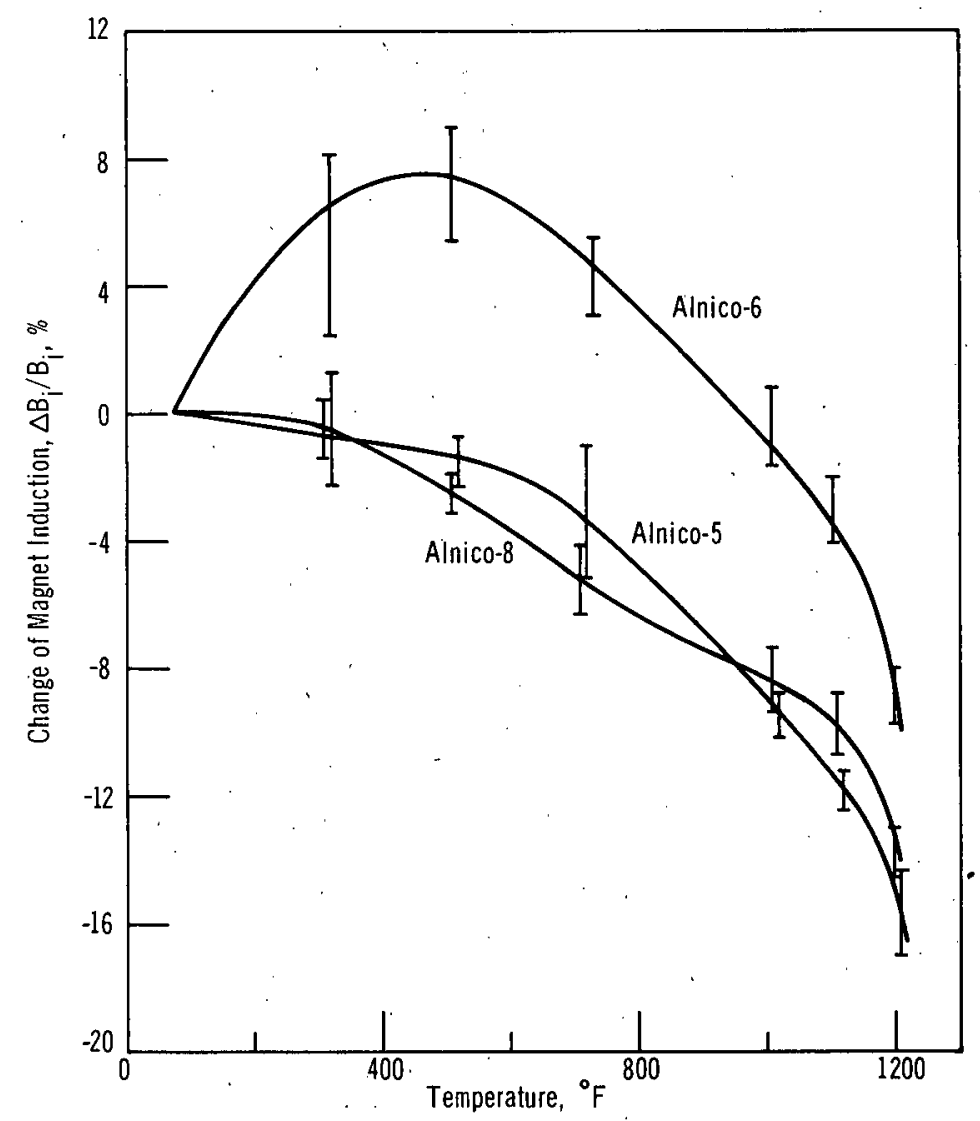

Fig. I.C.1

Reversible Changes in Remanence of Rod Magnets with an $\mathrm{L} / \mathrm{D}$ of 2 . The bars show the maximum deviation from the mean for all samples tested.

(b) Prototype Permanent-magnet Flowmeter Tests. There has been no response from industry to fabricate the EBR-II flowmeters, so a delay is expected in the procurement for FFTF. A preliminary design of the prototypical FFTF flowmeter for the CCTL has been completed.

\footnotetext{
* Standard Prócedure for Temperature Stabilizing Alnico Permanent Magnets, ANL Specification ANL-HTILMFBR-406, June 1968.
} 
(ii) Signal Lead Connectors for Sodium Service (A. P. Grunwald)

Last Reported: ANL-7445, p. 34 (Ap'il 1968).

Early in the July checkout, it became apparent that the lower male portion of the FFTF Prototype Signal Lead Connector of the assembly became more tightly engaged in the sleeve of the transition piece; no change was observed in the relationship of the upper male portion to the same sleeve. After several weeks during installation and test at low temperatures, the tightening progressed to the point where a definite interference fit resulted.

When the unit was removed from the testing rig and disassembled, it was found that both mating parts were still round within $<0.002$ in., but the sleeve ID was smaller than the pretest nominal value of 4.500/4.50l in. The smallest diameter, 4.495/4.496 in., was at "datum A" (see Fig. I.C.2). The length of the reduced area was $\sim 2 \frac{1}{2}$ in., and the decrease occurred gradually and regularly and was centered around "datum A."

From the location of the diameter reduction with respect to the seal weld between the sleeve and the wrench flats, it seems likely that stresses that introduced creep in the weld zone were responsible for the mishap.

The sleeve was remachined to $4.500 / 4.501$ in. To avoid further deformation, the sleeve was wrapped with heater wire, thermocouples attached, and an asbestos blanket applied. Several heating and cooling cycles were performed; the ID of the sleeve was measured twice during each cycle--at temperature and after cooling (soaking temperatures were $150,250,300$, and $360^{\circ} \mathrm{F}$ ). After each cycle, the diameter returned to $4.500 / 4.501 \mathrm{in}$.

The connector unit is being reassembled and the springforce calibrations (which were interrupted by the distortion of the sleeve) are being resumed. Temperature testing and experiments in sodium will follow.

3. Fuel Handling, Vessels, and Internals--Core Component Test Loop (R. A. Jaross)

Last Reported: ANL-7478, p. 45 (July 1968).

The FFTF fuel subassembly flow testing program continued in the CCTL. The desired operating conditions for this test of $400 \mathrm{gpm}$ flow at $1060^{\circ} \mathrm{F}$ were reached on July 23 . Operation continued at those conditions until August 16, when a small sodium leak occurred in the bottom seal 


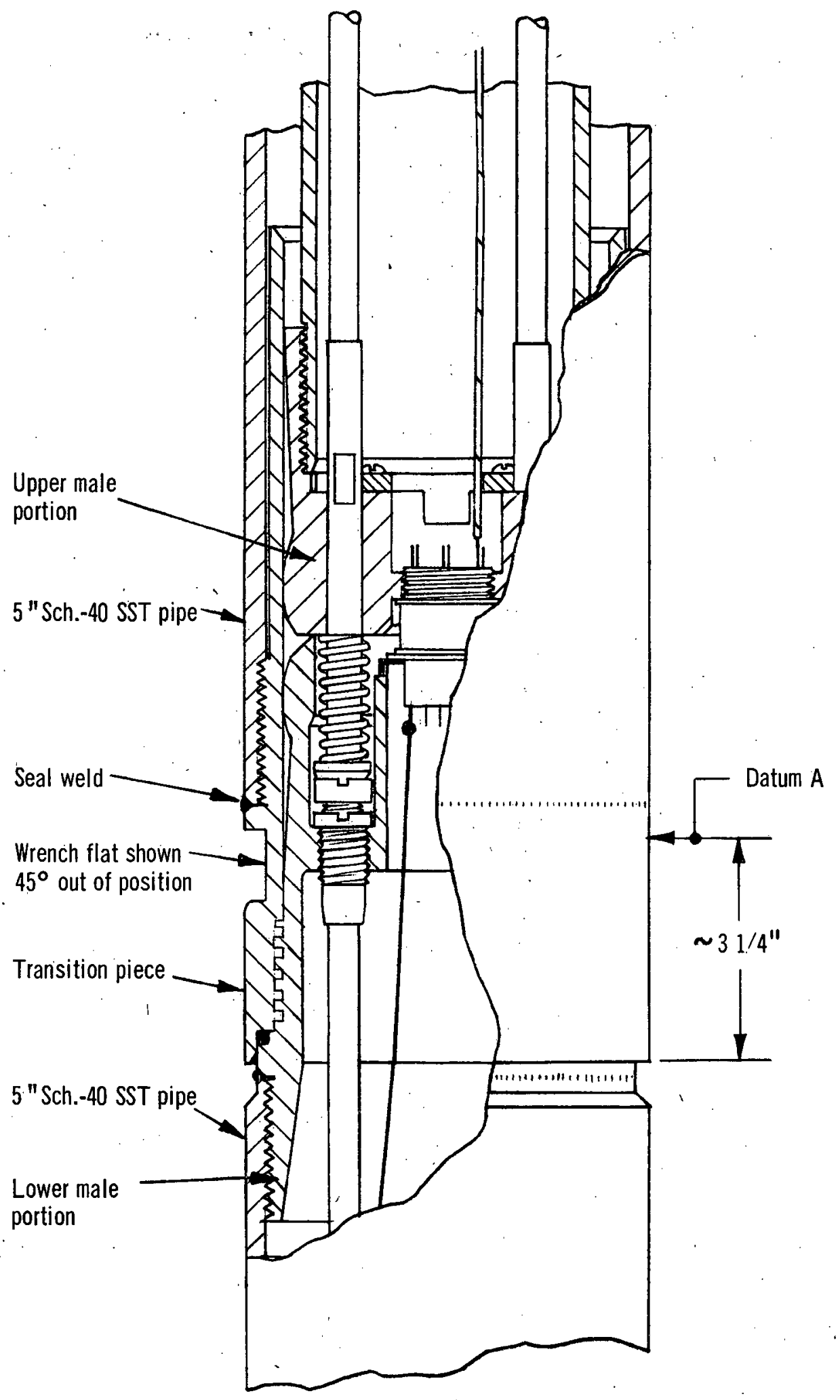

Fig. I.C.2. Signal Lead Connector 
valve of the cold-trap system. This is a bellows-sealed valve with conventional packing for seal backup. Sodium leakage was limited to a. small buildup around the valve hand wheel. There was no leakage of liquid sodium to the test facility enclosure and no sodium fire. A replacement bellows assembly is being installed. The cause of the failure has not yet been determined. The loop as well as all of the remaining loop components and instrumentation have operated reliably. An operating factor of approximately $97 \%$ was achieved between July 23 and August 16.

The leakage of pump seal oil reported in ANL- 7478 has continued and appears to have stabilized at about 0.6 liter/hr. The oil has been carefully collected and measured, and an accurate inventory of the oil in the 'system has been maintained. The results tend to confirm the pump manufacturer's position that although this rate of oil leakage is excessive, it is tolerable and that the oil does not leak into the loop and contaminate the sodium. This conclusion is also confirmed by carbon analysis of sodium samples.

Although the oil leakage rate is considered acceptable, it is higher than desired, and the experience to date suggests that this condition will not improve, such as might occur as a result of "wear-in". of the seal. Also, comparison of the leakage experience with this and other pumps suggests that the seal leakage may be the result of inaccurate assembly. Consequently, plans are being developed to disassemble the upper bearing and seal assembly to permit inspection of the component parts.

Analyses of two sodium samples taken on July 29 indicate carbon concentrations of 22 and 14 ppm (as compared to an average value of 19 ppm after original filling of the loop).

\section{Systems and Plant--LMFBR}

1. 1000-MWe Plant

a. Contract Management, Technical Review and Evaluation (L. W. Fromm)*

Last Reported: ANL-7478, pp. 45-47 (July 1968).

The work scopes for three additional development studies (pooltype primary system, refueling system, and dynamic analysis and control) are being prepared and plans made for their implementation. RDT has indicated that they plan to make funds available to ANL this fiscal year to start these studies.

* See also Sect. III.A.5. 
The Atomics International contract supplement has been approved by $\mathrm{CH}-\mathrm{AEC}$ and $\mathrm{ANL}$, and sent to the contractor for his approval.

Arrangements have been completed for General Electric to present the results of their $1000-\mathrm{MWe}$ study work to RDT personnel on September 10-11, 1968. Tentative plans àre being made for similar presentations by Westinghouse and Atomics International later in September and in October, respectively.

(i) Babcock \& Wilcox Co. Subcontract. In conjunction with Tasks II and III, draft conceptual system design descriptions (CSDD) were received for the reactor vessel, instrument and control, reactor support, intermediate coolant, and plant electrical systems.

In the Task-IV area, the contractor has essentially completed Subtask I which identifies and classifies the research and development requirements for the reference concept. Preparation of the SubtaskII program descriptions is approximately 50\% complete.

The quarterly report for the period March 1, 1968 to May 31, 1968 has been written.

(ii) Westinghouse Electric Corp. Subcontract. System design descriptions have been completed for the fuel handling, plant equipment, cleanup and decontamination, cover gas, and various sodium auxiliary systems. The trade-off study of the modular versus the right circular cylindrical core has been initiated. Also, the plant availability study has been started.

The Task-III reference plant has been defined with the aid of computerized optimization studies. Through use of this information, design has started on the intermediate heat exchangers, steam generators, and sodium pumps, as well as the final architect-engineering.

The radial neutron and blast shield has been defined.

Definition of the requirements for the research and development program for the systems and components are approximately $80 \%$ complete. The research and development requirements for sodium technology have been drafted.

(iii) General Electric Co. Subcontract. The Task-II report has been drafted.

The Task-III core parametric work has been completed. Final drawings of the reactor, the mechanical components, and the fuelhandling system have been completed. The optimization studies for the core and system have been integrated. 
The final drawings from the architect-engineer have been received. The cost of the mechanical components is being estimated.

The Task-IV work has been started, and a preliminary draft is scheduled for completion the end of August.

(iv) Combustion Engineering, Inc., Subcontract. The final volume of the Task-II and -III report, Volume III, has been delayed and is expected to be issued in September.

The Task-IV work is about 50\% complete. The work during the month concentrated on core design for which information is needed to define research and development programs.

(v) Atomics International Subcontract. Atomics International's expenditures on the $1000-\mathrm{MWe}$ work is now over $80 \%$ of the total contract amount. All major Task-III analytical activities have been completed, and interpretation of the parametric study results is underway. Differential power costs over a range of reactor outlet temperatures have been developed for the base and variations of the fuel cycle and equipment costs.

Preparation of component CSDDs is continuing, with revision of the major CSDDs to follow.

Comparison of the AI cylindrical-geometry core with a modular core will be based on the reference core developed during the LMFBR Task Force Fuel Cycle Study, rather than the 10-module reactor design developed earlier. 
E. EBR -II

1. Research and Development

a. EBR-II System Design Descriptions (E. Hutter)

Last Reported: ANL-7478, p. 47 (July 1968).

Work continues on the draft manuscript for Volume II, Primary

System. All material to be submitted for review in the future will be prepared and submitted by chapters, rather than as topical paragraphs that are portions of chapters.

b. Reactor Experimental Support--Reactor Analysis and Testing

(R. R. Smith)

Last Reported: ANL-7478, pp. 47-51 (July 1968).

$\rightarrow$ (i) Nuclear Analysis and Safety

(a) Flux-Wire Irradiations: Two sets of flux-wire irradiations were performed during Run 29D, the first to map a general flux profile across the reactor, and the second to provide details of flux perturbations near control rods and experiments. Results of the first mapping agreed within a few percent with reaction-rate patterns previously observed in Run 25A, in which there was similar core geometry. Detailed results of the numerical values will be reported later.

(b) Insertion of a 91-pin, 70\% Enriched Subassembly. Calculated flux distributions that are used to predict the reactivity of loading changes were updated to reflect the change to a depleted-uranium blanket and a 91-subassembly core. The flux patterns were obtained from MACH-I calculations in cylindrical geometry by means of transverse buckling derived from two-dimensional calculations (with cross-section set 238 ). The calculated reaction rates agreed with experimental foil-irradiation data of Run 29D to within a few percent.

Three measured loading changes were compared with reactivity calculations at the start of Run 29D, and a factor of 1.3 was required to adjust the calculations to fit experimental data. After this adjustment, the calculated loss between Runs $29 \mathrm{C}$ and $29 \mathrm{D}$ was 252 Ih (measured: $247 \mathrm{Ih}$ ). The calculated change for the restoration of fuel in place of flux wires and relocation of experimental Subassembly XO36 from position $7 \mathrm{E} 4$ to $7 \mathrm{E} 1$ was 102 Ih (measured: $96 \mathrm{Ih}$ ). The calculated (and measured) change from a half-loaded to a fully loaded subassembly in position $4 \mathrm{~A} 3$ was 183 Ih. 
At the end of Run 29D, a $91-$ pin, $70 \%$ enriched experimental subassembly, in which the temperature change of sodium was about $33 \%$ greater than in a normal subassembly, was inserted in the reactor. A good advance estimate of the worth of this subassembly was particularly desirable to have, so that if flux peaking occurred in the enriched region it would be recognized by the associate reactivity perturbation. The method for calculating its worth was that discussed above.

This method yielded a value of 119 Ih for the interchange of the $70 \%$ enriched subas sembly for a normal, $52.5 \%$ enriched subassembly. This value was confirmed by subsequent experimental measurement. This agreement was regarded as fairly good evidence that no undesirable flux peaking occurred in the enriched subassembly.

The gamma scan of an irradiated 37 -pin, $70 \%$ enriched subassembly also showed no significant evidence of flux peaking.

However, a control rod adjacent to the enriched subassemblies was found by calibration to have about $5 \%$ greater reactivity worth than previously, indicating slight possible peaking in the neighborhood of the enriched subassembly. Available evidence indicates that the flux peaking in the vicinity of the $70 \%$ enriched subassembly was slight, and that fuel temperatures would not significantly exceed the values calculated from "unperturbed fluxes.

(c) Mark-IIA Safety Analysis--Code Development. Asimple method of computing subassembly reactivity worth for safety studies is being developed. The computer code W $\phi \mathrm{RTH}$ was written, and several test cases submitted. The results of the test cases are tabulated in Table I.E.1, and compared with calculations by Kirn and Dean. The Kirn-Dean calculations have been multiplied by 1.3 to agree with experimental substitution worths: The values calculated with the $\dot{W} \phi R T H$ code do not require any experimental adjustment, but $W \phi R T H$ appears to overpredict near the core center and underpredict near the core edge.

TABLE I.E.1. Galculated Subassembly Worth

\begin{tabular}{|c|c|c|c|c|c|c|c|c|}
\hline \multirow{2}{*}{$\begin{array}{c}\text { Core } \\
\text { Position }\end{array}$} & & \multicolumn{3}{|c|}{ Subassembly } & & \multicolumn{2}{|c|}{ Reactivity (Ih) } & \multirow{2}{*}{$\begin{array}{l}\text { Deviationa. of } \\
\text { W } \phi \text { RTH from } \\
\text { Kirn-Dean (\%) }\end{array}$} \\
\hline & & Withdrawn & & Inserted & . & W $\phi \mathrm{RTH}$ & Kirn-Dean & \\
\hline $1 \mathrm{~A} 1$ & & 2162 & & $w-13$ & & -66.4 & -60.2 & +10.3 \\
\hline $2 \mathrm{El}$ & & 2038 & & 2107 & & 1.24 & 1.09 & +13.8 \\
\hline 3.22 . & & 291 & & 2106 & ' & 7.46 & 7.53 & -0.93 \\
\hline $3 \mathrm{E} 2$ & & 2066 & & $w-14$ & & -22.2 & -23.6 & $\because-5.9$ \\
\hline $3 \mathrm{Fl}$ & & 2121 & & 2103 & & 6.16 & 6.47 & $\therefore-4.8$ \\
\hline $4 \mathrm{Al}$ & & 2134 & & $W-15$ & & -15.0 & -17.0 & $-11.8^{\circ}$ \\
\hline $4 \mathrm{~B} 1$ & & 2.166 & & 2080 & & -42.2 & -42.8 & -1.4 \\
\hline $4 \mathrm{Cl}$ & & 2051 & : & 2174 & & 1.14 .0 & 119.0 & $=4.2$ \\
\hline $4 \mathrm{Fl}$ & $"$ & 2165 & $\because$ & 2104 & & -39.9 & -41.8 & -4.5 \\
\hline $5 B 4$ & & 2070 & & $W-16$ & & -15.0 & -16.9 & -11.2 \\
\hline
\end{tabular}

${ }^{a}$ A positive sign signifies overprediction and a negative sign underprediction. 
In the calculation, spherical reactor geometry is assumed. Real and adjoint fluxes are computed, from which is otope worth per kilogram is obtained as a function of radius. The subassembly reactivity worth is obtained as a function of spherical radius by superimposing weighted isotope worths. A fourth-order polynomial of the form

$$
w(x)=a_{0}+a_{1} r^{2}+a_{2} r^{3}+a_{3} r^{4}
$$

is least-squares fitted to subassembly worth distribution in spherical geometry. The spherical radius $r$ is identified with the cylindrical radius $R$ and the axial position $z$ by

$$
r=\left(R^{2}+z^{2}\right)^{1 / 2}
$$

The subassembly worth in the cylindrical system is then computed from

$$
W(R)=\frac{1}{H} \int_{-H / 2}^{H / 2} W(r) d z,
$$

where $H$ is the subassembly height.

An improvement which would use one-dimensional cylindrical geometry instead of spherical geometry is under consideration. This approach has the disadvantage of requiring specification of the energydependent axial bucklings ( 22 for 22 energy groups).

The modification of the M $\varnothing$ NA code through contract

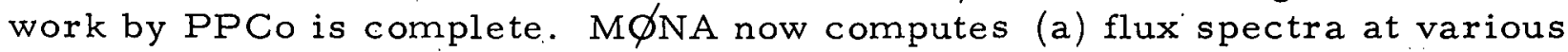
mesh points, (b) reaction rates and reactor-rate ratios, (c) detailed neutron balance by energy groups, (d) spectral indices (median and average flux energy, and median and average fission, absorption, and capture energies), (e) total flux, and (f) critical enrichment.

$$
\text { c. Nuclear Analysis Methods Development (P. J. Persiani) }
$$

Last Reported: ANL-7478, pp. 51-54 (July 1968).

(i) Investigation of a Mixed Oxide Fuel for EBR-II. Some of the characteristics of a mixed oxide fuel loading for EBR-II were investigated in a series of one-dimensional diffusion-theory (by MACH 1 Code)* calculations. EBR-II was represented in spherical geometry, and cross section Sets Nos. 224 and 238 were used.

The EBR-II core was assumed to contain 64 mixed oxide fuel subassemblies, 14 control or safety subassemblies ( $2 / 3$ loading of fuel.S/A),

* Meneley, D. A., Kvitek; L. C., and O'Shea, D. M., MACH 1, A One-dimensional Duffusion-theory Package, ANL-7223 (June 1966). 
and 13 experimental subassemblies ( 9 containing fuel and 4 containing structural material). For the seven-row core (containing 127 subassemblies) the types of subassemblies were assumed to occur in the same proportion as in the 6-row core (containing 91 subassemblies). A fuel subassembly is composed of $36 \mathrm{v} / 0$ fuel, $44 \mathrm{v} / 0$ sodium, and $20 \mathrm{v} / \mathrm{o}$ steel. The fuel is $\mathrm{UO}_{2}-20 \mathrm{v} / 0{ }^{239} \mathrm{PuO}_{2}$ at $85 \%$ theoretical density. A total of eight arrangements of the mixed oxide loading were investigated with both cross-section sets.

A description of the arrangements and some results of the calculations using Set No. 224 are presented in Table I.E.2. Although the results based on the two cross-section sets differ somewhat, the trend and general magnitude of the results may be obtained from the data in Table I.E.2.

TABLE I.E.2. Description and Results of One-dimensional Calculations of EBR-II

\begin{tabular}{|c|c|c|c|c|c|c|c|c|c|}
\hline Problem No: & 301 & 306 & 307 & 308 & 309 & 310 & 311 & 312 & 313 \\
\hline Core Loading & Run 27 & Oxide & Oxide & Oxide & Oxide & Oxide & Oxide & Oxide & Oxide \\
\hline Number of Rows & 6 & 6 & 6 & 6 & 6 & 6 & 7 & 7 & 7 \\
\hline Reflector Material & SS & $\mathrm{Ni}$ & $\mathrm{Ni}$ & $\mathrm{Ni}$ & SS & None & $\mathrm{Ni}$ & $\mathrm{Ni}$ & None \\
\hline Number of Rows & 2 & 2 & 4 & 9 & 2 & & 3 & 8 & \\
\hline Blanket & Dep U & Dep U & Dep U & None & Dep U & Dep U & Dep U & None & Dep U \\
\hline U enrichment $(\mathrm{a} / \mathrm{o})$ & $\sim 50$ & 52.9 & 48.2 & 45.0 & 57.8 & 57.6 & 35.6 & 32.1 & 42.2 \\
\hline$\nu \Sigma_{f} \max / a v g$ & 1.44 & 1.40 & 1.35 & 1.31 & 1.44 & 1.47 & 1.42 & 1.37 & 1.52 \\
\hline $\begin{array}{l}\phi(0) \times 10^{15} \text { at } 45 \mathrm{MW} \\
\mathrm{Na} \text { worth }\end{array}$ & 2.5 & 3.1 & 3.2 & 3.3 & 3.0 & 2.7 & 2.7 & 2.9 & 2.5 \\
\hline$-\Delta \mathrm{k} / \mathrm{k} / \Delta \nu \times 10^{9}$ & 2.6 & 3.8 & 3.8 & 3.7 & 3.7 & 3.3 & 2.7 & 2.5 & 2.5 \\
\hline
\end{tabular}

${ }^{a}$ Based on a $1 \%$ decrease of sodium density in core center.

Before interpreting the results, one must realize the broad scope of the study and approximate nature of representing the reactor. The results indicate relative magnitudes and the directions of trends; the data are not useful for design applications.

The uranium enrichment for criticality ranges between $32 \mathrm{a} / \mathrm{o}$ (7-row core with full nickel reflector) to $58 \mathrm{a} / \mathrm{o}$ (6-row core with steel or depleted uranium around the core). There seems to be no problem in this area. The enrichment can be increased significantly if the need arises. Also, most modifications of the reactor, such as increasing the thickness of the nickel reflector, do not require large variations in enrichment of the core. The assumed ${ }^{239} \mathrm{Pu}$ content of the blanket is too large in these calculations, causing the enrichment for Problem 310 to be a little low.

A 6-row, oxide-fueled core has a larger sodium worth than a 6-row, metal-fueled core, whereas a 7-row, oxide-fueled core has about the same sodium worth as the 6-row, metal-fueled core. The ratio of peak to average power density depends mostly on reflector or blanket material rather than on the fuel or size of the core. For the same power level the flux at the reactor center is slightly greater in an oxide fuel loading than for a metal fuel loading; thus the flux level in an oxide- or metal-fueled core depends more strongly on the engineering limits to power production than on neutronic considerations. As mentioned previously, the engineering 
aspects are not considered here. Calculations indicate that one gram of

${ }^{239} \mathrm{Pu}$ is equivalent to $1.75 \mathrm{~g}$ of ${ }^{235} \mathrm{U}$. Use of this relationship yields the same equivalent loading of ${ }^{235} \mathrm{U}$ in both the oxide and metal fuel cores.

There are important neutronic characteristics, such as the power coefficient and dynamic properties, which have yet to be investigated. Any conclusion as to the desirability of an oxide fuel loading of EBR-II must wait for a complete analysis.

(ii) Calculation of Heating Rates in Reflector or Inner Blanket of EBR-II. To obtain the neutron and gamma heating rates from the MAC code, * the neutron-flux distribution must first be calculated. The SNARG code** has been used to calculate the flux for the cases given in Table I.E.3. The core dimension in spherical geometry is obtained by a critical-radius search for the Run-27A loading. The value of $\mathrm{k}_{\mathrm{eff}}$ was then calculated for other loadings based on the equivalent dimensions for the spherical representation of EBR-II above. The value of $k_{e f f}$ for a blanket system is a little higher than experimental measurements and is being investigated.

TABLE I.E.3. Description and Results for SNARG Problems

\begin{tabular}{|c|c|c|c|c|c|}
\hline Problem No.: & 1027.00 & 1027.02 & 1027.10 & 1027.20 & 1027.30 \\
\hline $\begin{array}{l}\text { Core Material } \\
\text { Number of Rows }\end{array}$ & $\operatorname{Run}_{6} 27 \mathrm{~A}$ & $\underset{6}{\operatorname{Run} 27 \mathrm{~A}}$ & $\underset{7}{\operatorname{Run}} 27 \mathrm{~A}$ & $\begin{array}{l}\text { Run 27A } \\
6+3 \text { Subassemblies } \\
\text { in Row } 7\end{array}$ & $\operatorname{Run}_{6} 27 \mathrm{~A}$ \\
\hline Reflector Material & None & SS & $\mathrm{Ni}$ & $\mathrm{Ni}$ & $\mathrm{Ni}$ \\
\hline Number of Rows & - & 2 & 3 & $4-3$ Subassemblies & 9 \\
\hline Blanket & Dep U & Dep U & Dep U & Dep U & None \\
\hline$S_{n}$ Order & 8 & 8 & 2 & 2 & 2 \\
\hline $\begin{array}{l}\text { Initial } k_{\text {eff }} \\
\% \text { Fuel Replaced }\end{array}$ & 0.997 & 1.000 & 1.150 & 1.075 & 1.076 \\
\hline by Steel & $\therefore$ & - & 5.6 & 2.0 & 2.3 \\
\hline $\begin{array}{l}\mathrm{S}_{\mathrm{n}} \text { Order for } \\
\text { Fuel Replacement }\end{array}$ & - & - & 8 & 8 & 8 \\
\hline
\end{tabular}

For the last three loadings, enough fuel was replaced with steel to obtain a system which was just critical. The results are included in Table I.E.3.

The fluxes generated from these problems are being used as input into the MAC code.

\footnotetext{
* Peterson, E. G., MAC-A Bulk Shielding Code, HW-73381 (April 1962).

** Duffy; G. J., et al., SNARG-1D, A One-dimensional Discrete-ordinate Transport Theory Program for the CDC-3600, ANL-7221 (June 1966).
} 
d. Fuel Performance Studies--Mark I Series

Last Reported: ANL-7478, p. 54 (July 1968).

(i) Irradiation of Encapsulated Mark-IA Fuel Elements (M. A. Pugacz)

Irradiation of experimental Subassembly XO17 containing five Mark-IA encapsulated fuel elements was to be completed August 13 at the end of Run 29 with EBR-II. At that time, experimental Subassemblies XO17 and XO15 had been exposed to $7220 \mathrm{MWd}$ of operation. The status of the irradiations of the current encapsulated Mark-IA fuel elements is shown in Table I.E.4.

TABLE I.E.4. Status of the Irradiations of the Encapsulated Mark-IA Fuel Elements

\begin{tabular}{|c|c|c|c|c|c|}
\hline $\begin{array}{l}\text { Element } \\
\text { No. }\end{array}$ & $\begin{array}{c}\text { Subassembly } \\
\text { No. }\end{array}$ & $\begin{array}{l}\text { Max ID } \\
\text { Cladding } \\
\text { Temp } \\
\left({ }^{\circ} \mathrm{F}\right)\end{array}$ & $\begin{array}{c}\text { Target } \\
\text { Burnup } \\
(\mathrm{a} / \mathrm{o})\end{array}$ & $\begin{array}{c}\text { Current } \\
\text { Burnup } \\
(\mathrm{a} / \mathrm{o})\end{array}$ & Remarks \\
\hline $\mathrm{BF} 02$ & XO15 & 913 & 3.5 & 2.3 & \multirow{2}{*}{$\begin{array}{l}\text { Continuing } \\
\text { irradiation }\end{array}$} \\
\hline $\mathrm{BF} 03$ & $\mathrm{XO} 15$ & 913 & 3.5 & 2.3 & \\
\hline BF 04 & XOl7 & 936 & 2.25 & 2.3 & \multirow{5}{*}{$\begin{array}{l}\text { Irradiation } \\
\text { terminated }\end{array}$} \\
\hline BF05 & XO17 & 936 & 2.25 & 2.3 & \\
\hline $\mathrm{BF} 08$ & XO17 & 936 & 2.25 & 2.3 & \\
\hline BF 09 & $\mathrm{XO} 17$ & 936 & 2.25 & 2.3 & \\
\hline BFll & XOl 7 & 936 & 2.25 & 2.3 & \\
\hline BF01 & $\mathrm{XO} 28$ & - & 3.0 & 0.55 & \multirow{4}{*}{$\begin{array}{l}\text { Out of reactor; } \\
\text { request made for } \\
\text { reinsertion }\end{array}$} \\
\hline BF 06 & $\mathrm{xO} 28$ & - & 3.0 & 0.55 & \\
\hline BF 0.7 & $\mathrm{XO} 28$ & - & 3.0 & 0.55 & \\
\hline BF 12 & $\mathrm{xO} 28$ & - & 3.0 & 0.55 & \\
\hline
\end{tabular}

The fuel elements from XOl7 will be sent to the FCF, after removal from the reactor, for weighing and dimensional measurements. The capsules will be sent to the TREAT reactor for neutron radiography, and then to Illinois for de-encapsulation and direct examination.

Preliminary plans are being made for a comprehensive experiment to investigate the performance of Mark-I-type fuel under advanced conditions of temperature and burnup not presently attainable in regular driver-fuel subassemblies. Encapsulated fuel elements will be irradiated in special B-37 subassemblies. Variables to be studied include reactor power level ( 50 and $62.5 \mathrm{MW}$ ), burnup, element type (Mark-IA and $-I B)$, stainless steel cladding composition, level of cold work of the cladding, and the silicon content in the fuel. 
e. Mark II Driver Fuel Element Development (J. H. Kittel)

(i) Element Irradiation Tests.

(a) $\frac{\text { Irradiation of Encapsulated Mark-II Fuel Elements }}{\text { (M. A. Pugacz) }}$

Last Reported: ANL-7478, pp. 54-55 (July 1968).

As of August 13, the experimental encapsulated Mark-II fuel elements in Subassembly XO29 had been exposed to $3266 \mathrm{MWd}$ of operation in EBR-II, which coincided with the end of Reactor Run 29. At the end of Run 30 the calculated burnup of the elements in the subassembly. will range from 2.02 to $2.54 \mathrm{a} / 0$. At that time ten fuel elements will be removed and tested extensively with particular attention to the relative merits of the three restrainer designs. The restrainer design for the unencapsulated subassemblies is dependent on the results obtained from this exposure.

The remaining 27 capsules will be tested by eddycurrent inspection techniques to verify the integrity of the sodium bond. These capsules and ten new capsules will be loaded into a subassembly for insertion into the reactor for two additional fuel cycles, which are to provide an approximately $1 \mathrm{a} / \mathrm{o}$ burnup. At that time five of the 27 fuel elements will be removed and replaced by five new elements. This cycle will continue until the last 12 of the original 37 fuel elements have an accumulated burnup of about $7 \mathrm{a} / \mathrm{o}$.

1. A series of burst tests has been made with five acceptable top-weld closures of Mark-II capsules and with eight closures that were rejected because $\mathrm{X}-\mathrm{ray}$ inspection indicated excessive wall thinning or porosity at the weld joint.

The results are summarized in Table I.E.5. Three important conclusions were drawn from these tests:

(1) The bursting pressures of the rejected closures were not significantly different from the bursting pressures of acceptable welds.

(2) The burst failures did not occur at the closure weld or in the heat-affected zone of the weld in any of the tests.

(3) The burst failures generally occurred in the heat-affected zone of the original seam weld of the tubing.

(b) Irradiation of Instrumented Prototype Mark-II

Last Reported: ANL-7478, p. 55 (July 1968).

Capsule CP-58 containing three prototype Mark-II elements was neutron radiographed on July 18 when the fuel had attained 
a maximum calculated burnup of $1.8 \mathrm{a} / \mathrm{o}$. Examination of the radiographs showed a uniform density of fuel. The fuel appeared to be in intimate contact with the cladding, and there were no apparent localized bulges which would indicate cladding deformation.

TABLE I.E.5. Burst Tests of EBR-II Capsule Closure Welds

\begin{tabular}{|c|c|c|c|c|c|c|c|}
\hline \multirow{2}{*}{$\begin{array}{c}\text { Capsule } \\
\text { No. }\end{array}$} & \multirow{2}{*}{$\begin{array}{l}\text { Location } \\
\text { of Capsule } \\
\text { Closure }\end{array}$} & \multirow{2}{*}{$\begin{array}{c}\text { Result of } \\
\text { Weld } \\
\text { Inspection }\end{array}$} & \multirow{2}{*}{$\begin{array}{c}\text { Reason } \\
\text { for } \\
\text { Rejection }\end{array}$} & \multicolumn{3}{|c|}{ Minimum Weld Thickness } & \multirow{2}{*}{$\begin{array}{c}\text { Bursting } \\
\text { Pressure } \\
\quad \text { (psi) }\end{array}$} \\
\hline & & & & (in.) & $(\% \circ$ & of Wall Thickness) & \\
\hline 1 & Top & Acceptable & - & $>0.020$ & & $>100$ & 8800 . \\
\hline 2 & Top & Acceptable & - & $>0.020$ & r & $>100$ & 8700 \\
\hline 3 & Bottom & Acceptable & - & $>0.020$ & & $>100$ & 8500 \\
\hline 4 & Top & Acceptable & - & $>0.020$ & & $>100$ & 8600 \\
\hline 5 & Top & Acceptable & - & $>0.020$ & & $>100$ & 8400 \\
\hline 33 & Bottom & Unacceptable & Porosity & $>0.020$ & & $>100$ & 8500 \\
\hline 210 & Top & Unacceptable & Thinning & 0.016 & & 81 & 8700 \\
\hline 222 & Top & Unacceptable & Thinning & 0.014 & . & 68 & 8500 \\
\hline 224 & Top & Unacceptable & Thinning & 0.016 & & 79 & 8400 \\
\hline 231 & Top & Unacceptable & Thinning & 0.013 & & 65 & 8800 \\
\hline 235 & Top & Unacceptable & Thinning & 0.013 & & 64 & 8600 \\
\hline 271 & Top & Unacceptable & Thinning & 0.015 & & 74 & 8400 \\
\hline 273 & Top. & Unacceptable & Porosity & $>0.020$ & & $>100$ & 8500 \\
\hline 274 & Top & Unacceptable & Thinning & 0.012 & & 58 & 8500 \\
\hline
\end{tabular}

These specimens were assembled with crimp-type restrainers that were located 0.2 in. above the fuel. The two elements that had thermocouples inserted in axial holes in the fuel had elongated $6 \%$ and were not in contact with the bottom edge of the restrainer. The other element, which was assembled with a null-balance-type pressure transducer, had a measured fuel elongation of $16 \%$, and the top of the fuel was pressing against the restrainer.

This capsule has been reinserted in the reactor, and the irradiation will continue until approximately $3.5 \mathrm{a} / \mathrm{o}$ burnup. At that time the elements will again be examined by neutron radiography.

(c) In-reactor Compatibility Studies (K. F. Smith)

Last Reported: ANL-7478, pp. 55-56 (July 1968).

The design of a capsule for irradiation of $\mathrm{U}-5 \mathrm{w} / \mathrm{O} \mathrm{Fs}$ versus Types 304 and 316 stainless steel for a compatibility evaluation has been completed, subject to a thermal analysis. Detailed design of the heater coil will then follow in cooperation with a vendor.

The type of heater under consideration is characterized by a swaged-coil section with terminals unreduced in size. This design proved to be quite successful in Chalk River and UK applications. 
f.' Equipment--Fuel Related

(i) Improved Gripper and Holddown Force-Limit Devices (E. Hutter)

Last Reported: ANL-7457, p. 64 (May 1968)

The temporary electrical connections and interlocks for the system devised to measure packing-gland friction on the gripper have been planned. Brackets have been fabricated for mounting a linear resistance potentiometer on the gripper carriage--a strip-chart will receive signals from the potentiometer proportional to the force required to overcome packing-gland friction. The results of these measurements will help determine the force range for the new force-limit device. Detailed experimental procedures for these measurements are being written.

(ii) New Control Rod Subassemblies (E. Hutter)

Last Reported: ANL-7478, pp. 57-59 (July 1968).

(a) Greater-worth Control Rod. The mockup of the $\mathrm{B}_{4} \mathrm{C}$ cluster-absorber follower is being fabricated. Pressure drops and orifice requirements will be checked by flow experiments. Stresses in the $\mathrm{B}_{4} \mathrm{C}$ cluster-grid support are being analyzed; detailed drawings are being made of the control rod.

(iii) Engineering Consultation

Last Reported: ANL-7445, p. 73 (April 1968).

(a) Fuel-element Modeling. Modification of the SWELL code, which predicts fuel-element lifetime, has continued; the secondgeneration version of the code, SWELL-2, is now operational. A report describing SWELL-2 is about $80 \%$ complete. SWELL-2 differs from the original version of the SWELL code in that: (1) the cladding is assumed to fail when the sum of the damages from primary creep, secondary creep, thermal-cycle fatigue, approximate strain from thermal-cycle ratcheting, and strain from inexorable fuel swelling equals unity (in the earlier version, failure was assumed to have occurred when damage from only secondary. creep and thermal-cycle fatigue equalled unity or at the onset of thermalcycle ratcheting; thermal stresses were assumed to increase gross secondary creep, but are not now considered to do so); (2) total cladding strain now includes swelling from fast-neutron irradiation, but this strain is not considered to contribute to cladding damage; (3) the fuel-compartment porosity is considered to be distributed quite uniformiy over the entire compartment rather than being restricted to that fuel in which, due to low temperature, all fission gas is retained; and (4) creep of the fission-gas plenum is included as a mechanism for reducing plenum pressures. 
SWELL-2 does not properly"account for the elastoplastic properties of the fuel; this deficiency is being rectified.

Typical SWELL-2 results are shown in Figs. I.E.1 through I.E.4. In Fig. I.E.1, calculated burnups at failure are shown for a basic mixed-oxide element similar to those irradiated in large numbers in the Dounreay Fast Reactor and to those scheduled for unencapsulated irradiation in EBR-II. To obtain agreement with experimental data in the linear-heat-flux range of $4-12 \mathrm{~kW} / \mathrm{ft}$ in which most of the data have been obtained, the arbitrary ratio between the pressure of the fission gas retained in the fuel:and the pressure exerted by the fuel on the cladding was taken to be 2.0 under all conditions. Also shown in the figure are the calculated consequences of increasing the coolant temperatures and the ratio of cladding thickness, to diameter, decreasing the ratio of plenum to fuel volume and the effective fuel density, and subjecting the cladding to one condition of abnormal operation near end of life.

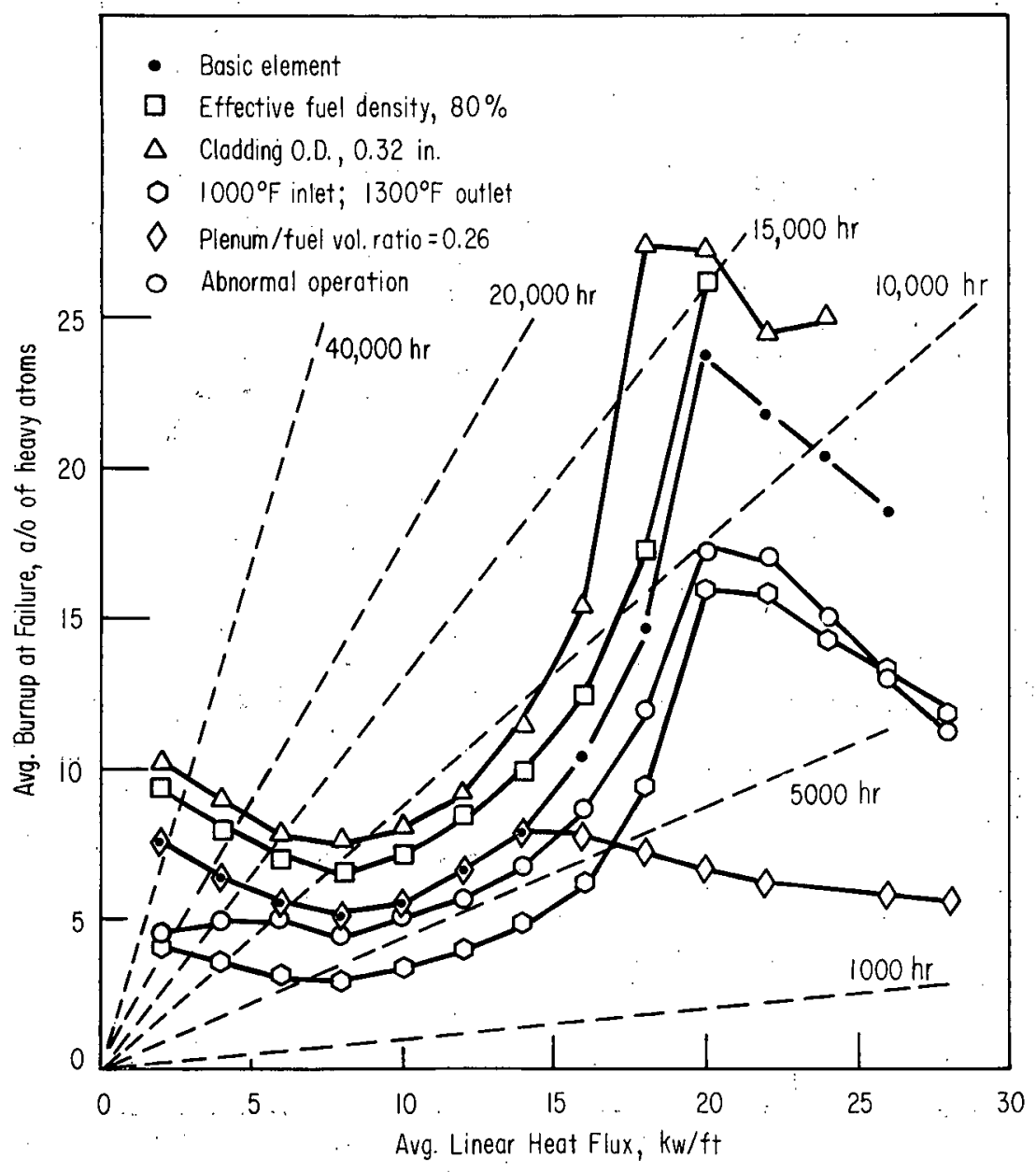

Fig. I.E.1. Calculated Burnup at Failure vs. Linear Heat Flux for Mixed-oxide Stainless Steel-clad Fuel Elements (basic furel-element conditions: / inlet temp, $900^{\circ} \mathrm{F}$; outlet temp, $1200^{\circ} \mathrm{F}$; cladding $\mathrm{OD}, 0.23$ in.; ID, 0.20 in.; plenum/fuel-volume ratio, 1.32 ; effective fuel density, $85 \%$ ). Lifetimes (in hours) at failure are shown by broken lines. 


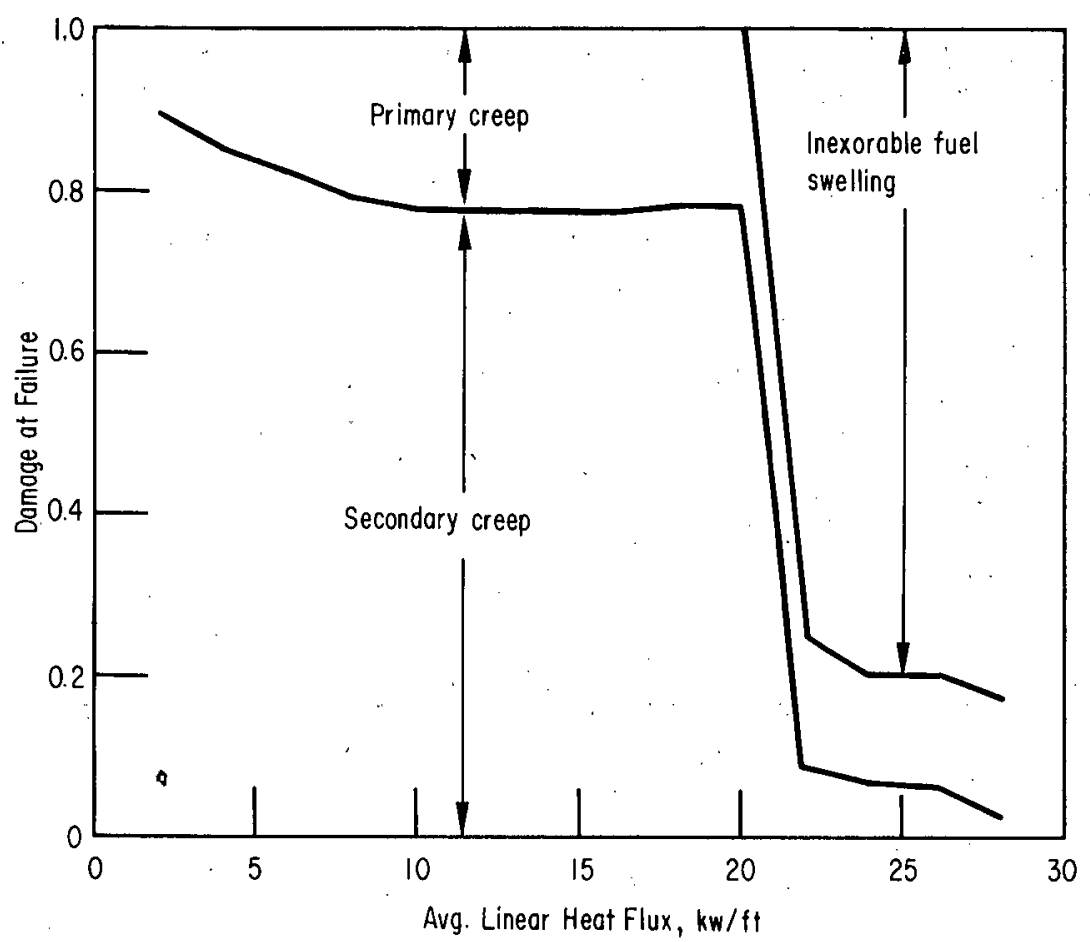

Fig. I.E.2. Calculated Distribution of Cladding Damage at Failure vs. Linear Heat Flux for Basic Fuel Element

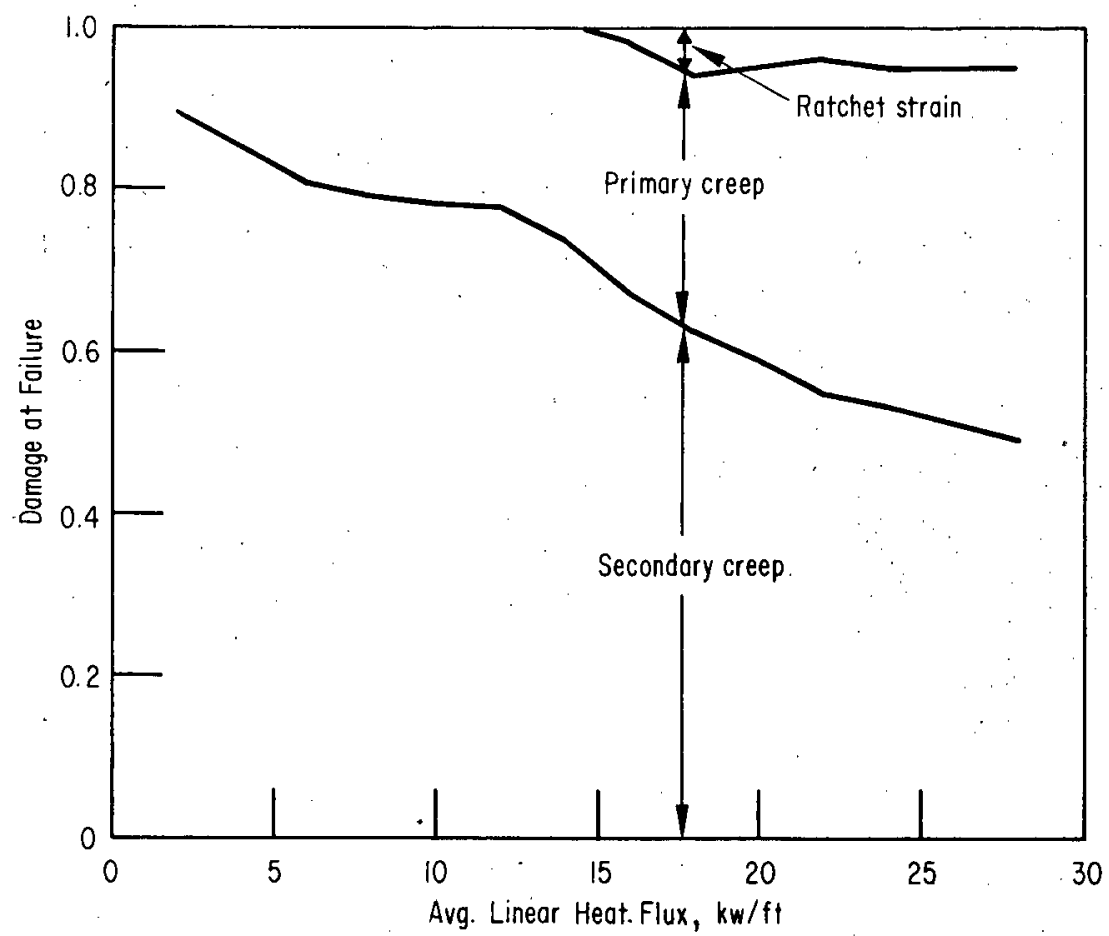

Fig. I.E.3. Calculated Distribution of Cladding Damage at Failure vs. Linear Heat Flux for Fuel Element with Plenum/Fuelvolume Ratio of 0.26 


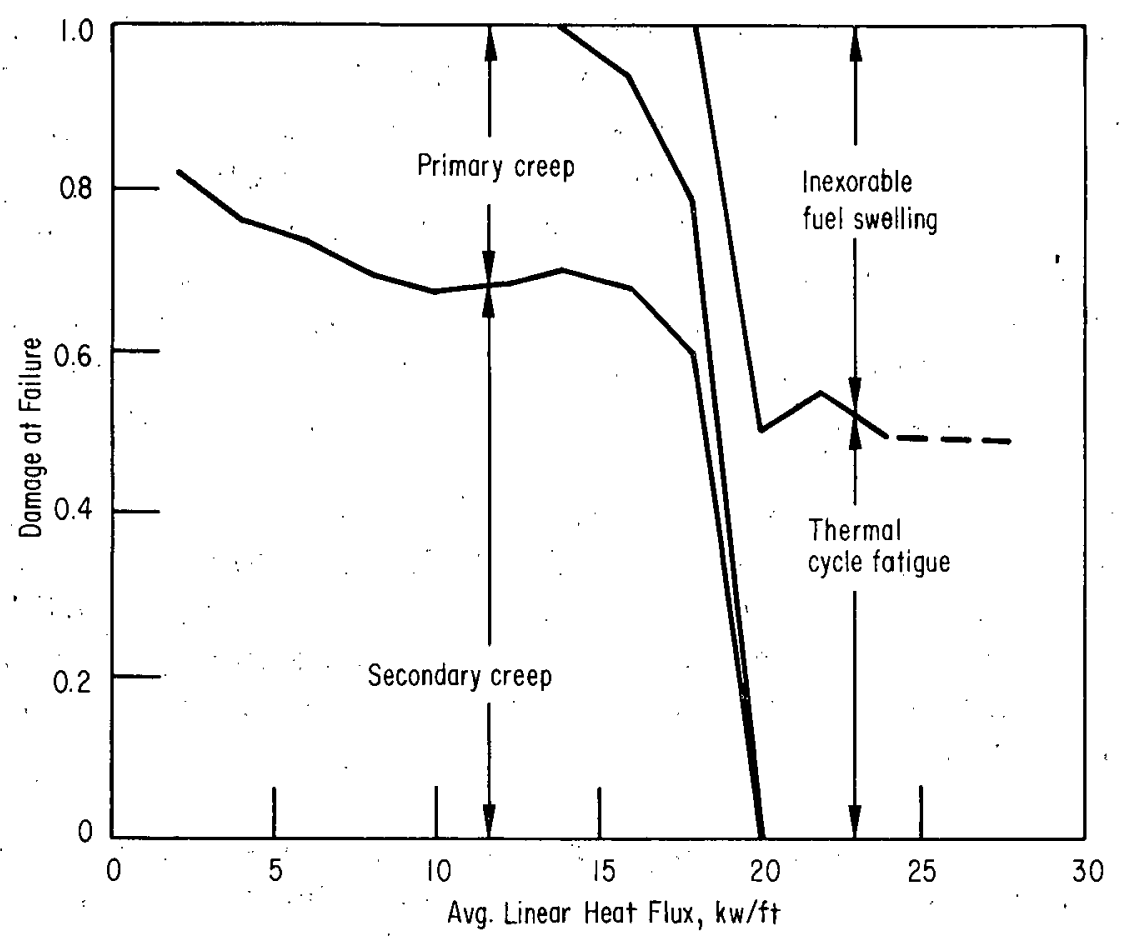

Fig. I.E.4. Calculated Distribution of Cladding Damage at Failure vs. Linear Heat Flux for Fuel Element with Cladding OD of 1.32 in.

Most of the results seem qualitatively correct. The minima at $8 \mathrm{~kW} / \mathrm{ft}$ represent the point at which the average temperature (and thus the pressure) of the fission gas retained in the fuel no longer increases with heat flux, since at higher heat fluxes the gas in the hot central region of the fuel is released. The maxima at about $20 \mathrm{~kW} / \mathrm{ft}$ indicate the point where nearly all gas is released from the fuel but where inexorable fuel swelling becomes significant. Fission-gas-plenum pressures are so high for the fuel element with the low ratio of plenum to fuel volume that the release of fission gas from the fuel is not effective in increasing burnup.

These results indicate that high burnups are achievable in the neighborhood of $20 \mathrm{~kW} / \mathrm{ft}$, so that there is a strong incentive to establish whether operation with molten fuel is permissible.

obtained as follows:

The abnormal-operation curve in Fig. I.E.l was

At the conclusion of each set of calculations for normal operation (which were made in incremental steps of $0.2 \mathrm{a} / \mathrm{o}$ burnup), the power and coolant-temperature rise were changed twice. First, the power and coolant-temperature rise were each increased by a factor of 1.2 , corresponding to a $20 \%$ overpower situation. The extra primary strain and inexorable fuel swelling caused by this overpower were evaluated to see if they would cause failure; if so, the calculations were concluded. 
If not, the second change consisted of altering the power by a factor of 0.05 and the coolant-temperature rise by a factor of 2.0, corresponding to the worst conditions during a flow-coastdown situation. Again, the likelihood of failure was checked and the calculations either concluded or advanced to the next burnup increment for further consideration of normal operation. Below $8 \mathrm{~kW} / \mathrm{ft}$ and at $20 \mathrm{~kW} / \mathrm{ft}$, the failures were due to flow coastdown; from 8 . to $18 \mathrm{~kW} / \mathrm{ft}$, the failures were due to overpower. All these failures occurred near the hot end of the element. Above $20 \mathrm{~kW} / \mathrm{ft}$, the failures were due to overpower and occurred nearer the middle of the element.

Figures I.E.2 through I.E.4 indicate the calculated distribution of damage in the cladding at failure. For the basic fuel element (see Fig. I.E.2), most damage is due to secondary creep, until inexorable swelling becomes controlling. Below $20 \mathrm{~kW} / \mathrm{ft}$, failure occurs near the hot end of the element; above $20 \mathrm{~kW} / \mathrm{ft}$, failure occurs closer to the middle of the element.

In the case of the fuel elements having a low ratio plenum to fuel volume (see Fig. I.E.3), cladding strain due to thermalcycle ratcheting (probably calculated pessimistically) contributes to failure above $15 \mathrm{~kW} / \mathrm{ft}$. Below $20 \mathrm{~kW} / \mathrm{ft}$, failure occurs near the hot end of the element; above $20 \mathrm{~kW} / \mathrm{ft}$, failure occurs at the middle of the element. For the thick-cladding element (see Fig. I.E.4); thermal-cycle fatigue and inexorable swelling have approximately equal effects above $20 \mathrm{~kW} / \mathrm{ft}$. Failure occurs near the hot end of the fuel element at all heat fluxes.

For calculating fatigue and ratcheting strain, one ther mal cycle per day was assumed. No attempt was made to estimate the influence of radiation damage on fatigue life.

\section{g. New Subássemblies Design and Experimental Support (E. Hutter)}

Last Reported: ANL-7478, pp. 59-60 (July 1968).

(i) Irradiation Subassemblies. Table I.E.6 summarizes the design status of the various types of EBR-II irradiation subassemblies.

(a) Mark-A. Evaluation of several alternative modifications to the Mark-A irradiation subassembly to allow irradiation of experimental ceramic fuels at temperatures above normal EBR-II operating temperatures (see Progress Report for April 1968, ANL-7445, p. 75) continues.

A summary of recent calculations and test results has been prepared for discussion with the concerned experimenters. 
TABLE I.E.6 Element Description for EBR-II Irradiation Subassemblies

\begin{tabular}{|c|c|c|c|c|c|c|}
\hline Type & No. & $0 . D$. (in. $)^{a}$ & D (in. $)^{a}$ & $\begin{array}{l}\text { Wire Diameter } \\
\quad \text { (in.) }\end{array}$ & Length (in.) & Remarks \\
\hline A-19 & 19 & 0.375 & 0.335 & None & $39-7 / 8$ & Has dimpled shroud tube \\
\hline $\begin{array}{l}\text { B-7 } \\
\text { B-19 } \\
B-37 \\
B-37 A \\
B-61\end{array}$ & $\begin{array}{r}7 \\
19 \\
37 \\
37 \\
61\end{array}$ & $\begin{array}{l}0.8055 \\
0.375 \\
0.290 \\
0.250 \\
0.220\end{array}$ & $\begin{array}{c}0.750 \\
0.335 \\
0.250 \\
- \\
0.188\end{array}$ & $\begin{array}{l}\text { None } \\
0.097 \\
0.0565 \\
0.091 \\
0.0515\end{array}$ & $\begin{array}{l}57-7 / 8 \\
60-7 / 8 \\
60-7 / 8 \\
60-7 / 8 \\
60-7 / 8\end{array}$ & Elements touch \\
\hline $\begin{array}{l}C-19 A \\
C-19 \\
C-37\end{array}$ & $\begin{array}{l}19 \\
19 \\
37\end{array}$ & $\begin{array}{l}0.328 \\
0.290 \\
0.220\end{array}$ & $\begin{array}{l}0.284 \\
0.250 \\
0.188\end{array}$ & $\begin{array}{l}0.049 \\
0.080 \\
.0 .0515\end{array}$ & $\begin{array}{l}44-3 / 8 \\
44-3 / 8 \\
44-3 / 8\end{array}$ & $\begin{array}{l}\text { High-temp mixing } \\
\text { High-temp mixing } \\
\text { High-temp mixing }\end{array}$ \\
\hline D & \multicolumn{6}{|c|}{$\begin{array}{l}\text { Development of preheating design halted due to insufficient core height for individual heating and test elements } \\
\text { in series. }\end{array}$} \\
\hline $\begin{array}{l}E-19 \\
E-37\end{array}$ & $\begin{array}{l}19 \\
37\end{array}$ & $\begin{array}{l}0.312 \\
0.250\end{array}$ & $\begin{array}{l}0.268 \\
0.218\end{array}$ & $\begin{array}{l}0.078 \\
0.038\end{array}$ & $\left.\begin{array}{l}29 \\
29\end{array}\right\}$ & Collector design continuing \\
\hline $\mathrm{F}-37$ & 37 & 0.250 & - & 0.0625 & $60-7 / 8$ & $\begin{array}{l}\text { Single encapsulation } \\
\text { Fabrication progressing }\end{array}$ \\
\hline G-37 & 37 & 0.250 & - & 0.0373 & $60-7 / 8$ & Design halted \\
\hline $\mathrm{H}-37$ & 37 & 0.250 & - & 0.040 & $60-7 / 8$ & Tests progressing \\
\hline
\end{tabular}

a Tolerance on these diameters is \pm 0.001 in. except for $B-7$, for which the tolerances are \pm 0.0005 in. on the 00 and \pm 0.003 in on the 10 .

(b) Mark-F. Fabrication of hardware for the first inreactor subassemblies has been essentially completed.

(c) Mark-H. Hydraulic testing has been completed. Drawings are being prepared for a subassembly that would be installed in the inner-blanket region.

h. Instrumented Subassembly (E. Hutter)

(i) Research and Development

Last Reported: ANL-7438, p. 29 (March 1968).

(a) Prototype Fuel-pin Thermocouples. A 1/16-in.-OD tantalum-sheathed, thoria-insulated, W-3\% Re $/ \mathrm{W}-25 \% \mathrm{Re}$ thermocouple tested at $1980^{\circ} \mathrm{C}$ gave stable output $\pm 0.6 \%$ for $260 \mathrm{hr}$ before the emf drifted downward. Subsequently, a sheath failure was found in the region of the thermocouple that was at temperatures between 600 and $900^{\circ} \mathrm{C}$. Such failures have been noted before (see Progress Report for February 1968, ANL-7427, p. 31) and are due to carbon contamination of the tantalum sheath. The presence of carbon has been verified by X-ray diffraction and chemical analyses.

A similar carbon contamination of a $1 / 16-$ in.-OD tantalum tube was noted after $90 \mathrm{hr}$ at $1985^{\circ} \mathrm{C}$ in a $5 \times 10^{-4}$ Torr vacuum. The vacuum atmosphere was analyzed by a residual-gas analyzer, and traces of elemental carbon and a variety of hydrocarbons were found in the furnace. The apparent sources of the carbon are the oils used in the mechanical and oil-diffusion pumps that are a part of the furnace facility.

The furnace will be cleaned. In the future the pump oils will be trapped before they reach the furnace to enable longer thermocouple tests. 
(b) Tantalum Sheath. Delivery of tantalum sheathing for the EBR-II Instrumented Subassembly fuel-pin thermocouples is expected in early October.

i. Process Chemistry (D. W. Cissel)

Last Reported: ANL-7478, pp. 60-61 (July 1968).

(i) Sodium Coolant Quality Monitoring and Control

(a) Primary Sodium

(1) Radionuclides. The results of an analysis for radionuclides of a sample of primary sodium taken July 16, 1968 are

$$
\frac{{ }^{137} \mathrm{Cs}(\mu \mathrm{Ci} / \mathrm{g})}{1.42 \times 10^{-2}} \quad \frac{{ }^{131} \mathrm{I}(\mu \mathrm{Ci} / \mathrm{g})}{2.16 \times 10^{-4}}
$$

(2) Trace Metals. A sample of primary sodium taken July 25, 1968 was analyzed for trace-metal impurities by atomic absorption. The results are listed in Table I.E.7.

TABLE I.E.7. Trace-metal Impurities in Primary Sodium

\begin{tabular}{lc|cc}
\hline Metal & Concentration (ppm) & Metal & Concentration (ppm) \\
\hline $\mathrm{Co}$ & $<0.1$ & $\mathrm{~Pb}$ & 11.4 \\
$\mathrm{Mn}$ & $<0.02$ & $\mathrm{Cd}$ & $<0.2$ \\
$\mathrm{Ni}$ & $\sim 0.1$ & $\mathrm{Sn}$ & 20.9 \\
$\mathrm{Cu}$ & 0.25 & $\mathrm{Cr}$ & $<0.04$ \\
$\mathrm{Bi}$ & 1.2 & $\mathrm{Al}$ & $<0.2$ \\
\hline
\end{tabular}

(b) Secondary Sodium

(1) Trace Metals. A sample of secondary sodium taken July 29, 1968 was analyzed for trace-metal impurities by atomic absorption. "The results are listed in Table I.E.8.

TABLE I.E.8. Trace-metal Impurities in Secondary Sodium

\begin{tabular}{lc|cc}
\hline Metal & Concentration $(\mathrm{ppm})$ & Metal & Concentration $(\mathrm{ppm})$ \\
\hline $\mathrm{Pb}$ & 1 & $\mathrm{Mn}$ & $<0.02$ \\
$\mathrm{Cd}$ & $<0.02$ & $\mathrm{Bi}$ & $<0.2$ \\
$\mathrm{Cú}$ & $\mathrm{Sn}$ & $<4$ \\
$\mathrm{Ni}$ & $\sim 0.1$ & $\mathrm{Al}$ & $<0.2$ \\
$\mathrm{Co}$ & $<0.1$ & $\mathrm{Cr}$ & $<0.05$ \\
\hline
\end{tabular}

(2) Carbon. One sample of secondary sodium, taken July 22, 1968, was analyzed for total carbon by the oxyacidic-flux method. The average of three aliquots was $3.3 \pm 0.6 \mathrm{ppm}$. 
: j. Experimental Irradiation and Testing (D. W. Cissel)

Last Reported: ANL-7478, pp. $62-65$ (July 1968).

(i) Experimental Irradiations

(a) Status of Experiments in EBR-II. The status of the experimental irradiations in EBR-II as of August 31 is shown in Table I.E.9.

Experimental subassemblies XG02, XO17, and X900 were discharged following the completion of Run 2.9.

Experimental subassemblies XO39 and XO40 were loaded into core positions $3 \mathrm{C} 2$ and 5B2, respectively. Subassembly XO39 contains nine capsules previously irradiated in Subassembly XO11. Subassembly $X O 40$ contains fuel elements that are unencapsulated, i.e., the cladding is cooled directly by the EBR-II primary coolant. Both of these subassemblies constitute a "first" in EBR-II.

(b) Status of Irradiation Experiment Proposals Given Approval in Principle. Table I.E.10 summarizes the present status of all irradiation experiments that have been given approval in principle but have not been inserted in the reactor.

(c) Design of New Experimental Subassembly. Flow testing continued of mockups of a modified Mark-A subassembly having transparent upper mixing plenum walls. Additional flow tests were performed with two dye channels to study various devices for mixing of high- and lowtemperature shroud-tube-effluent streams for the GE Group-5 program. These latest tests were consistent with earlier ones in indicating the mixing to be unsatisfactory in a plenum length of a standard Mark-A subassembly $(\sim 4$-in. plenum length).

However, GE recently informed ANL that by utilizing the maximum outlet temperature for a Row-4 position, an acceptable compromise for the Group- 5 irradiation was possible (that is, an outlet temperature $100^{\circ} \mathrm{F}$ above the calculated outlet temperatures without uncertainty. factors for the adjacent standard subassemblies at a reactor power of $50 \mathrm{MWt}$ ). Therefore, no modification of the Mark-A subassembly will be required for the GE Group-5 irradiation. 
TABLE I.E.9. Status of EBR-II Experimental Irradiations

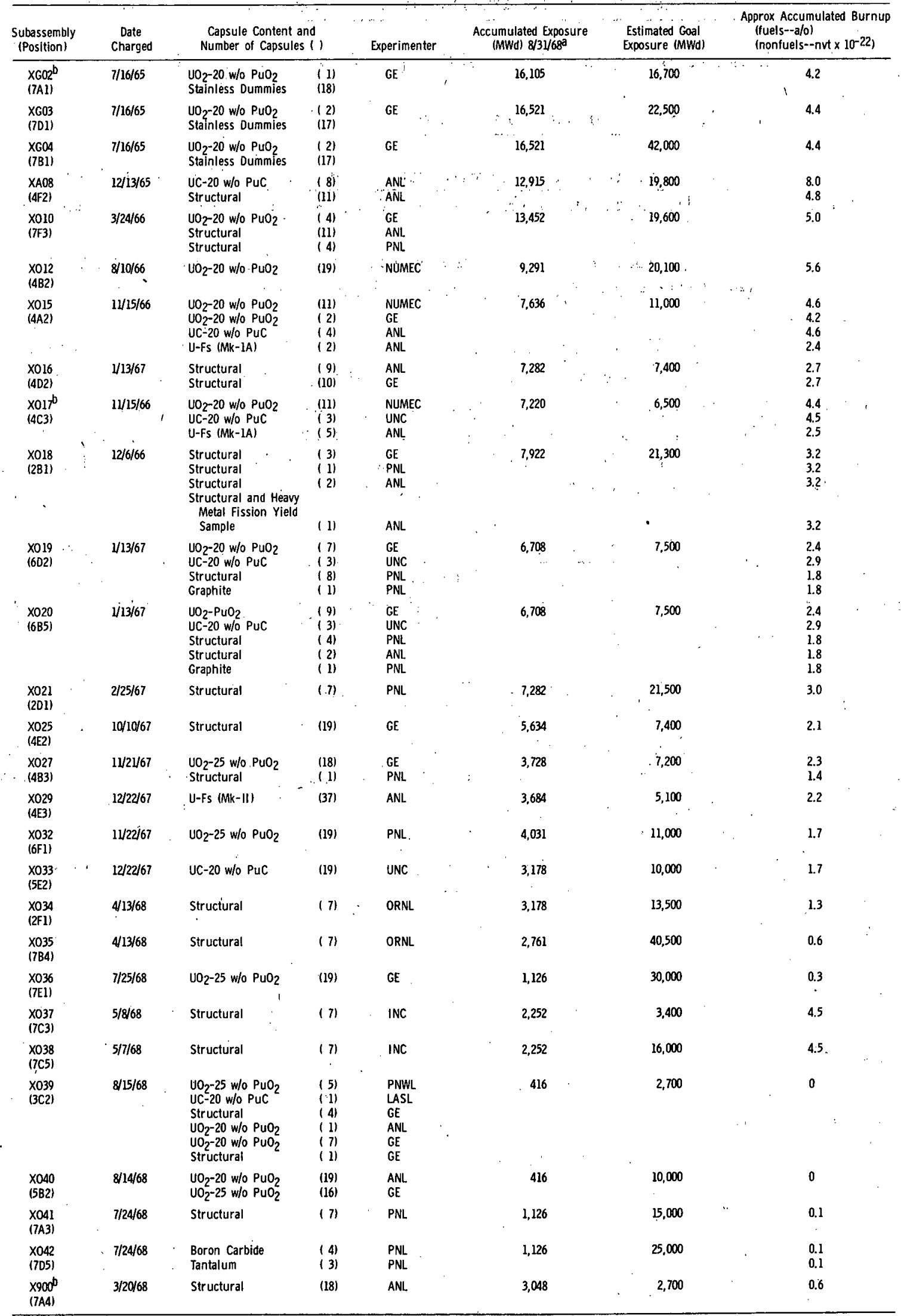

Accumulated exposure during August was 940 MWdt.

berminated at end of Run 29. 
TABLE I.E.10. Status of Experiments with Approval in Principle

\begin{tabular}{|c|c|c|c|c|c|}
\hline Sponsor & Material of Test & $\begin{array}{l}\text { No. of } \\
\text { Capsules }\end{array}$ & $\begin{array}{l}\text { Suggested } \\
\text { Reactor } \\
\text { Rowa }\end{array}$ & $\begin{array}{l}\text { Date of } \\
\text { AIP }\end{array}$ & $\begin{array}{r}\text { Estimated } \\
\text { Delivery }\end{array}$ \\
\hline ANL & $\begin{array}{l}\text { Oxide fuel, Group 0-3 } \\
\text { Carbide fuel, Group C-5 } \\
\text { Mk-II fuel (unencap) } \\
\text { Mk-II fuel (encap) })^{\mathrm{b}} \\
\text { Metal fuel, M-4 } \\
\text { Structural, Group S-9 } \\
\text { Magnetic materials } \\
\text { Instrumented subassembly }\end{array}$ & $\begin{array}{r}19 \\
19 \\
455 \\
25 \\
19 \\
19 \\
7 \\
1\end{array}$ & $\begin{array}{l}3 \\
2 \\
\text { Core } \\
4 \\
3 \\
4 \\
7 \\
5\end{array}$ & $\begin{array}{l}9 / 22 / 67 \\
9 / 22 / 67 \\
9 / 22 / 67 \\
6 / 3 / 67 \\
2 / 13 / 68 \\
9 / 22 / 67 \\
6 / 8 / 67 \\
5 / 9 / 68\end{array}$ & $\begin{array}{l}12 / 68 \\
1 / 69 \\
10 / 68 \\
6 / 68^{C} \\
10 / 68 \\
9 / 68 \\
9 / 68 \\
2 / 69\end{array}$ \\
\hline BMI & Nitride fuels & 8 & 7 & $2 / 13 / 68$ & $9 / 68$ \\
\hline GE & $\begin{array}{l}\text { Oxide fuels, Group } 7 \\
\text { Oxide fuel, Group 5 } \\
\text { Oxide fuel (unencap), Group 9A } \\
\text { Oxide fuel (unencap), Group 9B } \\
\text { Oxide fuel (unencap), Group 9C } \\
\text { Oxide fuel (unencap), Group 9D }\end{array}$ & $\begin{array}{r}4 \\
16 \\
37 \\
37 \\
37 \\
37\end{array}$ & $\begin{array}{l}4 \\
4 \\
4 \\
6 \\
5 \\
7\end{array}$ & $\begin{array}{l}9 / 2 / 66 \\
1 / 20 / 67 \\
1 / 20 / 67 \\
5 / 9 / 68 \\
5 / 9 / 68 \\
5 / 9 / 68\end{array}$ & $\begin{array}{l}2 / 68 \mathrm{C} \\
10 / 68 \\
8 / 68 \\
10 / 68 \\
9 / 68 \\
9 / 68\end{array}$ \\
\hline LASL & $\begin{array}{l}\text { Oxide insulators } \\
\text { Carbide fuels }\end{array}$ & $\begin{array}{l}1 \\
6\end{array}$ & $\begin{array}{l}8 \\
3\end{array}$ & $\begin{array}{l}6 / 6 / 67 \\
2 / 27 / 67\end{array}$ & $\begin{array}{l}9 / 68 \\
11 / 68\end{array}$ \\
\hline NRL & Structural materials & 7 & 7 & $9 / 6 / 67$ & $10 / 68$ \\
\hline ORNL & $\begin{array}{l}\text { Oxide insulators } \\
\text { Sol-gel oxide fuel }\end{array}$ & $\begin{array}{l}7 \\
5\end{array}$ & $\begin{array}{l}8 \\
4\end{array}$ & $\begin{array}{l}9 / 21 / 67 \\
5 / 9 / 68\end{array}$ & $\begin{array}{l}11 / 68 \\
9 / 68\end{array}$ \\
\hline PNL & $\begin{array}{l}\text { Oxide fuel (unencap), PNL-3 } \\
\text { Oxide fuel (unencap), PNL-4 } \\
\text { Oxide fuel (unencap), PNL-5 } \\
\text { Graphite materials } \\
\text { Thermocouple materials }\end{array}$ & $\begin{array}{r}37 \\
37 \\
37 \\
7 \\
5 \\
2\end{array}$ & $\begin{array}{l}3 \\
4 \\
3 \\
7 \\
4 \\
4\end{array}$ & $\begin{array}{l}9 / 21 / 67 \\
9 / 21 / 67 \\
9 / 21 / 67 \\
7 / 31 / 67 \\
7 / 31 / 67 \\
7 / 31 / 67\end{array}$ & $\begin{array}{c}9 / 68 \\
10 / 68 \\
10 / 68 \\
\text { Indefinite } \\
1 / 69 \\
2 / 68^{C}\end{array}$ \\
\hline UNC & $\begin{array}{l}\text { Carbide fuel (UNC 129-147) } \\
\text { Carbide fuel (UNC 185-190) }\end{array}$ & $\begin{array}{r}19 \\
6\end{array}$ & $\begin{array}{l}7 \\
3\end{array}$ & $\begin{array}{l}6 / 6 / 67 \\
1 / 20 / 67\end{array}$ & $\begin{array}{l}10 / 68 \\
6 / 68^{\mathrm{C}}\end{array}$ \\
\hline W & $\begin{array}{l}\text { Carbide fuel }(+V \text {-alloy) } \\
\text { Carbide fuel }(+V \text {-alloy) }\end{array}$ & $\begin{array}{l}2 \\
9\end{array}$ & $\begin{array}{l}3 \\
4\end{array}$ & $\begin{array}{l}9 / 21 / 67 \\
9 / 21 / 67\end{array}$ & $\begin{array}{c}10 / 68 \\
\text { Indefinite }\end{array}$ \\
\hline
\end{tabular}

aBased upon fission rates at a reactor power of $45 \mathrm{MWt}$.

Replacements for capsules of same type whose irradiation is nearing completion (e.g., Subassembly X029).

${ }^{\mathrm{C}}$ Date received.

(d) Other Work. The following depleted-uranium blanket subassemblies were installed at the beginning of Run 29C for power operation through the end of Run 29. They contained melt-wire capsules in the top adapter. These subassemblies have been removed from the reactor and are being neutron radiographed to determine which melt wires have melted.

\begin{tabular}{cc}
$\begin{array}{c}\text { Subassembly } \\
\text { No. }\end{array}$ & $\begin{array}{c}\text { Reactor } \\
\text { Location }\end{array}$ \\
\cline { 3 - 3 } A-898 & 7 A3 \\
A-899 & $7 D 4$ \\
U-1212 & $8 E 3$ \\
U-1195 & $9 E 4$ \\
U-1194 & $12 E 6$ \\
U-1398 & $16 E 9$
\end{tabular}

Temp Bracket Determined from Neutron Radiograph

$\left({ }^{\circ} \mathrm{F}\right)$

$813-845$

$813-845$ 


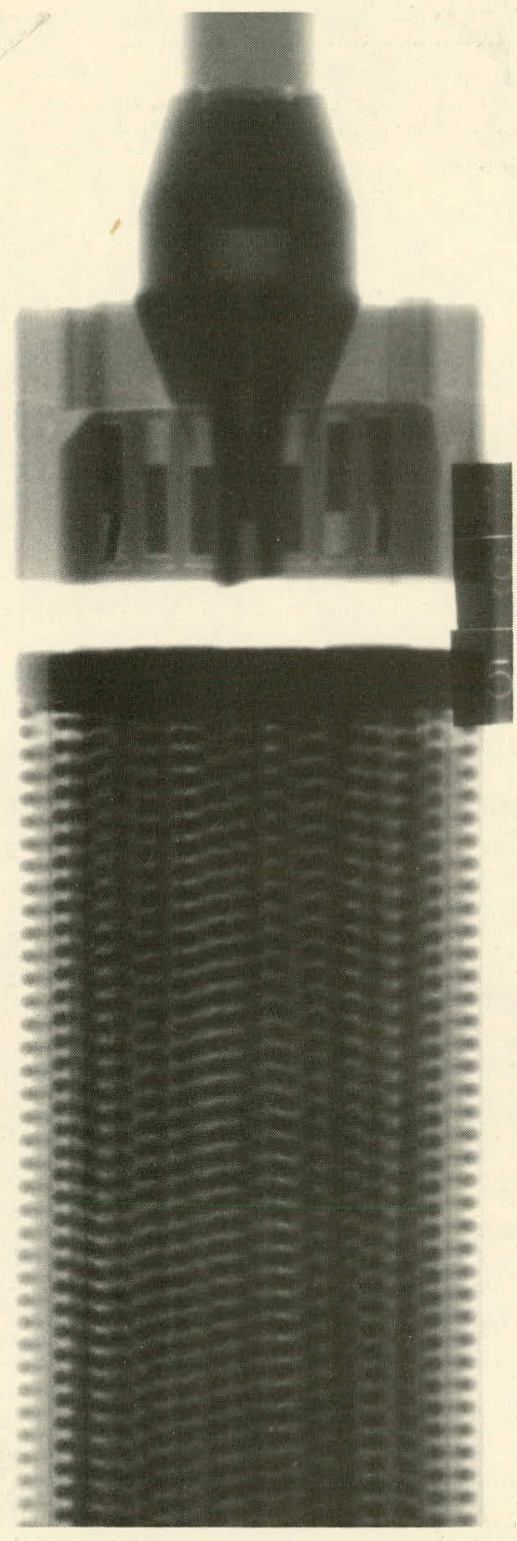

Fig. I.E.5. Neutron Radiograph of Melt-wire Capsules in Subassembly U-1195
Figure I.E. 5 shows the neutron radiograph of the melt-wire capsules in U-1195. The outer pair of gold-indium wires are visible, and the follower weights are in the upper position. All the other melt wires have melted and the follower weights have dropped. One of the follower weights for a zinc-silver wire (next-to-outer position) has not dropped all the way.

The following experimental irradiation subassemblies were flowtested: $\mathrm{XO} 41, \mathrm{XO} 42, \mathrm{XO} 39$ Prototype, and $\mathrm{XO} 40$.

Flow tests were completed to determine the internal orifice required for the controlled-flow subassembly experiment.

A special prototype control rod was flowtested to determine the effect on flowrate of the subassembly outlet screen in the proposal for the Bare Pins Fuel Irradiation Test No. 3. The screen reduced the flowrate through the subassembly by $3 \%$.

(ii) Handling and Examination

(a) $\frac{\text { Testing of Procedure for }}{\text { Removal of Subassembly }}$

(1) Cyclical Testing of

Stressed Capsules. Experimental subassembly X900 containing pressure-stressed tubing samples completed its scheduled exposure in the EBR-II inner blanket. The accumulated

fluence received by the test capsules was approximately $7 \times 10^{21} \mathrm{nvt}$. After a fifth and final washing cycle, the samples will be subjected to metallographic examination.

(2) EBR-II Subassembly Recycle Test. The recycled subassembly C-278, which had been irradiated to about $1.2 \mathrm{a} / \mathrm{o}$ burnup and then recycled four times from the primary coolant through the water-wash step, was disassembled. Routine fuel-pin surveillance has been started. 
k. FCF Process Analysis and Testing (M. J. Feldman)

Last Reported: ANL-7478, p. 65 (July 1968).

(i) Test and Analytical Methods

(a) Equipment. The milling machine and other parts for the stereomacroscope stage have been received. Shopwork will start next month.

(b) Interim Examination Program. Out-of-cell tests of equipment for leak testing and profilometry continued. The foil- and specimen-transport mechanism for neutron radiography is being installed in the Argon Cell.

Although out-of-cell tests of the capsule bond-testing: equipment have not been completed, the eddy-current coil for 3/8-in.-dia capsules (19 per subassembly) was utilized with a substitute capsule-drive mechanism. Inspections were made on the external bonds from eight capsules that had undergone previous irradiation in Subassembly XOll. Initial tests in the as-received condition showed some small indications of voids; however, after heating to $500^{\circ} \mathrm{F}$ followed by controlled cooling and bond testing, no voids were indicated in the external sodium bond. The initial void indications resulted from shrinkage voids. The capsules wereincorporated into Subassembly XO39 and the subassembly transferred to the reactor for further irradiation. Capsules that had been irradiated in Subassembly XG05 were also inspected and found to be free'of voids in the external sodium bond.

Checkout was performed on the remainder of the capsule bond-testing equipment. Final tests of this equipment will be made when the connecting components between in-cell and out-of-cell parts of the equipment have been obtained.

A transducer assembly for the eddy-current inspection of 3/8-in.-dia Mark-B capsules (37 per subas sembly) is being developed by ANL-MET.

1. FCF Equipment Improvement (M. J. Feldman)

Last Reported: ANL-7478, p. 65 (Jụly 1968).

(i) Auxiliary Equipment. The redesign of the viewing and small-item-handling plug for the transfer cell has been completed. The redesign includes tracks and grooved wheels for the plug. 
This installation, along with the installation of master slaves above the plug, will be coordinated with the installation of the FCF terminal of the pneumatic-tube sample-handling system.

(ii) Repair and Decontamination. Detailed designing is continuing on the equipment decontamination facility. The manipulator decontamination facility is progressing satisfactorily and the inside partitions are being completed. Beneficial occupancy is scheduled for the second quarter of FY 1969.

\section{m. Hot Fuel Examination Equipment (N. J. Swanson)}

Last Reported: ANL-7478, pp. 66-67) (July 1968).

Conceptual-design efforts centered on the development of reference designs for the building and the shielded cells. Conceptual work is also underway on work station modules and in-cell material-handling devices.

Participation by the architect-engineering firm, Norman Engineering Company, was resumed August 12, 1968. Their initial as signment is the preparation of a rough cost estimate for the facility as now envisioned, with recent changes in configuration and site. The new site is 100 to $200 \mathrm{ft}$ north of the FCF.

(i). General-purpose In-cell Material Handling. Detailed studies of the in-cell handling system requirements of the HFEF were accelerated this month to develop more complete preliminary design criteria for use with the revised concept of the reference configuration.

The work includes a review of the characteristics of a number of overhead handling systems, including several newly proposed concepts. Consideration was given to cell coverage, flexibility, material flow patterns, expected maximum loads, frequency of use, maintenance and repair problems, and emergency alternatives.

The design requirements for the handling systems of each. cell are being compiled with consideration of the factors listed above. Preliminary load calculations for the bridges, carriages, and columns for a variety of overhead handling concepts were made and the results used in the preparation of preliminary layouts of the systems.

Amplification and refinement of this work is continuing, but some tentative conclusions have been made.

(a) Some type of cell-wide general manipulation is required for the transfer cell, the assembly cell, and the decontamination cell. Possibly the cranes in these cells should be replaced with manipulators. 
(b) An independent, light-duty, material-transfer system is needed in the $70-\mathrm{ft}$ long main cell to move samples, tools, scrap, and supplies routinely. This system must be capable of bypassing the overhead systems. If this equipment is not provided at startup, provisions must be made for its later installation to avoid providing equivalent capabilities in the overhead systems.

(c) The capacity of the main-cell crane is being reduced to 4 tons and its assumed frequency of use reduced from routine to occasional. This change is posibible because the main-cell hatch doors will now be powered separately. The crane will then be needed only for infrequent movement of major pieces of equipment; removal of manipulator carriages and bridges for maintenance; and emergency removal of the hatch doors. All equipment will be less than 4 tons, and doors can be constructed with sectional shielding not exceeding 4 tons/section. The crane will be designed with two 1.5- or 2 -ton hoists to increase load stability and maneuverability, as well as to provide redundancy.

(ii) Utility Feedthroughs. A detailed conceptual design has been completed for an electrical-cable feedthrough which is capable of being changed without polluting the in-cell inert atmosphere or allowing the spread of contamination. To protect personnel, partial shielding is provided during all phases of the changing operation. The design incorporates a reusable shield plug and a separate seal plug. Organic seals between the seal plug and the feedthrough liner are radiation protected by $3 \mathrm{in}$. of lead, and the integrity of the seals can be continuously monitored. The feedthrough is 6 in. in diameter and can handle about 50 power or control conductors; the same general design can also be used for gas or Freon feedthroughs.

Two basically different design approaches have been considered for the seal plug. One is considerably cheaper than the other, but would have to be tested for manufacturing feasibility. This design uses an epoxy plug similar to a type currently used by ORNL and made by the Programmed and Remote Systems Corporation (PAR).

A detailed conceptual design for permanently installed, mineral-insulated (MI) cable has been completed to analyze the cost difference between this approach and the one mentioned above. A trade-off study between MI and "soft" (neoprene-covered) cable is es sentially complete. This study indicates that MI cable is not the best from the overall standpoint of operational flexibility and cost (which must include specially sealed cable terminations and connectors). If permanently installed MI cable is used, the seals and connectors must remain leaktight for the entire life of the facility. Also, the dielectric breakdown voltage in argon for MI cable is approximately $220 \mathrm{~V}$ : This would not be adequate for the lighting circuits if either low- or high-pressure sodium lamps are used. The use of MI cable in replaceable feedthroughs seems to offer no cost savings over soft cable. 
Conceptual layouts of two other utility feedthrough design approaches have been completed. One design has a removable seal plug located on the cold side of the cell with a. single cable feeding through a spiral sleeve imbedded in the concrete shielding wall. The other design, a multicable feedthrough, incorporates a sealed connector panel located in the shielding wall. The opening necessary to house the panel is.shielded by doors on the hot and cold side of the wall. Both approaches provide for cable changes after the facility is in operation, but they do not seem to be as versatile as the first concept mentioned above.

Contacts have been made this month with FFTF staff and with Grouse Hinds, a manufacturer of hermetically sealed reactor utility feedthroughs; to evaluate their approaches.

(iii) Electrical Distribution.' We are continuing to evaluate commercially available electrical connectors for in-cell use. Many special parameters must be considered; including voltage rating in argon, radiation resistance, degree of gas tightness, ease of remote handling, and usefulness for special instrumentation leads. Electrical connectors on hand are being mounted on a board and tested with Model-8 manipulators to evaluate the ease of remotely engaging and disengaging them. Reported radiation resistances of most of the insulating materials used in connectors are often sketchy or vague. However, based on REIC-21 (Radiation Effects Information Center) and its Addendum, the following materials appear to offer relatively high $\left(10^{9}\right.$ to $10^{10} \mathrm{R}$ ) radiation resistance: asbestos-filled phenolic, glass-filled diayll phthalate, epoxies cured with aromatic agents, and most fiber glass-reinforced laminates. Mica-filled phenolic is frequently used in connectors, but we have no data on its radiation resistance; we expect it to be similar to asbestos-filled phenolic.

We have learned that Westinghouse engineers are planning to test various connectors, conductors, and motors in an argon atmosphere. They expect to have considerable data available by the end of this year.

(iv) In-cell Lighting. A test procedure for the irradiation testing of the European sodium lamps is being written. The 55-W, indiumcoated lamps have now been received. These are the lamps proposed for the irradiation, vertical burning life, and light-depreciation tests.

The spectral responses of several high-resolution TV vidicon tubes were sought to see if the tubes would work well with lowpressure sodium lamps. Two representative vidicons (types $7735 \mathrm{~A}$ and $8507 \mathrm{~A}$ ) have their spectral response peaks at 550 nanometers. Their output is still $83 \%$ of peak at the wavelength of the low-pressure sodium lamps, 589 nanometers. 
(v) Manpower Status. There are now 6 staff and 2 salary people in the HFEF-Illinois Design Group; several are on the Project only part-time. Because of the level of operating funds now available to the Project, we do not plan to increase the manpower in this group until after construction funds are released.

n. Superheater and EM Pump Study and Test

(i) Superheater Vibration Study (G. S. Rosenberg)

Last Reported: ANL-7478, pp. 67-68 (July 1968).

An analytical study of the free and forced vibrations of a clamped beam with motion-limiting stops located at the center is being undertaken to determine the effects of baffle-tube clearances (which allow the tubes to impact with the baffles) on the vibrational characteristics and response of the tubes.

The deflection is expected to be symmetric about the center of the beam. Therefore, while the beam is in contact with the stop, the deflection is constant and the slope of the deflection curve is zero. With this observation, the assumption is made that while in contact with the stop the beam responds as two clamped-clamped beams each of length $l / 2$, where $\ell$ is the overall length of the beam. For the preliminary investigation, it is further assumed that for each phase of motion (i.e., motion between stops and motion while in contact with a stop) the beam responds as a system with a single degree of freedom (first-mode approximation). The beam-vibration problem can then be represented by an equivalent spring-mass system. The resulting nonlinear system is piecewise linear, which greatly facilitates further analysis.

The free-vibration problem was considered first. Because of the nonlinearity, the natural frequency of free vibration depends on the initial energy stored in the system. When no loss of energy on impact with a stop is assumed, the ratio of the natural frequency of the system to the natural frequency associated with unrestricted motion was derived as a function of the ratio of stiffnesses (before and during contact) and the instantaneous energy stored in the system. This energy can be expressed. in terms of the maximum amplitude of displacement or impact velocity. Alternatively, the natural frequency can be expressed as a function of either of these two parameters and the stiffness ratio. A set of curves was constructed that illustrates the increase in frequency associated with vibration between stops.

The forced-vibration case is of primary interest in heatexchanger-tube vibration, where the forcing function is induced by vortexshedding resulting from crossflow. The driving force is assumed to be 
sinusoidal with an amplitude and frequency that areflow-velocity dependent. An approximate solution to the forced motion is being derived by assuming the response to be sinusoidal at the driving frequency.

Computer codes have been written to evaluate an integral in the solution and to calculate the roots of a piecewise linear equation that will give the theoretically possible amplitudes of vibration. An end result of these calculations will be a set of curves of vibration amplitude versus crossflow velocity for various baffle-tube clearances.

\section{o. Feasibility: Study of Fuel Failure Detection--Chemical and Mechanical Methods \\ (i) Trace Elements Analytical Techniques (C. E. Crouthamel) \\ Last. Reported: ANL-7478, pp. 68-69 (July.1968).}

In choosing appropriate tagged elements for the identification of failed fuel elements in EBR-II, the type and concentration of impurities already present in the sodium coolant must be known. As part of this evaluation, two samples of EBR-II primary sodium, taken on February 5 and April 24, 1968, are being examined for impurity content. Because the impurities are present in such low concentrations in the sodium, separation from ${ }^{22} \mathrm{Na}$ activity is necessary to allow their detection by gamma spectrometry. Further details of the experiment to test the separation of impurities from the bulk sodium by ion exchange are reported below.

A sample of EBR-II: sodium weighing $\sim 2 \mathrm{~g}$ was dissolved in $5 \underline{\mathrm{M}} \mathrm{HCl}$ and passed through an anion-exchange column containing Dowex-1 resin. A gamma spectrum of the resin showed the presence of trace amounts

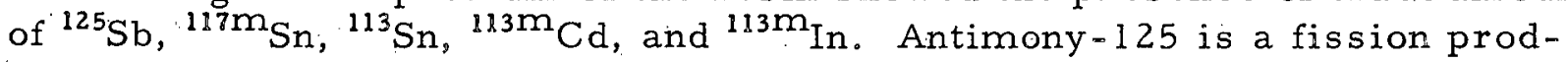
uct with a 2.2-yr half-life, and its presence could be due to a fuel-pin rupture or to fissioning of tramp uranium. The presence of tin was expected; the source of the tin (a Sn-Bi alloy seal) may also be the source of the cadmium impurity. Indium-113m is the daughter of ${ }^{113} \mathrm{Sn}$.

The resin was irradiated in CP-5 and assayed for shortlived activation products. After irradiation $35-\mathrm{hr}^{82}$ Br was the principal gamma emitter found. The hydrochloric acid used in the experiment was the source of the bromine. Copper and iron activities were barely. detectable.

The effluent from the anion-exchange separation was neutralized with ammonium hydroxide and slurried with Chelex-100 resin. The resin was separated from the solution and assayed for gamma activity. The gamma spectrum showed the presence of ${ }^{22} \mathrm{Na}$ and trace amounts of ${ }^{110 \mathrm{~m}} \mathrm{Ag}$. 
Two additional samples of EBR-II sodium have recently been received. The entire samples $(\sim 10 \mathrm{~g})$ will be processed by the above procedure to improve detection limits of these low-level impurities.

$$
\begin{aligned}
& \text { (ii) Sodium Loop--Tag Confirmation Study (F. A. Cafasso) } \\
& \text { Last Reported: ANL-7478, p. } 69 \text { (July 1968). } \\
& \text { Design, procurement, and assembly of components of a }
\end{aligned}
$$
loop for evaluating the chemical stability of isotopic tags in circulating sodium is continuing. All vessels and special fittings required for the loop are being fabricated. A steel framework, which will support two electromagnetic pumps, two flowmeters, a sampling reservoir and a cold trap, has been erected.

$$
\begin{aligned}
& \text { (iii) } \frac{\text { Mechanical Failed-fuel Locator }}{\text { (E. Hutter) }} \\
& \text { Last Reported: ANL-7478, p. } 69 \text { (July 1968). } \\
& \text { Drawings for the prototype failed-fuel locator have been } \\
& \text { completed and are being checked. A cost estimate and schedule for fabri- }
\end{aligned}
$$
cation are being prepared.

Design drawings of the sodium test loop are approximately $90 \%$ complete and are being checked. Purchase orders for structural support steel and for the speed controller for the sodium pump have been processed.

The hydraulic characteristics of the test loop have been analyzed and a safety analysis of the test loop has been submitted to the safety committee for review.

$$
\text { p. Materials-Coolant Compatibility (S. Greenberg) }
$$

(i) Materials Evaluation

(a) Reactor Materials

Last Reported: AN L-7371, pp. 32-33 (August 1967).

Control-rod subassembly L-457, fabricated with bushing rings of àluminum-bronze and of beryllium-copper alloys alternately placed, has been visually examined and photographed in the FCF Air Cell following its exposure (for $\sim 7 \frac{1}{2}$ mos) in the reactor core. The aluminumbronze bushings (as expected from the data on dissolution. rates in sodium obtained from samples of the two materials exposed to sodium in Materials Surveillance Subassembly No. 1) appeared definitely superior to the 
beryllium-copper bushings. Further detailed information (comparative weight, dimension changes, and results of metallographic examinations of, ring sections) will be reported when available.

(b) Unscheduled Evaluations

Last Reported: ANL-7460, pp.73-75 (June 1968).

The ex-reactor program initiated to uncover the factor(s) responsible for cracking and grain-boundary attack in one Type 304L stainless steel, seamless fuel-clad-tube removed from the EBR-II has been completed. Two hypotheses were considered: (1) the procedures used in cleaning the fuel element could have allowed heat-sensitized stainless steel to be exposed to concentrated sodium hydroxide solution, and (2) the grain boundaries could have been selectively carburized during fabrication or service.

Seamless and welded tubes of Type $304 \mathrm{~L}$ stainless steel with various preparation histories were exposed to $550^{\circ} \mathrm{C}$ sodium $\left(170^{\circ} \mathrm{C}\right.$ cold trap) in a circulating autoclave for periods of up to 5 weeks. The exposed specimens then were cleaned by one of three means: (1) moist argon, (2) moist argon followed by one week storage in the atmosphere, and (3) ethanol followed by distilled-water rinse, this being the standard procedure.

As a control experiment, sections of Type 304 welded and seamless tubing were given two different vacuum ampule heat treatments: (1) sensitization at $650^{\circ} \mathrm{C}$ for $4 \mathrm{hr}$, followed by 5 weeks at $550^{\circ} \mathrm{C}$, and (2) heat treatment at $550^{\circ} \mathrm{C}$ for 5 weeks without sensitization. These specimens were checked by the ethanol-water method.

The microstructures of the cleaning-procedure samples and vacuum heat-treatment specimens showed essentially the same features. The slight widening of the surface grain boundaries that was observed in these studies did not appear to be associated with the cleaning treatment or sodium exposure. Rather, it seemed to result from a combination of the composition and microstructure of the original tubing and subsequent heat treatment.

The hypothesis that damage was due to carburization was evaluated by diffusion couples of Type 304L tubing and steel inserts of varying carbon activity separated by the autoclave sodium. The steel inserts included Type 304 stainless steel $(0.06-0.08 \mathrm{w} / \mathrm{o} \mathrm{C})$, drill rod (0.9$1.1 \mathrm{w} / \mathrm{o} C)$, and plain carbon steel $(0.2-0.4 \mathrm{w} / \mathrm{o} \mathrm{C})$. The combinations were exposed for one week at $550^{\circ} \mathrm{C}$ in the sodium autoclave described above. Weight changes indicated a transfer of $\sim 1.1 \mathrm{mg} / \mathrm{in}$. from drill rod to Type $304 \mathrm{~L}$, and $\sim 0.4 \mathrm{mg} / \mathrm{in}$. from plain carbon steel to. Type $304 \mathrm{~L}$ stainless 
steel tubing. Metallographic examination revealed widening of the grain boundaries at the inner surface of the cladding. The microstructure of the Type $304 \mathrm{~L}$ stainless steel tubing with the plain carbon steel insert closely resembled that of the damaged reactor cladding. These results gave strong support to the carburization-damage hypothesis.

In a final study, tubes were streaked with Apiezon-N grease or a graphite-containing substance (dry graphite film) and exposed for one week to $550^{\circ} \mathrm{C}$ sodium. In the contaminated areas only, the resulting microstructures resembled closely the damaged microstructure. This result simulated the actual in-reactor. damage that appeared in an isolated area rather than continuously around the circumference of the tubing.

Combined with the observations reported in ANL-7460, these studies lead to the conclusion that the in-reactor damage was associated with selective carburization of the grain boundary. Further, the carbon source was probably associated intimately with the areas of attack, possibly caused by grease or similar carbonaceous material accidentally picked up on the outer surface of the fuel-element tubing during fabrication or handling.

\section{q. Driver Fuel Transient Performance Studies--TREAT Experiments \\ (i) Mark IA Fuel TREAT Experiments (P. J. Persiani) \\ Last Reported: ANL-7478, p. 71 (July 1968).}

(a) Fuel-motion Studies at TREAT. The pulsed-induction field apparatus that was developed to measure fuel motion inside of Mark-IA or Mark-II fuel elements during transient irradiation in TREAT was shipped to Idaho for a preliminary test with an unirradiated Mark-IA fuel element. Although the system was designed primarily for measurements of irradiated fuel elements, we believe that measurements with the unirradiated fuel element will provide some indication of the feasibility of the method.

Good data on the thermal expansion of the unirradiated fission alloy is also available as a rough check on the amount of motion measured by the motion detector. In the irradiated fuel elements, the fuel will have swelled nearly to the jacket, but in the unirradiated fuel.element the normal sodium-filled annulus exists between jacket and fuel. This high conductivity layer of sodium causes considerable attenuation of the current field as it diffuses into the fuel element and renders the measurement of fuel motion more difficult in the unirradiated than in the irradiated fuel element. Nevertheless, a preliminary analysis of the data indicates that successful motion measurements were obtained in 5 of 6 transients. The results are summarized below: 


\begin{tabular}{|c|c|c|c|c|}
\hline $\begin{array}{c}\text { Transient } \\
\text { No. }\end{array}$ & $\begin{array}{c}\text { Integrated } \\
\text { Power } \\
(\mathrm{MW} \text {-sec })\end{array}$ & $\begin{array}{l}\text { Peak } \\
\text { Power } \\
(\mathrm{MW})\end{array}$ & $\begin{array}{c}\text { Indicated Jacket Temp } \\
\text { Rise at Center of } \\
\text { Fuel Element }\left({ }^{\circ} \mathrm{C}\right)\end{array}$ & $\begin{array}{l}\text { Approx Fuel } \\
\text { Motion (mm) }\end{array}$ \\
\hline \multicolumn{5}{|c|}{ Capsule 1} \\
\hline 1222 & 23 & 78 & 290 & 2.5 \\
\hline 1223 & 35 & 86 & 408 & 3.8 \\
\hline 1224 & 43 & 96 & 445 & $\begin{array}{c}\text { Erratic } \\
\text { indications }\end{array}$ \\
\hline \multicolumn{5}{|c|}{ Capsule 2} \\
\hline 1225 & 43 & 96 & 446 & 4.2 \\
\hline 1226 & 43 & 94 & 482 & 4.3 \\
\hline 1227 & 56 & 100 & 680 & 5.1 \\
\hline
\end{tabular}

During transient 1224 , and to some extent near the end of transient 1223, erratic signals were received from the motion detector. Visual examination of the fuel element after transient 1224 indicated that it had become severely bent due to the presence of a collar near the top of the fuel element, which constrained the free vertical movement of the fuel element. This collar was modified in Capsule 2 so that consistent motion measurements were obtained through the entire series of transients performed. Transients 1225 and 1226 were intended to be identical to provide a test of the consistency of signals obtained from the motion-detection equipment.

A motion-detector transducer was also provided for the bottom of the fuel element. A preliminary analysis of the signals from this transducer indicates that no vertical motion of the fuel took place.during the transients, but that some lateral motion of the fuel element within the transducer occurred at certain stages of some of the transients.

\section{r. Systems Engineering}

(i) Surveillance, Evaluation, and Studies of Systems (R:A. Jaross and G. S. Rosenberg)

Last Reported: ANL-7478, pp. $72-73$ (July 1968).

(a) Study of Effects of Sodium-Water Reaction. A computer code for analyzing the response of a network of sodium lines was tested for two problems of pressure generation in sodium circuits.

In one problem, the network consisted of seven nodes and seven branches of equal area." The pressure source was a step function at the closed end of one branch. Fluid-velocity changes at the source node were predicted correctly. Pressure and velocity variations at open ends, at closed ends, and at multiple-branch nodes were also treated properly. 
In the second problem, the network consisted of a single sodium column with one end closed ard the other a free surface. The pressure source at the closed end was a zone of isothermally expanding gas. The mass of the gas increased at a rate that decreased linearly with the gas-zone pressure.

The equations governing reaction-product zone dynamics at a node of a pipe network (developed earlier in the present study) were incorporated as a pressure-source subroutine in the network-analysis code. The second test problem described above was analyzed with this pressure source.

Spherical reaction-product bubble growth at early times was analyzed assuming incompressible radial flow of the surrounding unreacted sodium. A complete break of one steam tube at the sodium side of the tube sheet in the EBR-II superheater was considered. In one millisecond, the bubble pressure dropped from its initial value, which was the steam reservoir pressure of 1325 psia, to 393 psia. During this time, the radius of the hemispherical bubble increased from $0.53 \mathrm{in}$. (the inner radius of the steam tube) to 3.02 in.

The growth of a spherical bubble was examined with the compressibility of the unreacted sodium taken into account. The effect of compressibility was slight. The bubble pressure decreased to 368 psia at one millisecond, while the bubble radius at the same time was 3.11 in. The changes from the values predicted by the incompressible theory are insignificant.

(b) Fuel-handling Machine--Argon Cooling System. An auxiliary power supply for the dc compressor was installed for turbine operation during emergency periods. The auxiliary power supply is normally on line in parallel with the battery supply and serves as the supply as long as either normal or emergency power is available.

(c) Reactor Temperatures. The converters for both the hot- and cold-leg reactor differential temperature instruments were replaced by new $\mathrm{MV} / \mathrm{I}$ converters. The new converters can be matched, thereby eliminating the requirement for signal-conditioning amplifiers. The elimination of the signal-conditioning equipment eliminates a major source of potential error and drift in the system.

(ii) Instrumentation Improvements (B. C. Cerutti)

(a) Constant-power System. Following the addition of the battery-operated power supply, the constant-power sets have been isolated successfully nearly thirty times during perturbations in the site power system. While isolating the site power system for inspection by the factory 
representative, the switches reclosed unexpectedly, blowing the fuses. The factory representative is investigating the cause of this malfunction.

Checks performed on the switches have shown that they break down during a transient voltage spike caused when the mechanical relay in the system opens. A temporary dv/dt filter has been added to the system as a test. The voltage can be limited, but the SCR's used as switches should be replaced with SCR's of a higher voltage rating to improve the operation. The factory representative has recommended (1) that the $\mathrm{dv} / \mathrm{dt}$ filter be added to the system, (2) that the SCR's be replaced with SCR's having a higher voltage rating, and (3) that the flywheel on the motorgenerater set be removed to eliminate the added inertia in the system.

\section{Operations}

\section{a. Reactor Plant (G. E.De egan and J. R. Davis)}

Liast Reported: ANL-7478, pp. 75-79.(July 1968).

The reactor was operated for $940 \mathrm{MWdt}$ in Runs $29 \mathrm{D}$ and $30 \mathrm{~A}$ during August. Run 29D was completed on August 13. Between runs, experimental subassemblies XO39 and XO40 as well as six flux-wire subassemblies were loaded in the core for flux mapping. Following the flux mapping, fuel handling for Run $30 \mathrm{~A}$ was completed, and the reactor was restarted on August 21. With AEC approval for 50-MWt operation of EBR-II, reactor power was raised to that level for the first time on August 26. After physics measurements at various powers following this increase, operation continued satisfactorily at $50 \mathrm{MWt}$ through the end of the month. The cumulated total of EBR-II operation is 19,528 MWdt.

Table I.E.11 summarizes the loading changes during August.

b. Fuel Cycle Facility. (M。 J F F eldman)

Last Reported: ANL-7478, pp.79-86 (July 1968).

\section{(i) Fuel Production}

(a) Hot Line Operation. Table I.E.12 summarizes the production activities for August. Primary effort was directed toward producing two 91 -element subassemblies of $70 \%$ enriched fuel. Criticality rules restrict the amount of other fuel that can be processed while the $70 \%$ enriched fuel is being processed. 
TABLE I.E.11. Loading Changes in EBR-II during August 1968

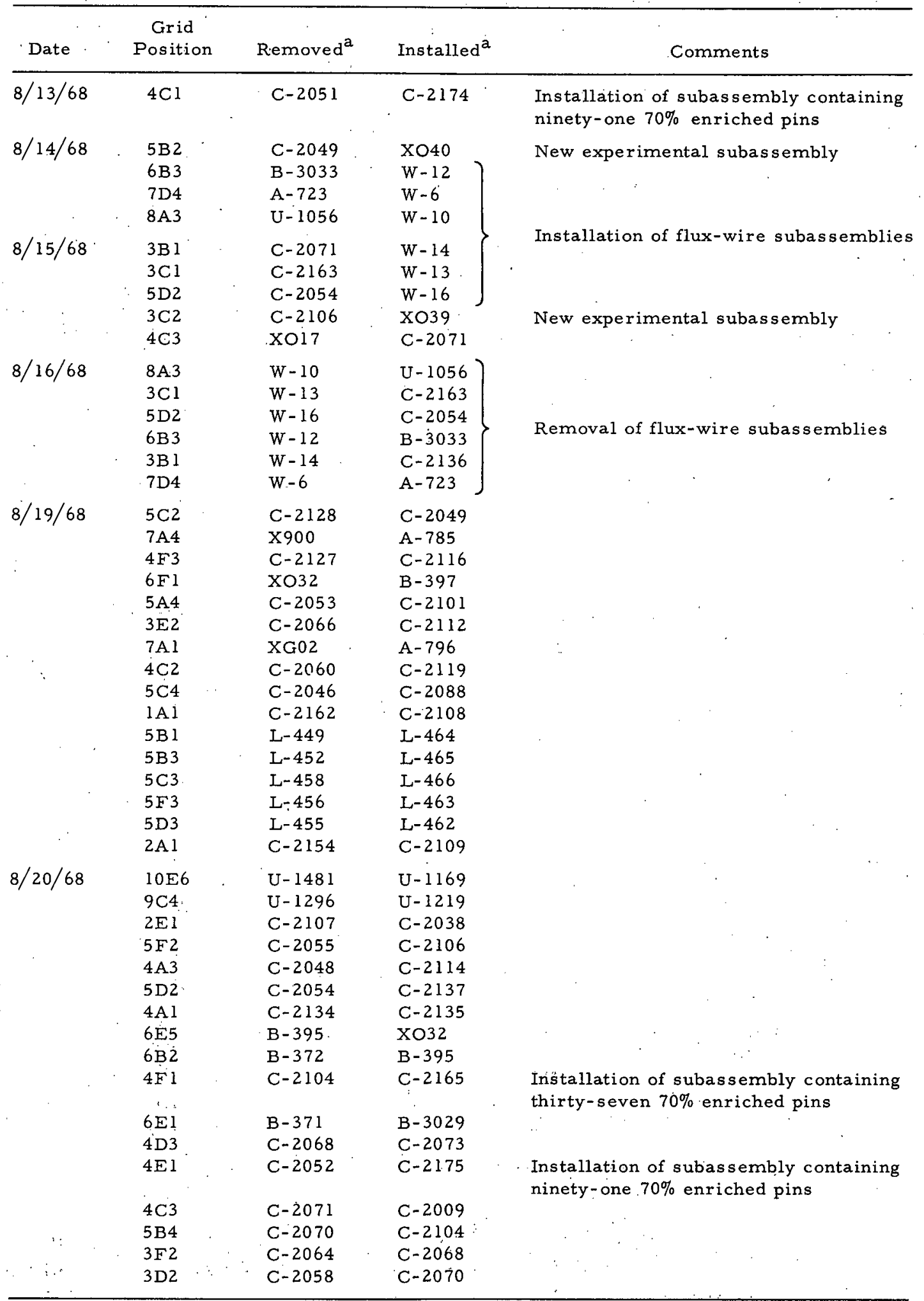

${ }^{a} A--$ Depleted-uranium inner-blanket subas sembly.

B--Row-6-type driver fuel subassembly.

"C--Driver fuel subas sembly.

L--Control rod subassembly.

$\mathrm{U}$--Depleted-uranium outer-blanket subassembly.

W--Flux-wire subassembly.

$\mathrm{X}$--Experimental subas sembly. 
TABLE I.E.12. Production Summary for FCF Hot Line

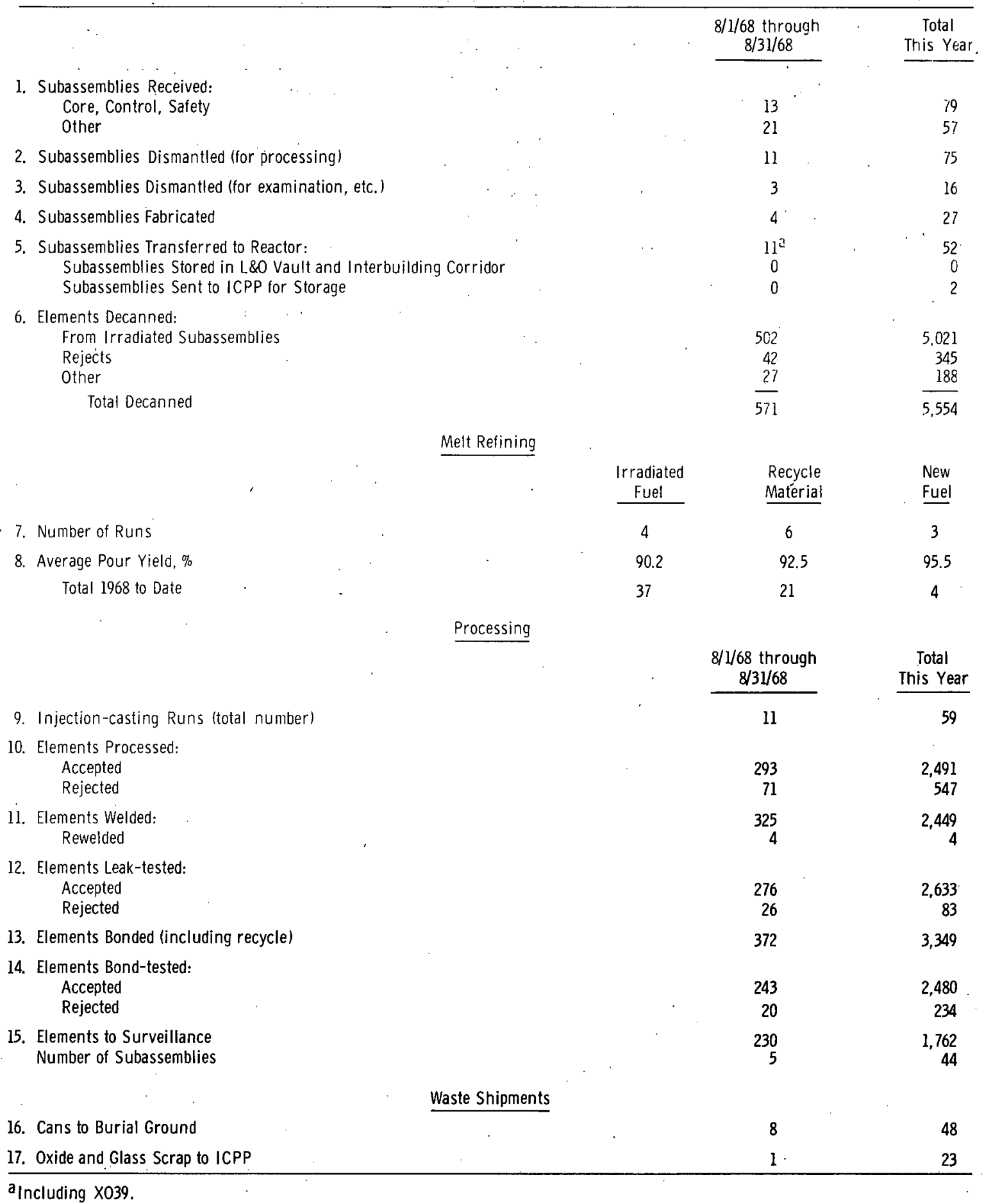

Shipment of radioactive fuel that contains excessive amounts of silicon to the recovery facility (ICPP) has been curtailed pending redesign and approval of the primary shipping container. As a result of this curtailment, the fuel-storage problem in the argon cell has not been resolved. Alternative storage areas for the reject fuel are being investigated. 
The cause of the high silicon concentrations has not been defined, but runs that have been made subsequent to those that resulted in the high silicon concentrations have not shown high silicon levels. Temporary procedural changes have been made in the injection-casting operations to help resolve the high silicon problem. Heels (approximately $3 \mathrm{~kg}$ ) from previous casting runs are no longer added to the melt-refining ingot (approximately $10 \mathrm{~kg}$ ) to make up a 12 - to $13-\mathrm{kg}$ charge. Because of mold breakage, the heels can become contaminated with silicon from the Vycor mold pieces. The number of molds that can be cast from a $10-\mathrm{kg}$ charge is only 85, compared to 105 that are cast from a $13-\mathrm{kg}$ charge. The heels are presently being segregated for use in runs that utilize only heels for the charge material. Investigation of the cause of the high silicon content is continuing.

Evaluation of the casting parameters for injection casting is continuing in an effort to define the causes of the varying pin yields from injection casting (see ANL-7478).

The need to repair several small leaks that were found during the out-of-cell test period has delayed installation of the replacement for the second injection-casting furnace.

As a result of the aforementioned conditions (handling of $70 \%$ enriched fuel, limited fuel-storage capacity, erratic casting yield, reduced number of molds used per run, and delay in installation of the replacement casting furnace), the fuel-pin production rate has been lower than scheduled.

Operations in which stainless steel blanket subas semblies were received from the reactor, washed, and sent to the burial ground have been completed. A total of 28 blanket subassemblies were transferred to the FCF; 26 were sent to the burial ground, and 2 were held for examination.

Six depleted-uranium subassemblies with melt wires in the top-end fixtures were received, sent to TREAT for neutron radiography, and transferred to the burial ground.

The electrical and mechanical feedthroughs for the neutron radiography equipment have been installed in the argon cell.

(b) Cold Line Operation. Normal production is continuing in the cold line. A summary of the month's production data is given in Table I.E.13.

In addition to the normal production activities, acceptance inspections were continued for pins and elements received from Aerojet. 
TABLE I.E.13. Production Summary for Cold Line

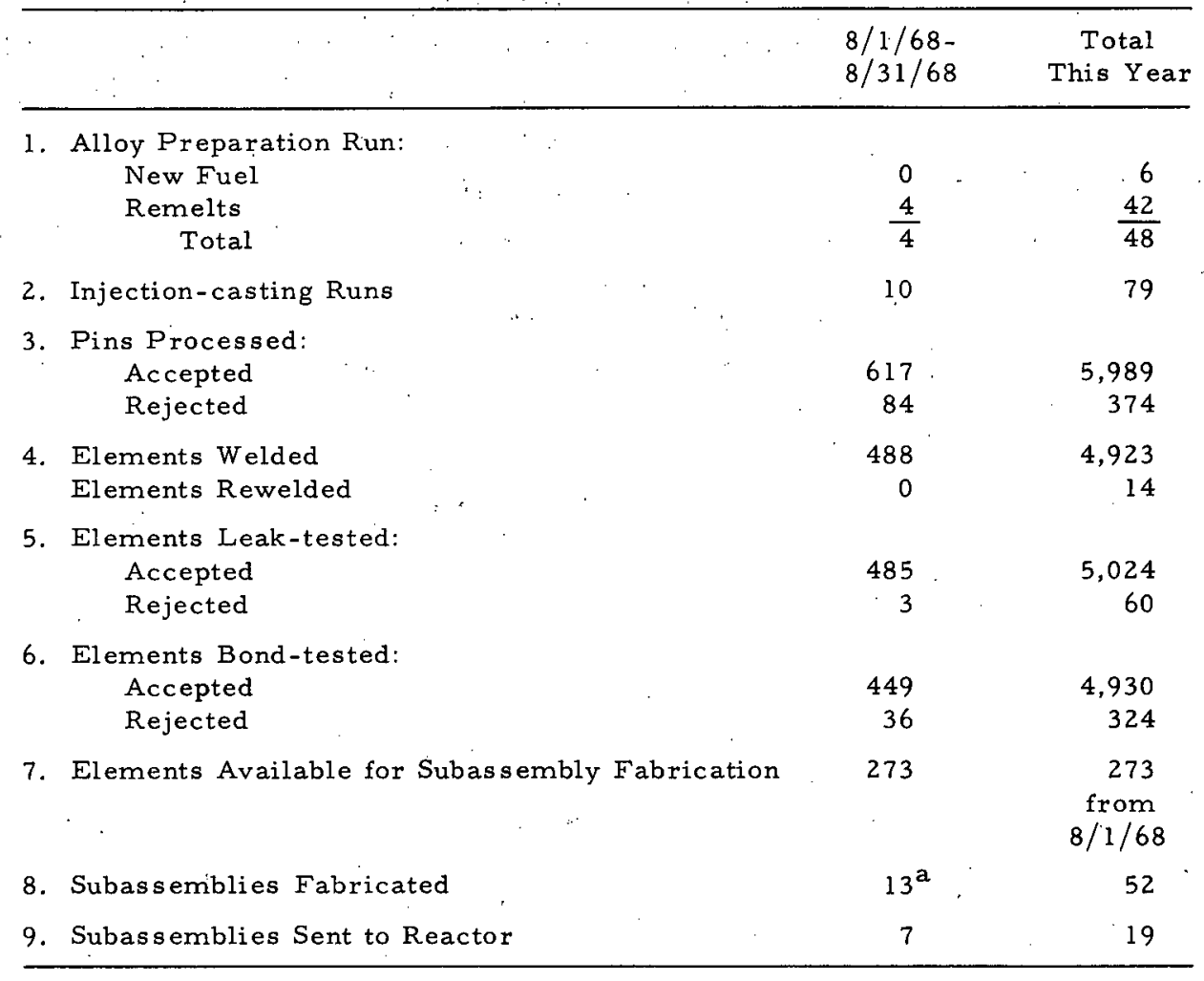

ancludes accept elements from last month which were not assembled into subas semblies.

(ii) Analyses (M. J. Feldman, J. P. Bacca, and E. R. Ebersole) (a) Chemical Analyses. The number of fuel-product analyses on hot line, cold line, and vendor fuel samples, together with the average values and ranges, are tabulated below:

\begin{tabular}{|c|c|c|c|}
\hline Analyzed for & Number & Average Value & Range \\
\hline $\mathrm{U}($ total $)$ & 13 & $94.67 \mathrm{w} / \mathrm{o}$ & $94.14-95.37$ \\
\hline${ }^{235} \mathrm{U}(\%$ of total $\mathrm{U})$ & 13 & $51.97 \mathrm{w} / \mathrm{o}$ & $51.38-52.17$ \\
\hline${ }^{239} \mathrm{Pu}$ & 7 & I 324 ppm & $1156-1420$ \\
\hline Mo & 21 & $2.51 \mathrm{w} / \mathrm{o}$ & $2.40-2.60$ \\
\hline $\mathrm{Ru}$ & 21 & $1.88 \mathrm{w} / \mathrm{o}$ & $1.81-2.02$ \\
\hline $\mathrm{Rh}$ & 19 & $0.265 \mathrm{w} / \mathrm{o}$ & $0.245-0.282$ \\
\hline $\mathrm{Pd}$ & 21 & $0.180 \mathrm{w} / \mathrm{o}$ & $0.163-0.199$ \\
\hline $\mathrm{Zr}$ & 17 & $0.087 \mathrm{w} / \mathrm{o}$ & $0.061-0.125$ \\
\hline $\mathrm{Nb}$ & 23 & $0.010 \mathrm{w} / \mathrm{o}$ & $0.0063-0.014$ \\
\hline $\mathrm{Si}$ & 65 & $554 \mathrm{ppm}$ & $254-1510$ \\
\hline $\mathrm{Al}$ & 22 & $151 \mathrm{ppm}$ & $84-207$ \\
\hline $\mathrm{C}$ & 6 & $258 \mathrm{ppm}$ & $136-325$ \\
\hline $\mathrm{Cr}$ & 19 & $60 \mathrm{ppm}$ & $23-120$ \\
\hline $\mathrm{Fe}$ & 24 & $375 \mathrm{ppm}$ & $97-886$ \\
\hline $\mathrm{Ni}$ & 19 & $151 \mathrm{ppm}$ & $95-202$ \\
\hline & $\mathrm{s}: \overline{310}$ & & \\
\hline
\end{tabular}


Analyses for surveillance of irradiated pins from the reactor are tabulated below:

\begin{tabular}{|c|c|c|c|}
\hline Analyzed for & Number & $\begin{array}{l}\text { Average Value } \\
\text { (ppm) }\end{array}$ & Range \\
\hline Al & 13 & 250 & $50-424$ \\
\hline C & 12 & 372 & $172-708$ \\
\hline $\mathrm{Fe}$ & 15 & 273 & $120-520$ \\
\hline $\mathrm{Si}$ & 25 & 291 & $100-695$ \\
\hline Tc & 7 & 300 & $80-443$ \\
\hline${ }^{139} \mathrm{La}$ (burnup) & 3 & & \\
\hline
\end{tabular}

(b) Postirradiation Analysis of EBR-II Fuel

(1) Mark-IB Fuel Surveillance. The third EBR-II driver subassembly (C-2134) of the Mark-IB fuel-surveillance program attained target burnup of $0.97 \mathrm{a} / \mathrm{o}$ at the end of Run 29. Elements of the subassembly will be subjected to postirradiation examination following dècay cooling.

(2) Surveillance of Cold-line Fuel. "Subassembly C-2121 reached target burnup of $\overline{0.80}$ a/o at the end of Run $29 \mathrm{C}$. Elements from this subassembly are currently being examined. Results are not yet available.

(3) Irradiation Program for 70\% Enriched Fuel. This program consists of the irradiation of a series of driver subassemblies containing fuel elements fabricated from $70 \%$ enriched U-5 w/o Fs alloy. In these experiments, the $70 \%$ enriched fuel is irradiated in EBR-II at a reactor power level of $45 \mathrm{MWt}$, but under conditions of higher temperatures which simulate those which would be experienced at higher power operation and higher power densities in the reactor. Postirradiation examinations are employed to assess the effects of the increased operating temperatures on the irradiation swelling of the fuel.

The second subassembly of this program, C-2166, reached target burnup at the end of Run 29C. This subassembly contained $37 \mathrm{U}-5 \mathrm{w} / \mathrm{o} \mathrm{Fs}$ elements with a. ${ }^{235} \mathrm{U}$ enrichment of approximately $70 \%$, and 54 standard U-5 w/o Fs driver elements with an enrichment of approximately $52 \%$. The $70 \%$ enriched elements were positioned in a central cluster of the element array, surrounded by the normal $52 \%$ enriched elements. Irradiation of the subassembly was carried out in reactor grid position 4Bl. As shown in Table I.E.14, the calculated maximum burnup of the $70 \%$ elements ranged from 0.55 to $0.58 \mathrm{a} / \mathrm{o}$. The table illustrates the comparable values for the normal $52 \%$ enriched elements. 
TABLE I.E.14. Summary of Fabrication and Irradiation Data for EBR-II Subassembly C-2166, 70\% Enriched Fuel

(Irradiated in Reactor Grid Position 4B I)

\begin{tabular}{|c|c|c|c|c|c|c|c|c|}
\hline \multirow{2}{*}{$\begin{array}{l}\text { Injection- } \\
\text { casting } \\
\text { Batch } \\
\text { Number }\end{array}$} & \multirow{2}{*}{$\begin{array}{c}{ }^{235} \mathrm{U} \\
\text { Enrichment } \\
\text { in Fuel } \\
(\mathrm{w} / \mathrm{o})\end{array}$} & \multirow{2}{*}{$\begin{array}{l}\text { Silicon } \\
\text { Content } \\
\text { of Fuel } \\
\text { (ppm) }\end{array}$} & \multirow{2}{*}{$\begin{array}{l}\text { Number } \\
\text { of } \\
\text { Elements }\end{array}$} & \multirow{2}{*}{$\begin{array}{c}\text { Element } \\
\text { Burnup } \\
\text { Range } \\
(\mathrm{a} / \mathrm{o})\end{array}$} & \multicolumn{2}{|c|}{$\begin{array}{c}\text { Total Volume } \\
\text { Swelling of } \\
\text { Fuel }(\Delta \mathrm{v} / \mathrm{v}, \%)\end{array}$} & \multicolumn{2}{|c|}{$\begin{array}{l}\text { Calculated Fuel } \\
\text { Centerline } \\
\text { Temperature }\left({ }^{\circ} \mathrm{F}\right)\end{array}$} \\
\hline & & & & & Average & Range & Maximum & Range \\
\hline 0700 & 69.78 & 260 & 15 & $0.55-0.58$ & 3.0 & $2.2-3.5$ & 1133 & $1094-1133$ \\
\hline 0701 & 69.63 & 496 & 22 & $0.55-0.58$ & .3 .3 & $2.2-4.0$ & 1134 & $1088-1134$ \\
\hline 4296 & 52.07 & 438 & 10 & $0.45-0.47$ & 2.1 & $1.8-2.4$ & 1046 & $955-1046$ \\
\hline 4270 & 52.03 & 365 & 16 & $0.44-0.47$ & 1.9 & $1.6-2.3$ & 1049 & $958-1049$ \\
\hline 4271 & 52.18 & 509 & 28 & $0.43-0.47$ & 1.8 & $1.5^{a}-2.6$ & 1046 & $941-1046$ \\
\hline
\end{tabular}

${ }^{a}$ Excludes element No. 72 , which indicated anomalous swelling of $0.4 \%$.

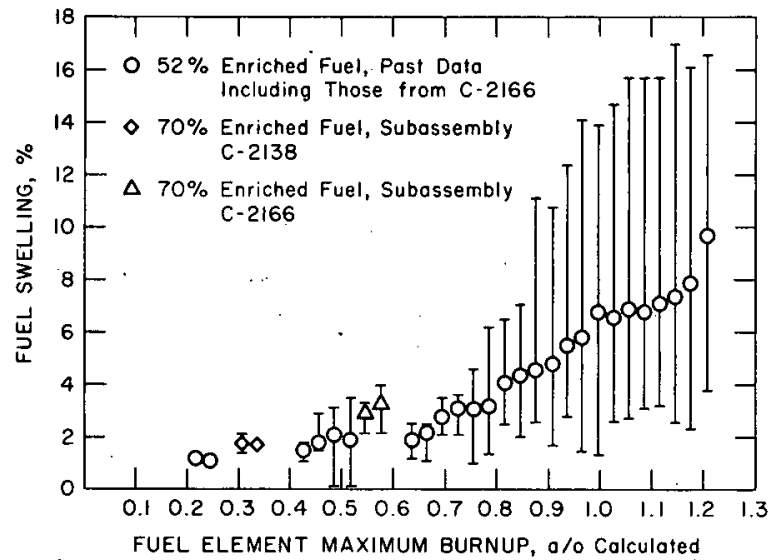

Fig. I.E.6. Postirradiation Surveillance Results for $70 \%$ Enriched Fuel in Subassem bly $\mathrm{C}-2166$. A verage increase in fuel volume vs. fuel-element maximum burnup.

Postirradiation examinations of the elements indicated that swelling of the $70 \%$ fuel averaged about $3.2 \%$, and ranged from 2.2 to $4.0 \%$. These values are illustrated in Fig. I.E.6, which presents fuel swelling as a function of calculated burnup. In addition, the figure indicates swelling of $70 \%$ fuel in the first $70 \%$ irradiation subassembly of this program, C-2138, along with swelling data obtained in the past for normal $52 \%$ enriched U-5 w/o Fs alloy.

It can be observed in Fig. I.E.6 that swelling of the $70 \%$ enriched elements from C-2166, although still low, is slightly higher than that observed in the past for normal $52 \%$ enriched driver elements following comparable burnup but irradiated at somewhat lower centerline temperatures.

From these data, it has been concluded that the third subassembly of the program (C-2165), which is now being held in the EBR-II storage basket after having been irradiated to the same burnup as C-2166, should be reinstalled in the core at the beginning of Run 30 in order to accumulate additional burnup. The recommended level of burnup is $0.80-0.85 \mathrm{a} / \mathrm{o}$, and this should be attained with completion of approximately one-half of Run 30. At that time, the subassembly will be subjected to postirradiation examinations to evaluate fuel swelling and other pertinent features.

As mentioned in Sect. I.E.2.b.(i)(a), two additional subassemblies: C-2174 and C-2175, of this program have been fabricated. Each contains a full 91 -element complement of $70 \%$ enriched elements. Irradiation of these subassemblies to as yet unspecified burnup levels will begin during Run 30. 
(4) Extended-burnup Subassembly C-291. This subassembly (Experiment 1 of Task 10, EBR-II Fuel Performance Studies-Mark I Series) is one of three subassemblies containing specially selected $\mathrm{U}-5 \mathrm{w} / \mathrm{O} \mathrm{Es}$ alloy (MCS-type with a nominal silicon content of $300 \mathrm{ppm}$ ) which are intended to investigate the performance of the alloy at burnups greater than $1.2 \mathrm{a} / \mathrm{o}$. Subassembly $\mathrm{C}-291$ reached a calculated target burnup of $1.31 \mathrm{a} / \mathrm{o}$ at the end of Run 29C. Preliminary postirradiation results for fuel swelling are especially encouraging. The data indicate an average swelling of $5.2 \%$ for the two batches of fuel (4137 and 4142) represented in the subassembly, and a maximum individual element swelling of $6.3 \%$. The data are presently being subjected to additional analysis. Based on the swelling results obtained for C-291, Subassembly C-2027 or B-362 will probably be recommended for irradiation to $1.4 \mathrm{a} / \mathrm{o}$. These subassemblies are similar to C-291, and are being held in the reactor storage basket after having accumulated maximum calculated burnups of $1.20 \mathrm{a} / \mathrm{o}(\mathrm{C}-2027)$ and $1.16 \mathrm{a} / \mathrm{o}(\mathrm{B}-362)$.

(c) Production Analysis. As previously reported,* one batch of restrainers was used which were made of. Type 304 stainless steel that was slightly low in chromium and slightly high in nickel as compared to normal Type 304 stainless steel. Initial investigations had shown that normal welds were produced with these restrainers. Postirradiation examination of restrainers from this batch has been conducted by metallographic means. The restrainers came from Subassembly C-2077 which had reached $0.8 \mathrm{a} / \mathrm{o}$ burnup in the reactor. There was no indication of any carburization, decarburization, or erosion of the restrainers or weld areas that had been. exposed to the sodium during the irradiation period. Additional restrainers from this batch will be examined when subassemblies known to contain them are removed from the reactor.

The loss of material from the beryllium-copper bushings on EBR-II control rods has been observed and reported in the past.** The loss of material from the bushing resulted from the change in properties of the beryllium copper because of overaging in the reactor. A control subassembly (L-457) in which aluminum-bronze bushings were substituted for beryllium-copper bushings in alternate bushing rings has been tested in the reactor to compare the suitability of the two materials. The subassembly was in the primary tank a total of $7608 \mathrm{hr}$, in the reactor grid $2333 \mathrm{hr}$, and was at an average power level of $42 \mathrm{MWt}$ for $1354 \mathrm{hr}$. The approximate sodium temperature at the bushings while the subassembly was in the grid was $700^{\circ} \mathrm{F}$. A preliminary visual inspection of the bushings from this test subassembly indicates that the aluminum-bronze bushings have indeed worn less than the beryllium-copper bushings. About 6 mils of

\footnotetext{
* See Progress Report for February 1968, ANL-7427, pp. 89-91.

** Progress Report for December 1967, ANL-7403, p. 51.
} 
material have worn away from the beryllium-copper bushings; but there is no evidence of material loss from the aluminum-bronze bushings.. A complete examination including weight loss and dimensional determinations, chemical analyses, and metallography, will be carried out on the bushings in the near future.

\section{PUBLICATIONS}

Effects of Finite Size in $4 \pi$-Recoil Proportional Counters

R. Gold and E. F. Bennett

Nucl. Instr. Methods $\underline{63}, 285$ (1968)

An Otpimized Dual Perturbation Technique

L. B: Miller, G. H. Miley,* and P. F. Gast

Proc. Intern. Conf. on the Utilization of Research Reactors and

Reactor Mathematics and Computation, Mexico City, May.2-4, 1967.

Centro Nuclear de Mexico, 1968, Vol. 2, p. 1121

Accuracy of the Quasistatic Treatment of Spatial Reactor Kinetics

K. O. Ott and D. A. Meneley

Proc: Brookhaven Conf. on Industrial Needs and Academic

Research in Reactor Kinetics. BNL-50117 (April 1968),

pp. $192-212$

*University of nllinois. 


\section{GENERAL REACTOR TECHNOLOGY}

A. Applied and Reactor Physics Development

1. Theoretical Reactor Physics--Research and Development

a. Cross Section Data Evaluation (C. N. Kelber)

Last Reported: ANL-7478, p. 87 (July 1968).

- Data for neutron cross sections for almost all materials on Category 1 ENDF/B tapes $114,115,116$, and 117 have been processed through DAMMET, ET $\not E$, and MERMC2 to produce an $M C^{2}$ library tape. This tape will be used in $\mathrm{MC}^{2}$ calculations for the $\mathrm{ENDF} / \mathrm{B}$ fast reactor benchmark problems which involve ZPR-3 Assemblies 11 and 48 . Some materials were modified by use of CRECT to obtain compatibility with $\mathrm{MC}^{2}$ format restrictions. Some data from earlier tapes were also processed for materials for which no Category 1 data have been distributed.

b. Reactor Computations and Code Development (B. J. Toppel)

(i) ARC System

Last Reported: ANL-7478, p. 87 (July 1968).

The modules comprising the $\mathrm{MC}^{2}$ capability in the ARC system have been modified and augmented to provide more flexible and user-oriented input, as well as to extend the dimensions of the code.

The input, which now conforms to standard ARC input specifications, permits a completely random sequence of input cards and eliminates the need for redundant input data.

The code dimensions have been extended to allow 70 broad energy groups, 2000 resolved resonances, and 100 energy points in the unresolved resonance region. The previous limits, as with the CDC-3600 version of $\mathrm{MC}^{2}$, were 49 broad groups, 800 resolved resonances, and 25 unresolved energy points.

(ii) Fuel-cycle Package

Last Reported: ANL-7445, pp. 100-101 (April 1968).

A procedure of cross-section collapse has been added to the Fuel-cycle Package. In this procedure the energy range may be collapsed into any number of energy groups. In addition, region-dependent cross sections are created as noted below: 
The method of cross-section collapse has been codified as an ARC system module so that it may be utilized in conjunction with any ARC cróss-section set. By use of linear flux weighting; this module creates collapsed region-dependent microscopic group cross sections.

The calculational procedure is as follows:

$$
\begin{aligned}
& \bar{\sigma}_{J}^{r}(m)=\sum_{j} \sigma_{j}^{r} \phi_{j}(m) / \sum_{j} \phi_{j}(m), \\
& \bar{\sigma}_{J \rightarrow K}^{S}(m)=\sum_{k \text { in } K} \sum_{j}{ }_{i n} \sigma_{j \rightarrow k}^{S} \phi_{j}(m) / \sum_{j} \phi_{j}(m),
\end{aligned}
$$

and

$$
\bar{\phi}_{J}(m)=\sum_{j} \phi_{j}(m)
$$

where

$j$ is the jth group,

$\mathrm{J}$ is the Jth collapsed group,

$\sigma_{j}^{r}$ is the microscopic cross section for reaction $r$ and group $j$,

$\phi_{j}(m)$ is the flux in group $\mathrm{j}$ in region $\mathrm{m}$,

$\sigma_{j \rightarrow k}^{s}$ is the microscopic scattering cross section from group $j$
to group $k$,

$k$ is the kth group,

$\mathrm{K}$ is the Kth collapsed group,

$\sigma_{\mathrm{J}}^{\mathrm{r}}(\mathrm{m})$ is the collapsed region-dependent microscopic cross section for reaction $r$ in group $J$ in region $m$, and

$\sigma_{\mathrm{J} \rightarrow \mathrm{K}}^{\mathrm{S}}(\mathrm{m})$ is the collapsed region-dependent microscopic scattering cross section from group $J$ to group $K$ in region $m$. 
2. Nuclear Data--Research and Development.

\section{a. Reactor Code Center (M. Butler)}

Last Reported: ANL-7478, p. 97 (July 1968).

New versions of three library programs have been received. These include: LION, the 3-dimensional transient and steady-state temperature distribution program from Knolls Atomic Power Laboratory; $2 \mathrm{DB}$, the 2-dimensional diffusion burnup program from Battelle Pacific Northwest Laboratory; and GAFGAR, a program used to calculate neutron spectra and group-averaged cross sections from Gulf General Atomic.

Four programs were as similated into the Code Center library this month and are now available for distribution. Three of these are the KAPI CDC 6600 programs CURFIT, a general curve-fitting program, our program number 43; SOR2, stress analysis for shells of revolution, our program number 80; and LION, our program number 299. The fourth program incorporated this month is the new UNIVAC 1108 version of $2 \mathrm{DB}$ from BNWL, our program number 325.

\section{B. Reactor Fuels and Materials Development}

1. Fuels and Cladding

a. Research and Development

(i) Behavior of Reactor Materials

(a) Fuel Element Behavior Modeling (P. G. Shewmon)

(1) Development and Solution of New Differential Equations for Creep of Cladding Subject to Timedependent Changes in Stress (J.H. Gittus)

Not reported previously.

When the stress produced in fuel-element cladding by expansion of the fuel changes in magnitude due to an alteration in heat rating, the creep rate of the cladding also changes. The new creep rate depends not only on the new value of the stress, but also on the metallurgical structure that deformation at the previous stress has produced in the cladding. Conventional assumptions are that this metallurgical structure depends solely on the prior creep strain (the strain-hardening hypothesis) or on the duration of the prior creep process (the time-hardening hypothesis). Neither assumption is capable of predicting the experimentally observed effect of temporarily reducing the stress to zero. Since no strain occurs 
during the period at zero stress, the strain-hardening hypothesis would lead to the expectation that creep would recommence at the previous rate upon restoration of the stress. The time-hardening hypothesis, on the contrary, predicts that hardening will continue during the period at zero stress so that creep recommences at a lower rate upon reapplying the stress. In fact, the period at zero stress actually softens the material (for example, stainless steel) so that, when the stress is reapplied, the material creeps more rapidly.

A new model of creep has been developed to remedy this deficiency. The model is based on an analysis of the dynamic behavior of a statistical assembly of edge dislocations. These dislocations, which move intermittently, are impelled by the joint effects of stress and temperature. Sinks such as precipitates and grain boundaries immobilize a proportion of the moving dislocations, and other dislocations are immobilized by mutual intersection or glide polygonization. Sources operate to generate new dislocations, and some of the immobilized dislocations can be remobilized later by stress-aided thermal fluctuations.

Formal analysis of this model has produced the following differential equations that jointly define the creep behavior of the theoretical solid:

$$
\begin{aligned}
& \dot{\rho}=-\dot{\epsilon}_{1}\left[\left(\underline{\rho}-\underline{\rho}_{\infty}\right)\left(\mathrm{K}_{4} \underline{\rho}+\mathrm{K}_{6}\right)+\mathrm{K}_{\theta}(\underline{\rho}-1)\right]-\mathrm{K}_{8}(\underline{\rho}-1), \\
& \dot{\epsilon}=\dot{\epsilon}_{1} \underline{\rho},
\end{aligned}
$$

and

$$
\dot{\epsilon}=\int_{t} \ddot{\epsilon} \cdot d t
$$

where

$$
\begin{aligned}
\underline{\rho} & =\rho / \rho_{0} ; \\
\underline{\rho}_{\infty} & =\rho_{\infty} / \rho_{0} ; \\
\rho & =\text { the mobile dislocation density; } \\
\rho_{0} & =\text { the value of } \rho \text { at } t=0 ; \\
\rho_{\infty} & =\text { the value of } \rho \text { at } t=\infty ; \\
t & =\text { time; } \\
\dot{\epsilon} & =\text { the strain rate; } \\
\epsilon & =\text { the total creep strain produced in time } t \\
\ddot{\epsilon} & =\text { the strain rate at } t=0 ;
\end{aligned}
$$


$\mathrm{K}_{4}=$ the second-order rate constant for immobilization by glide polygonization;

$\mathrm{K}_{6}=$ the first-order rate constant for the combined (competitive). effects of source operation and immobilization by stationary. obstacles;

$\mathrm{K}_{\theta}=$ the rate constant for stress-aided thermal recovery;

and

$K_{8}=$ the rate constant for thermal recovery at zero stress.

A FORTRAN. IV computer code, CLADEF (i.e., CLAdding DEFormation, I.D. No. 68E8229), has been written and used with the ANL CDC-3600 computer to solve these equations. The effects of a stress cycle are computed by a predictor-corrector procedure, and the output consists of graphs and tables of $\epsilon, \dot{\epsilon}$, and $\underline{\rho}$ as functions of $t$.

About one hundred runs have been made by using CLADEF to explore the effects of various values of the input parameters. The results are in good agreement with the results of creep experiments in which the stress acting on the specimen has been changed (or reduced to zero) during the course of the test. For example, Fig. II.B.l shows experimental results obtained by Kennedy, * who temporarily removed the load during creep tests. Fig. II.B. 2 is the comparable result produced by solution of the new creep equations.

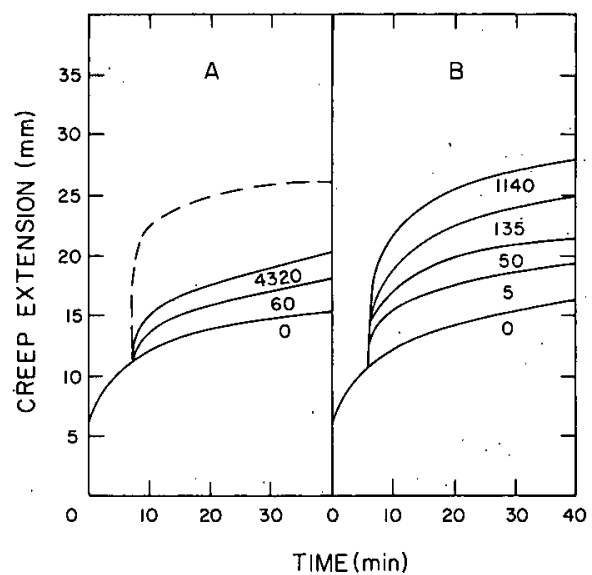

Fig. II.B.1. Creep of Pure Lead Interrupted for the Number of Minutes Written under Each Curve (after Kennedy, 1955)

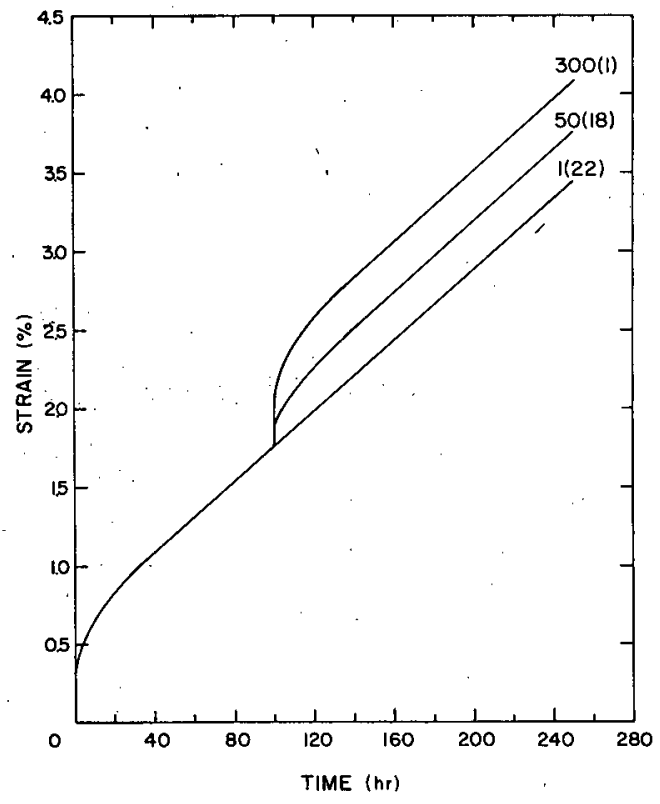

Fig. II.B.2. Creep of Theoretical Solid In terrupted for the Number of Hours Written after Each Curve. (Expt. No. is in parentheses.)

* Kennedy, A. J., Proc. Phys. Soc. 68, Sect. B, 257-276 (1955). 
Figure II.B.3 shows how, according to the new equation, a sudden reduction in stress causes the creep rate to fall to a low value that subsequently increases with the passage of time. This behávior was also observed by Mitra and McLean.* Figure II.B.4 is a CLADEF diagram that illustrates how this effect occurs when the stress is temporarily reduced (at $300 \mathrm{hr}$ ) and eventually restored (at $600 \mathrm{hr}$ ); the logarithm of $\dot{\epsilon}$ has been plotted against time. Mitra and McLean found, furthermore, that $\Delta \sigma / \Delta t$ increased with $\ddot{\epsilon}$, where $\Delta \sigma$ is the reduction in stress and $\Delta t$ is the period of time that must subsequently elapse before $\dot{\epsilon}$ attains a new, constant value (see Fig. II.B.4 for a definition of $\Delta t$ ). The CLADEF solutions of the new differential equations exhibit precisely this behavior, as is exemplified in Fig. II.B.5.

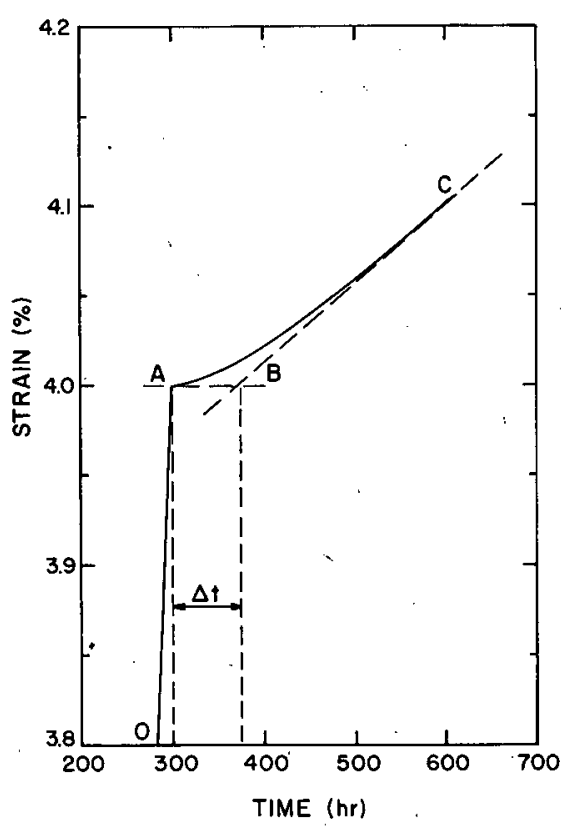

Fig. II.B.3. Detail of the StrainTime Plor for Expt. 1

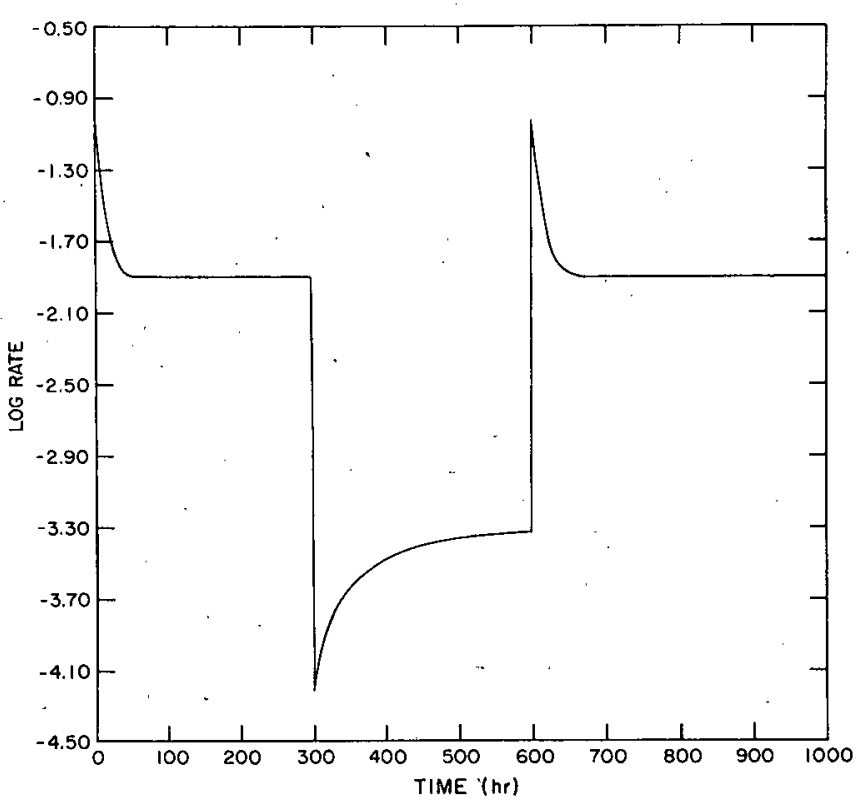

Fig. II.B.4. Graph Drawn by the Computer Showing How the New Creep Equation Predicts That an Acceleration of Strain Rate Will Occur Immediately after a Stress Reduction (at $300 \mathrm{hr}$ )

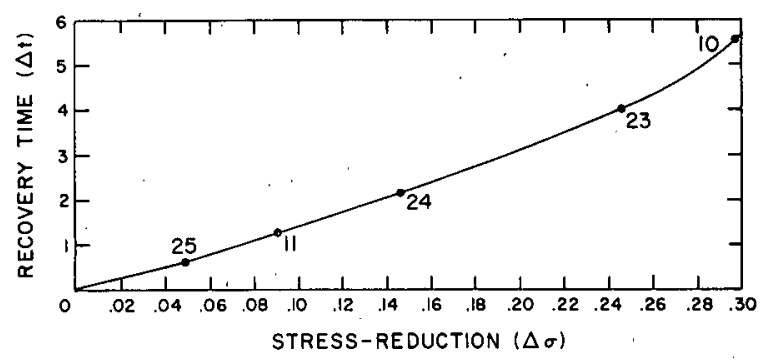

*Mitra, S. K., and McLean, D., Proc. Roy. Soc. (London) A295, 288-299 (Dec. 6, 1966).
Fig. II.B.5

Variation of Recovery Time $\Delta t$ with Stress Reduction $\Delta \sigma$ for Theoretical Solid (Expt. No. Opposite Each Point) 
(b). Thermal Properties of LMFBR Fuels (O. L. Kruger)

Last Reported: ANL-7460, pp. 92-93 (June 1968).

(1) Preparation of Thermal-diffusivity Specimens of (U, $\mathrm{Pu}) \mathrm{O}_{2}$. Disc specimens of (U-20 w/o $\left.\mathrm{Pu}\right) \mathrm{O}_{2}$ obtained from Nuclear. Materials and Equipment Corp., Apollo, Pa., had a characteristic microstructure of dense grains surrounded by porous material at the grain boundaries. Although this structure is typical of certain fabrication processes, specimens of uniform density must also be investigated. Specimens of solidsolution oxide with porosities ranging from 0 to $25 \%$ a re needed to evaluate the density-correction equations, particularly at temperatures above $1000^{\circ} \mathrm{C}$. These disc specimens are being fabricated from coprecipitated (U-20 w/o $\mathrm{Pu}_{2} \mathrm{O}_{2}$ powder. The relatively fine powder is mixed with $0.5 \mathrm{w} / \mathrm{o}$ Carbowax binder, cold pressed at 20,000 psi, and sintered in hydrogen at temperatures ranging from 1400 to $1800^{\circ} \mathrm{C}$. Since these discs must be measured to $2000^{\circ} \mathrm{C}$, density will be controlled by particle size or density of the recrushed material rather than by sintering temperature. The final specimen may be equilibrated at $2000^{\circ} \mathrm{C}$ to assure structure stability at high temperatures.

(2) Thermal Diffusivity of Polycrystalline $\mathrm{UO}_{2}$. A laser heat-pulse technique was used to measure the thermal diffusivity of $\mathrm{UO}_{2}$ from 400 to $2000^{\circ} \mathrm{C}$. The disc specimen, $0.750 \mathrm{in}$. in diameter by $0.469 \mathrm{in}$. thick, was coated with tungsten and annealed at $1500^{\circ} \mathrm{C}$ prior to measurement. The specimen was heated in a vacuum of $10^{-6}$ Torr for measurements taken to $1500^{\circ} \mathrm{C}$, and in flowing high-purity argon for measurements at higher temperatures. Argon at a pressure of $1 \mathrm{~atm}$ reduced the rate of oxygen loss from the specimen. The measurements at temperatures above $1500^{\circ} \mathrm{C}$ were made as rapidly as possible to reduce oxygen loss and diffusion of the tungsten coating.

Thermal diffusivity of $93.7 \%$ dense $\mathrm{UO}_{2}$ as a function of temperature is shown in Fig. II.B.6. Each point on this curve repre-

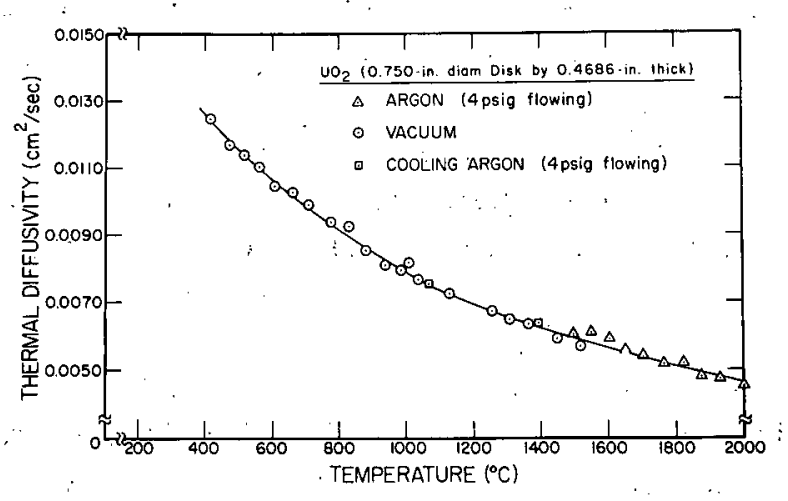

Fig. II.B.6. Thermal Diffusivity of $\mathrm{UO}_{2}$ sents an average of three determinations. The diffusivity of $\mathrm{UO}_{2}$ at $400^{\circ} \mathrm{C}$ is $0.0125 \mathrm{~cm}^{2} / \mathrm{sec}$, which is considerably less than the value of $0.0145 \mathrm{~cm}^{2} / \mathrm{sec}$ for $\mathrm{PuO}_{2}$ at the same temperature. The curves for $\mathrm{UO}_{2}$ and $\mathrm{PuO}_{2}$ cross at about $700^{\circ} \mathrm{C}$, and at $2000^{\circ} \mathrm{C} \mathrm{UO}_{2}$ has a slightly higher diffusivity than - $\mathrm{PuO}_{2}$. These data will be analyzed further on the basis of specimen density, porosity corrections, and thermal conductivity. 
The results of chemical analyses for impurity elements and oxygen content of the $\mathrm{UO}_{2}$ and the $\mathrm{PuO}_{2}$ specimens measured previously have been received. Spectrographic analysis revealed no major impurities in the $\mathrm{UO}_{2}$, but the $\mathrm{PuO}_{2}$ contained about $0.1 \mathrm{w} / \mathrm{o}$ aluminum. Attempts to equilibrate the plutonium dioxide to the stoichiometric composition of $\mathrm{PuO}_{2.00}$ have failed. This anomalous behavior weakens any conclusions derived from the data taken with the $\mathrm{PuO}_{2}$ specimen; therefore, new specimens will be prepared from high-purity oxide and measured to $2000^{\circ} \mathrm{C}$.

Pieces from the diffusivity discs are being examined with the metallograph and the electron probe. These examinations will show the pore structure of the oxides and the degree of tungsten penetration (if any) into the discs at high temperatures.

(3) Evaluation of Computer Codes for the Calculation of Oxide-fuel Temperatures. Several of the existing computer codes to determine the lifetimes of metallic and ceramic fuels were examined with emphasis being placed on techniques to calculate temperature profiles. A thoroughly realistic model of the thermal properties of ceramic-fuel elements under irradiation was not found in any of the codes considered. These codes were also unequipped to implement the results of current and projected fast reactor experiments (in particular those of the planned EBR-II Instrumented Subas sembly).

The codes considered were SWELL (and BEMOD), NEUKER (and KER-4), CYGRO, THTB, and FIGRO. Of these, FIGRO presents the most comprehensive and sophisticated thermal model of ceramicfuel behavior.

Trends in the investigation of the behavior of fast reactor fuels indicate that a more realistic code for a steady-state temperature profile can be written at this time. As data on properties are accumulated, this code could then be expected to give increasingly reliable results without significant alteration of the models employed. The output of the code would, optimally, be a description of the thermal properties of the fuel at any time. Overall thermal behavior of the fuel could then include transients, by inputting these conditions to a subroutine dealing with transient reactor situations.

Although FIGRO presents the groundwork for such a steady-state code, some adaptation is necessary for application to ceramic fast reactör fuels. In particular, realistic models of central void formation and fuel-clad gap conductance are needed. This adaptation will be carried out in the immediate future. The result will be a unique code exhibiting the following features: 
(a). The fuel will be divided into four radial regions (the unaffected, equiaxed grain, columnar grain, and the central void) with the porosity varying from region to region.

(b) The heat-generation rate in the fuel element will be a function of porosity, and the thermal conductivity will be a function of temperature and porosity.

(c) The normal output of the program will include a plot of temperature profile at any time that it is requested.

(d) The program will have the ability to accept a temperature profile (supplied by the EBR-II Instrumented Subassembly) and back calculate thermal conductivities at points in the cross section of the fuel, as well as back,calculate fuel-clad gap conductance.

(e) The program will facilitate the comparison of preirradiation and postirradiation data under the assumptions of the models employed, and will make maximum use of the existing data on in- and out-ofreactor properties.

\section{(c) Fission Gas Behavior in Uranium-Plutonium Carbide Fuels (L. C. Michels and J. O. Schiffgens)}

Last Reported: ANL-7478, p. 98 (July 1968).

Irradiation experiments are being planned to provide information on the in-pile swelling behavior of (U,Pu)C fuels. The irradiation capsules are being designed and instrumented to permit continuous measurement of fuel swelling as a function of burnup. Particular attention will be focused on intrinsic unrestrained swelling and on the effect of external restraint on swelling. The irradiation parameters to be investigated are burnup, fuel temperature, and restraining pressure. The approximate fixed parameters are given in Table II.B. 1 .

TABLE II.B.1. Fixed Parameters for the Irradiation of (U,Pu)C Fuels

\begin{tabular}{ll}
\hline \multicolumn{1}{c}{ Parameters } & \multicolumn{1}{c}{ Values } \\
\hline Fuel & Stoichiometric (U,Pu)C \\
Fuel composition & $20 \mathrm{w} / \mathrm{O} \mathrm{PuC}, 80 \mathrm{w} / \mathrm{O} \mathrm{UC}$ \\
Fuel enrichment & Natural uraniur \\
Pellet size & Diameter: $0.25 \mathrm{in}$. \\
& Length: 0.25 to $0.50 \mathrm{in}$. \\
Pellet density range & 80 to $96 \%$ theoretical density \\
Maximum burnup & $10 \mathrm{a} / 0$ \\
Maximum temperature of fuel center & $1800^{\circ} \mathrm{C}$ \\
Maximum temperature of fuel surface & $1000^{\circ} \mathrm{C}$ \\
Maximum restraining pressure & $10,000 \mathrm{psig}$ \\
\hline
\end{tabular}


Two capsule designs are being considered in which the restraining pressure is transmitted to the fuel pellet either hydrostatically, or mechanically. Brief descriptions of these designs are as follows:

(1) Hydrostatic-pressure Device. In this design a chamber containing the fuel pellet is completely filled with NaK. By applying the desired pressure to a small bellows at the top of the chamber, the restraining pressure is transmitted directly to the pellet via the surrounding $\mathrm{NaK}$. As the pellet swells during irradiation, the displaced NaK causes the bellows to expand. The elongation of the bellows is measured with a linear variable differential transformer that allows the continuous monitoring of swelling as a function of burnup. The primary advantage of this design concept is simplicity. The disadvantage associated with the concept arises from the difficulty of adequately accounting for the presence of fission gases in the closed, NaK-filled container.

(2) Mechanical-pressure Device. In this design the restraining pressure is applied directly to the fuel pellet by five rams. The rams are hydraulically activated by applying pressure to a small bellows joined to a closed, NaK-filled, interconnected tunnel network leading to the five rams. As the pellet swells during irradiation, the rams are pushed back into the NaK-filled network, displacing the NaK and causing the bellows to expand. The elongation of the bellows resulting from the net travel of all five rams is measured with a linear variable differential transforme $r$ and related to the amount of swelling as a function of burnup. The primary advantage of this design concept is that fission-gas release during irradiation will not interfere with the swelling measurements. The disadvantage associated with this concept is the fabrication of a relatively complex capsule.

With either concept, the only heat sources in the capsule are fission energy and gamma absorption; no internal heaters are contemplated. The temperature achieved in each capsule will be determined primarily by the capsule position in the reactor.

(d) Irradiation Behavior of Advanced Ceramic Fuels (L. A. Neimark and B. J. Koprowski)

Last Reported: ANL-7445, p. 102 (Apri1 1968).

Uranium sulfide Specimens S-7, S-8, S-9, and S-10 from Capsule ANL 56-8, and Specimens S-15, S-16, S-17, and S-18 from Capsule ANL 56-11 have been visually examined and measured for diametral changes. The specimens in Capsule ANL 56-8 attained estimated burnups of 8.0 to $10.2 \mathrm{a} / \mathrm{o}$ at maximum cladding temperatures of 535 to $750{ }^{\circ} \mathrm{C}$. The specimens in Capsule ANL 56-11 attained estimated burnups of 6.7 to $9.6 \mathrm{a} / \mathrm{o}$ at maximum cladding temperatures of 380 to $610^{\circ} \mathrm{C}$. 
All specimens except S-8 and S-9 exhibit cracks in the $\mathrm{Nb}-1 \mathrm{w} / \mathrm{o} \mathrm{Zr}$ cladding along with some additional surface defects, such as dimpling or discoloration. The cracks usually run along the axis of the element (there are also some circumferential cracks), and the crack interface usually lies at approximately 45 or $135^{\circ}$ to a plane tangent to the element at the crack line. Maximum diameter increases shown in Table II.B.2 were recorded in the cracked areas.

TABLE II.B.2. Design and Operating Parameters for Irradiated Specimens of US

\begin{tabular}{lclccccc}
\hline $\begin{array}{c}\text { Capsule } \\
\text { No. }\end{array}$ & $\begin{array}{c}\text { Specimen } \\
\text { No. }\end{array}$ & $\begin{array}{c}\text { Pellet } \\
\text { Form }\end{array}$ & $\begin{array}{c}\text { Smeared } \\
\text { Density } \\
(\%)^{\mathrm{a}}\end{array}$ & $\begin{array}{c}\text { Max } \\
\text { Cladding } \\
\text { Temp }\left({ }^{\circ} \mathrm{C}\right)\end{array}$ & $\begin{array}{c}\text { Estimated } \\
\text { Burnup } \\
(\mathrm{a} / \mathrm{o})\end{array}$ & $\begin{array}{c}\text { Max Dia } \\
\text { Increase } \\
(\%)\end{array}$ & Comments \\
\hline ANL 56-8 & S-7 & Cored & $76^{\mathrm{b}}$ & 535 & 8.0 & 1.2 & Failed \\
ANL 56-8 & S-8 & Solid & 88 & 725 & 10.2 & 2.1 & Apparently intact \\
ANL 56-8 & S-9 & Cored & 76 & 750 & 10.2 & 3.0 & Apparently intact \\
ANL 56-8 & S-10 & Solid & 92 & 690 & 10.2 & 8.4 & Failed \\
ANL 56-11 & S-15 & Cored & $79 \mathrm{c}$ & 380 & 6.7 & 4.2 & Failed \\
ANL 56-11 & S-16 & Solid & 92 & 510 & 9.1 & 4.0 & Failed \\
ANL 56-11 & S-17 & Solid & 88 & 500 & 7.6 & 2.0 & Failed \\
ANL 56-11 & S-18 & Solid & 77 & 610 & 9.6 & 6.6 & Failed \\
\hline
\end{tabular}

a The values in this column are corrected values and supersede those in previous monthly progress reports.

bPartially cored for center thermocouple. Smeared density for lower solid pellets is $88 \%$.

${ }^{c}$ Partially cored for center thermocouple. Smeared density for lower solid pellets is $92 \%$.

Although, in general the cladding diametral changes cannot be correlated with burnup, irradiation temperature, smeared density, or void deployment, the two specimens that survived intact achieved the highest burnup, operated at the highest temperature, and had among the smallest diametral increases. This result may indicate either a hightemperature plasticity of the fuel that allows swelling accommodation internally under restraint by the cladding, or reduced fuel swelling with the high-temperature release of fission gases.

2. Engineering Properties of Reactor Materials--Research and Development--High Temperature Mechanical Properties of Ceramic Fuels

a. High Temperature Mechanical Properties of Fuel Oxides

(i) Fission-induced Creep of Ceramic Fuels (R. F. Canon)

Not reported previously.

At lower temperatures, where the thermal creep rate is significantly reduced, measurements of in-reactor creep on metals have demonstrated the existence of an enhanced creep rate resulting from the neutron flux. Evidence also exists that a similar behavior occurs in fissioning fuel materials. Limited data are available for some $\mathrm{ZrO}_{2}-\mathrm{UO}_{2}$, 
$\mathrm{ThO}_{2}-\mathrm{UO}_{2}$, and $\mathrm{UO}_{2}$ systems, but much more data a re required. However, deformation measurements with the nuclear ceramics are complicated by the inherently low creep rates and by the extremely brittle behavior of ceramics at the lower temperatures of interest.

The use of a "helical spring" specimen geometry will overcome many of the experimental difficulties associated with creep measurements of ceramic materials. In particular, ceramics are susceptible to stress concentrations from the loading configuration and to the presence of microcracks inherent in these materials. For uniaxial elongation or compression of a helical specimen, the stress conditions are almost entirely torsional, which is a favorable stress mode for evaluation of mechanical properties. Also, the spiral geometry offers a practical magnification of approximately three orders of magnitude in the creep measurements (i.e., a creep rate of $10^{-7} \mathrm{~cm} / \mathrm{cm} / \mathrm{hr}$ would result in a spring deflection rate of approximately $10^{-4} \mathrm{~cm} / \mathrm{hr}$.

Work is in progress to develop a satisfactory fabrication technique for the production of 25-turn, helical specimens of $\mathrm{UO}_{2}$. Feasibility has already been demonstrated on several extruded and hand-wound samples. Specimens with "wire" diameters of 0.10 to $0.25 \mathrm{~cm}$ have been successfully extruded and sintered to approximately $91 \%$ of theoretical density. This work is continuing toward the development of a more uniform and reproducible technique. Other possible fabrication techniques, such as slip casting, are also being investigated.

The preliminary design of an experimental irradiation capsule is in progress. Initial plans call for the measurement of the creep rate of $\mathrm{UO}_{2}$ undergoing fission at sufficiently low temperatures $\left(\leq 600^{\circ} \mathrm{C}\right)$ so that thermal creep will be negligible. This will allow the determination of various aspects of fission-induced creep without the complications introduced by the presence of thermal creep. It is estimated that the present design will allow the determination of the creep rate of $\mathrm{UO}_{2}$ for any stress level over $35 \mathrm{~kg} / \mathrm{cm}^{2}$ with a fission rate up to approximately $3 \times 10^{13} \mathrm{f} / \mathrm{cm}^{3}-\mathrm{sec}$. The maximum centerline temperature within the samples should remain below $400^{\circ} \mathrm{C}$.

(ii) Elastic and Anelastic Properties in a Polycrystalline System $\mathrm{UO}_{2}-\mathrm{PuO}_{2}$ (A.W. Nutt)

Last Reported: ANL-7460, pp. $101-103$ (June 1968).

Physically mixed $\mathrm{U}_{0.8} \mathrm{Pu}_{0.2} \mathrm{O}_{2}$ powder was prepared by wet milling and vacuum drying $\mathrm{UO}_{2}$ and $\mathrm{PuO}_{2} ; \mathrm{l}$ w/o Carbowax 4000 was added as binder. The dried, physically mixed powder was pressed, granulated, and compacted into rectangular bars approximately 0.4 by 0.6 by $7.5 \mathrm{~cm}$. The specimens were heated slowly in a $\mathrm{He}-6 \mathrm{v} / \mathrm{o}_{2}$ atm to $350^{\circ} \mathrm{C}$ for 
binder removal. The furnace temperature was increased to $1525^{\circ} \mathrm{C}$ and held for $4 \mathrm{hr}$. The oxygen-to-metal (O/M) ratio of the sintered specimens was determined by using an oxidation-reduction technique in which $\mathrm{U}_{0.8} \mathrm{Pu}_{0.2} \mathrm{O}_{2,00}$ was defined as that stoichiometry attained at $850^{\circ} \mathrm{C}$ in a $\mathrm{CO}-\mathrm{CO}_{2}(10: 1)$ atmosphere, and found to be 1.984. The Förster resonance technique used to measure room temperature elastic properties of these specimens was described previously (see ANL-7460, p. 102).

A polycrystalline alumina sample of an elasticity standard (Prototype B) was provided by the National Bureau of Standards. Roomtemperature elasticity measurements were made with this bar and are compared in Table II.B.3 with those reported by the Bureau of Standards. The agreement shown between the two sets of values adds confidence to both the accuracy and precision of the present investigational data.

TABLE II.B.3. Comparison of the Reported Values of the National Bureau of Standards with Measured Data for NBS "Prototype B" Elasticity Standard

\begin{tabular}{lcc}
\hline \multicolumn{1}{c}{ Parameters Measured } & NBS Values & Measured Values \\
\hline Flexural Frequency (cps) & $1798.9 \pm 0.1$ & 1799 \\
Torsional Frequency (cps) & $10889.5 \pm 1$ & 10887 \\
Young's Modulus (kbar) & $3930.0 \pm 0.6 \%$ & 3929.8 \\
Shear Modulus (kbar) & $1594 \pm 0.4 \%$ & 1596.9 \\
Poisson's Ratio & $0.233 \pm 0.01$ & 0.230 \\
\hline
\end{tabular}

Measurements were made with ground specimens that had dimensional parallel-face tolerances of no greater than $\pm 0.002 \mathrm{~cm}$. The precision of all elastic measurements was better than $\pm 0.01 \%$, which was indicated by remeasuring each sample three times for each data point reported. The accuracy of the elastic data is approximately $\pm 1 \%$, as calculated from insertion of dimensional, mass, and frequency variation error into those equations used to calculate the elastic moduli. The base point of accuracy arises from comparison of the values of elastic moduli reported by the Bureau of Standards for the "Prototype B" with those obtained in this study.

Table II.B. 4 shows the variation of Young's modulus, shear modulus, and bulk modulus of $\mathrm{U}_{0.8} \mathrm{Pu}_{0.2} \mathrm{O}_{1.984}$ as a function of density. The bulk modulus of each sample was calculated from the shear modulus and average Young's modulus. Since these specimens were fabricated from the same batch and fired together, the assumptions were made that their respective grain sizes are equal and that observed property differences were caused by porosity variations. In all samples, the Young's modulus measured perpendicular to the pressing direction (edgewise modulus) was higher than that measured parallel to the pressing direction (flatwise modulus). 
TABLE II.B.4. Representative Data of the Change of

Elastic Moduli of $\mathrm{U}_{0.8} \mathrm{Pu}_{0.2} \mathrm{O}_{1.982}$ with Porosity

\begin{tabular}{|c|c|c|c|c|}
\hline $\begin{array}{l}\text { Density } \\
\left(\mathrm{g} / \mathrm{cm}^{3}\right)\end{array}$ & $\begin{array}{l}\text { Edgewise } \\
\text { Young's } \\
\text { Modulus } \\
\text { (kbar) }\end{array}$ & $\begin{array}{c}\text { Flatwise } \\
\text { Young's } \\
\text { Modulus } \\
\text { (kbar) }\end{array}$ & $\begin{array}{l}\text { Shear } \\
\text { Modulus } \\
\text { (kbar) }\end{array}$ & $\begin{array}{c}\text { Bulk } \\
\text { Modulus } \\
(\text { kbar })\end{array}$ \\
\hline 8.89 & 1309 & 1282 & 511 & 929 \\
\hline 8.92 & 1307 & .1271 & 507 & 939 \\
\hline 9.10 & 1370 & 1345 & 530 & 1032 \\
\hline 9.25 & 1443 & 1405 & 565 & 990 \\
\hline 9.31 & 1465 & 1450 & 566 & 1143 \\
\hline 9.35 & 1481 & 1445 & 570 & 1125 \\
\hline 9.43 & 1485 & 1467 & 573 & 1160 \\
\hline 9.52 & 1520 & 1505 & 600 & 1086 \\
\hline
\end{tabular}

Table II.B.5 illustrates the effect of a change of stoichiometry on the elastic moduli and internal friction of $\mathrm{U}_{0.8} \mathrm{Pu}_{0.2} \mathrm{O}_{2-\mathrm{x}}$. The $\mathrm{O} / \mathrm{M}$ ratio was changed by equilibrating for $2 \mathrm{hr}$ at $850^{\circ} \mathrm{C}$ in different atmospheres. No significant grain growth or cationic diffusion is assumed to have occurred upon reheating, as attested by reproducible results obtained upon reheating in the same atmosphere. No significant change of room-temperature elastic moduli or internal friction occurred for stoichiometries between 1.982 to 1.992. Since microstructurally polished sections gave no evidence of secondphase development, and since electron microprobe analyses indicated a very good degree of solid solution, no significant changes of room-temperature elastic moduli or internal friction will probably occur prior to second-phase development. Investigations of stoichiometry changes are currently being made, and the possibility exists to extend the $O / M$ ratio to greater than 2:0. Perhaps, elastic and anelastic measurements at higher temperature may prove necessary to show any significant change in these property measurements with stoichiometry. At the very least, a higher-temperature investigation will show the moduli change with temperature and delineate the internal-friction spectrum, thereby defining the onset of grain-boundary mobility and, as some authors feel, the beginning of creep.

TABLE II.B.5. Representative Data of the Dependence of Elastic Moduli and Internal Friction at $835^{\circ} \mathrm{C}$ upon Stoichiometry of $\dot{U}_{0.8} \mathrm{Pu}_{0.2} \mathrm{O}_{2-\mathrm{x}}$ with a Density of $9.25 \mathrm{~g} / \mathrm{cm}^{3}$

\begin{tabular}{|c|c|c|c|c|c|c|}
\hline Atmosphere & $\begin{array}{l}\mathrm{O} / \mathrm{M} \\
\text { Ratio }\end{array}$ & $\begin{array}{l}\text { Edgewise } \\
\text { Young's } \\
\text { Modulus } \\
\text { (kbar) }\end{array}$ & $\begin{array}{l}\text { Flatwise } \\
\text { Young's } \\
\text { Modulus } \\
\text { (kbar) }\end{array}$ & $\begin{array}{l}\text { Shear } \\
\text { Modulus } \\
\text { (kbar) }\end{array}$ & $\begin{array}{l}\text { Bulk } \\
\text { Modulus } \\
\text { (kbar) }\end{array}$ & $\begin{array}{l}\text { Internal } \\
\text { Friction } \times 10^{5} \\
\text { (average of } 6 \text { or } \\
\text { more points) }\end{array}$ \\
\hline $\mathrm{CO}-\mathrm{CO}_{2}(10 ; 1)$ & 1.992 & 1448 & 1413 & 567 & 999 & 1.55 \\
\hline $\mathrm{H}_{2}(\mathrm{dry})$ & 1.982 & 1447 & 1412 & 567 & 995 & 1.44 \\
\hline $\mathrm{CO}-\mathrm{CO}_{2}(10: 1)$ & 1.992 & 1454 & 1416 & 569 & 1000 & 1.34 \\
\hline $\mathrm{H}_{2}$ (dry) & 1.982 & 1455 & 1416 & 570 & 1005 & 1.41 \\
\hline
\end{tabular}




\section{Engineering Development}

1. Research and Development

a. Development of Master-Slave Manipulator Systems

(D. P. Mingesz and R. C. Goertz)

Last Reported: ANL-7478, pp. $111-112$ (July 1968).

(i) Mark E4A Electric Master-Slave Manipulator. As mentioned in ANL- $7 \overline{478 \text {, two fabricated parts on the upper and low }}$ er members of the master arm gave some signs of failure. Layout work has been started on castings to replace these.

Central Research Laboratory has advertised that they can manufacture the Mark E4A. They will deliver in one year and maintain an assured supply of spare parts.

(ii) Study of Remote Handling for LMFBR. A draft is expected within a month.

(iii) General Development. We are collecting insulating materials, magnet wires, lead wires, etc., that are known or estimated to have fairly good radiation resistance. These will be irradiated to establish their approximate useful limits for manipulator applications.

b. Heat Transfer and Fluid Flow

(i) Heat Transfer in Liquid Metal Heat Exchangers (R. P. Stein)

Last Reported: ANL-7478, pp. 113-114 (July 1968).

(a) Liquid-metal-heated Steam Generators. Leak checking of the experimental loop has progressed through the Freon piping to the mercury piping.

Calculations are being made to compare steamgenerator lengths predicted by the "exact" method based on fundamentals for the liquid-metal side to those predicted by the "engineering" method, which assumes a constant he'at-transfer coefficient on the liquid-metal side, using sodium and water as the working liquids (see Progress Report for June 1968, ANL-7460, pp: 106-107 for description and results of these calculations for mercury and Freon-11). Operating pressure, flowrates, and the difference between inlet-sodium temperature and saturation temperature are chosen to simulate operating conditions for an LMFBR-type steam generator. The computations use a concentric double-pipe configuration with water flowing in the inner pipe and sodium flowing in the annulus as a model. 
Initial results indicate that the ratios of the lengths predicted by the two methods will agree closely with those calculated with mercury and Freon-l 1 as working fluids. Further calculations are being. made to check this agreement over a wider range. If close agreement is found, as is expected, this will demonstrate the similarity between the mercury-Freon and sodium-water systems.

\section{(ii) Fog-flow Heat Transfer and Fluid Flow (R. P. Stein) \\ Last Reported: ANL-7457, pp. 115-116 (May 1968).}

The plannied experiment has been delayed for several weeks because a defective hot-wire probe was returned to the vendor for replacement. The probe is being changed to suit our requirements. Another probe indicated that the hot-wire anemometry system was operating successfully in air and as a droplet detector. A counting system has been procured to count droplet pulses and is being tested.

The fiber-optic detection system was completed. A regulated dc power supply was procured to power the light source in order.to eliminate noise; it was successful in maintaining a steady light intensity. The air-purging system, developed to counter the problem of droplet deposition within the detector, has not been successful. Therefore, the measurements made using the optical system have yielded no intelligible results. Further consideration is being given to the problem.

A droplet generator has been constructed that is capable of producing drops of quite uniform diameter that can be varied within defined limits. The generator, producing a stream of droplets, is based on the theory of Rayleigh waves. Consideration is being given to using this generator (1) as a source of droplets in the planned experiment, and (2) for calibration purposes in the development of the hot-wire anemometer as a droplet-size detector (work on this system is underway at Purdue). Because of the difficulties encountered with the optical-concentration measurement, an alternative procedure has been devised. With droplets of uniform size impacting on the hot wire, the droplet-number flux (number of drops/ $\mathrm{cm}^{2}-\mathrm{sec}$ ) is proportional to the liquid mass flux. The mass flux is the product of concentration and liquid convective velocity. It is expected that the convective velocity will be nearly uniform in the central region of the test duct. If the convective velocity is uniform, then mass flux is simply proportional to concentration in the central region. High-speed still photographs will be taken to check the validity of this hypothesis. Consideration is also being given to highspeed multiple photographic exposures to measure concentration.*

* Stein, R. P., et al., Investigation of Wet Steam as a Reactor Coolant, (CAN-2), UNC-5008-1, p. 149 (Aug 1962). 
c. Engineering Mechanics

(i) Anisotropic Thermoelasticity Studies (R. A. Valentin)

Last Reported: ANL-7457, p. 118 (May 1968).

(a) Specific Design Problem. Work has started on a specific design problem to aid in evaluating the utility of a quasi-static transversely isotropic thermoelasticity model in determining the relative motion of various core regions during power transients. The problem is somewhat analogous to the isotropic transient problem reported earlier; ${ }^{*}$ however, a new stress-function formulation is being employed and primary emphasis in the numerical evaluations will be placed on the displacement field. A decision has yet to be made concerning the specific effective elastic constants defining the core structure. It may prove feasible to evaluate the model displacement field as a function of various ratios of elastic constants and thereby produce a parametric study having general utility for the designer.

(ii) Structural Dynamics Studies--Parallel-flow-induced Vibrations (M. W. Wambsganss, Jr.)

Last Reported: ANL-7478, p. 114 (July 1968).

(a) Transducer Development. Development and evaluation of instrumentation designed to measure fluid pressure and component displacements associated with flow-induced vibration are continuing.

High-resistance shorts in the cable connectors that led to a malfunctioning of the miniature pressure transducers could not be repaired. Four new transducers are being built on a, test rod.

Characteristic vibration frequencies associated with the test specimen and internally mounted displacement transducers were obtained from shaker tests. These frequencies were identified with response peaks obtained from earlier flowtests of the assembly (see Progress Report for June 1968, ANL-7460, pp. 108-109). Difficulties in evaluation of the transducer hadarisen because of the small separation between characteristic frequencies of specimen and transducer rod.

A new transducer-test specimen assembly has been built and tested, in both air and water, on a shaker. The results of the tests indicate that the characteristic frequencies are sufficiently separated to allow good resolution of the responses to be obtained from flowtests. Flow tests and further evaluation of the transducer are planned.

*Valentin, R. A, , and Schoeberle, D. F., Transient Thermal Stresses Associated with Sudden Initiation of Internal Heat Generation in a Segment of a Circular Cylinder, ANL-7420 (1968). 
(iii) Structural Dynamics Studies--Crossflow-induced Vibrations (M. W. Wambsganss, Jr.)

New task not reported before.

The motion of cylindrical rods and banks of rods as influenced by a crossflowing fluid is being studied to develop new methods for analyzing, testing, and evaluating the reliability and structural life of heat exchangers. Because reactor heat exchangers have relatively complex geometries, boundary conditions, and flow patterns, the initial investigation is of a fundamental nature. Forcing functions are being characterized and various damping mechanisms are being studied.

(a) Experiment Design. Preliminary consideration was given to the design of experiments and subsequent test sections. Three basic types of experiments can be identified as: (1) single-tube models, (2) tube-bank models, and (3) heat-exchanger models.

Single-tube and tube-bank models will be employed in the first phase of the program, which involves fundamental studies designed to obtain a better understanding of the interaction and other phenomena associated with crossflow-induced vibration due to vortex shedding and buffeting. In the second phase, which is concerned with the application of results derived from the fundamental investigation, heat-exchanger models will be used. These later studies will enable us to evaluate the degree to which results obtained from laboratory models with idealized crossflow can be used to predict tube vibration in heat exchangers as well as reveal phenomena peculiar to heat-exchanger configurations.

Two test-specimen models are being considered: (1) a continuous-tube (beam) model and (2) a rigid tube attached to a concentric cylindrical rod that acts as a spring.

The size of the continuous-tube model (hence, testsection size) is governed by the requirement that the tube natural frequency must be within the range of realizable vortex-shedding frequencies. Such considerations give a required length-to-diameter ratio of approximately 75 . This implies a very wide test section ( 4 to $5 \mathrm{ft}$ ) or a small-diameter tube, which intuitively is undesirable.

The alternative test-specimen design of a springmounted, rigid tube has several advantages that make it the better design-at least for the fundamental studies of the first phase of the program. These advantages include: (1) the ability to vary easily tube natural frequency over a broad range, (2) a narrower test section can be used ( 12 in., which will allow for a greater range of flow velocities), (3) larger-diameter tubes can 
be used, which are more easily instrumented and which intuitively imply better defined vortex-shedding, and (4) the limiting case of a rigid tube is more easily achieved.

For tube-bank studies, a $5 \times 5$ tube bank is being considered with the tubes mounted on an equilateral triangular pitch.

\section{Chemistry and Chemical Separations}

1. Aqueous and Volatility Processes--Research and Development-Fluoride Volatility Process -

a. Development of.Head-end Steps (N. M. Levitz)

Last Reported: ANL-7478, pp. 114-115 (July 1968).

(i) Mechanical Decladding. Conceptual design studies of fluoride volatility processing plants for fast breeder reactor fuels are in progress (see also Sect. II.D.1.f). In the proposed process, individual fuel pins, cleaned of sodium, will be the feed for a step in which fuel will be mechanically separated from cladding. Decladding procedures such as crushing and ball milling have been tested previously (see Progress Report for June 1968, ANL-7460, p. 112) with chopped porcelain-filled rods simulating chopped fuel pins. Preliminary results were promising.

A design of a continuous ball mill for decladding has been prepared. The mill has two compartments--one for crushing the chopped pins and separating the oxide from the empty hulls, and the other for separating the hulls from the balls. An alternative, a roller-splitter-crusher, is being designed that will effect decladding by scoring a stainless steelclad fuel pin, then crushing and splitting it, liberating the fuel. A delayedneutron method* for monitoring hulls for the presence of residual fuel is being reviewed.

b. Fluorination Chemistry and Procedures. (M. J. Steindler)

Last Reported: ANL-7460, pp. 109-110 (June 1968).

A statistically designed series of five experiments simulating the fluoride volatility processing of fast breeder reactor fuels has been completed, results having been obtained recently for Run FF-A5. Run FF-A5 was a replicate of Run FF-A3. (see ANL-7460), performed to obtain an estimate of the standard deviation of the series of experiments.

* Strain, J. E., Ross, W. J., West, G. A., and Landry, J. W., The Design and Evaluation of a Delayed-neutron Leached Hull Monitor, ORNL-4135 (Feb 1968). 
In Run FF-A5, the simulated fuel was $\mathrm{UO}_{2}-20 \mathrm{w} / \mathrm{PuO}$ with added nonradioactive fission product oxides, and the fuel-to-alumina ratio was 0.3 . A 4 -hr oxidation with $20 \mathrm{v} / \mathrm{o}$ oxygen in nitrogen at $450^{\circ} \mathrm{C}$ was followed by a 3-hr fluorination with $10-15 \mathrm{v} / \mathrm{o}$ fluorine in nitrogen at $350^{\circ} \mathrm{C}$ to remove uranium, and then a $10-\mathrm{hr}$ fluorination with recycled $90 \mathrm{v} / \mathrm{o}$ fluorine at $450-550^{\circ} \mathrm{C}$ to remove plutonium. During the first hour of fluorinaticn with dilute fluorine, the ratio of uranium to plutonium in the uranium hexafluoride product trap $\left(\mathrm{NaF}\right.$ at $\left.100^{\circ} \mathrm{C}\right)$ was 4540 , indicating once again (see ANL-7460) that a good separation of uranium from plutoninm can be obtained with fluorine as the fluorinating agent and a suitable sct of operating conditions.

During recycle-fluorination, the peak production rate for $\mathrm{PuF}_{6}$ was $3.4 \mathrm{lb} /(\mathrm{hr})\left(\mathrm{ft}^{2}\right)$ during the second half hour of fluorination at $450^{\circ} \mathrm{C}$. For the reaction $\mathrm{PuF}_{4}(\mathrm{~s})+\mathrm{F}_{2}(\mathrm{~g}) \rightleftharpoons \mathrm{PuF}_{6}(\mathrm{~g})$, operation at $450^{\circ} \mathrm{C}$ was at $19.4 \%$ of the expected equilibrium, and the average rate of production for PuF 6 was $1.37 \mathrm{lb} /(\mathrm{hr})\left(\mathrm{ft}^{2}\right)$. The corresponding result for Run $\mathrm{FF}-\mathrm{A} 3$ was an average production rate of $1.19 \mathrm{lb} /(\mathrm{hr})\left(\mathrm{ft}^{2}\right)$ at $17.2 \%$ of equilibrium.

The final bed for Run FF-A5 contained $0.01 \mathrm{w} / \mathrm{o}$ uranium and $0.031 \mathrm{w} / \mathrm{o}$ plutonium, or $<0.1 \%$ of the uranium charged and $0.6 \%$ of the plutonium charged. The combined results for Runs FF-A3 and FF-A 5 give an average plutonium concentration of $0.04 \mathrm{w} / \mathrm{o}$ plutonium in the final bed. Th:ough use of the $F$-test ratio and analysis of variance, a value of $0.030 \pm$ $0.003 \mathrm{w} / \mathrm{O}$ plutonium was calculated for the standard deviation at the $80 \%$ confidence level.

c. Purification Procedures and Fission Product Chemistry

Last Reported: ANL-7460, p. 111 (June 1968).

(i) Neptunium Fluoride Chemistry. In the fluid-bed fluoride volatility process, a possible step will be passage of a gas stream containing $\mathrm{UF}_{6}, \mathrm{NpF}_{6}$, and other volatile fluorides through a bed of $\mathrm{NaF}$ pellets preferentially to fix neptunium. Calculations have been made, based on equilibrium constants for the reaction of solid $\mathrm{NaF}$ with gaseous $\mathrm{NpF}_{6}$, to determine the percentage of initial $\mathrm{NpF}_{6}$ removed at various $\mathrm{NaF}$ bed temperatures $\left(250-409^{\circ} \mathrm{C}\right), \mathrm{UF}_{6}$ presiures $(18-1330 \mathrm{~mm})$, and $\mathrm{NpF}_{6}$ concentrations (10-100 ppm). In general, the percentage of $\mathrm{NpF}_{6}$ removed as calculated increases as the initial concentration of $\mathrm{NpF}_{6}$ increases, and increases as the temperature of the $\mathrm{NaF}$ bed decreases.

Neptunium would probably have an initial concentration in the $\mathrm{UF}_{6}$ process stream of $100 \mathrm{ppm}$. The favored process pressure for $\mathrm{UF}_{6}$ is $133.0 \mathrm{~mm}$, and, at this pressure, the $\mathrm{NaF}$ bed must be kept above $409^{\circ} \mathrm{C}$ to 
avoid formation of $2 \mathrm{NaF} \cdot \mathrm{UF}_{6}$. At this concentration, pressure, and temperature, a maximum of $46 \%$ of the initial neptunium should be removed by equilibration with $\mathrm{NaF}$ in one equilibrium stage and a maximum of $70 \%$ in two stages.

d. Engineering-scale Development for FBR Fuels (N. M. Levitz)

Last Reported: ANL-7460, pp. $111-112$ (June 1968).

(i) Pulsed-gas Fluidization Studies. Pulsed flow of gas for fluid-bed fluoride volatility processes is being studied for possible use in chemical decladding, oxidation, and fluorination steps as an alternative to conventional steady-gas-flow fluidization. In pulsed flow, the entire bed expands during a pulse, then contracts during the interval when gas flow is shut off. Thus the mode of particle movement in a pulsed bed differs from that in a fluidized bed.

Studies have been initiated to determine heat-transfer coefficients between a metal surface and a pulsed bed, and to determine the mechanism of heat transfer in the bed. Design and construction of a 4-in.dia pulsed-bed column with an annular heater of 1.25-in. diameter have started. This apparatus will be used to measure heat-transfer coefficients and the residence time of particles on the heater surface. Three mathematical models for heat transfer have been postulated, and the experimental heat-transfer coefficients will be used to determine which of the models best represents the data in an attempt to establish the mechanism of heat transfer. The objective will be to obtain pulsing conditions (such as frequency of pulsation, pulse duration, and gas-flow rate) that give higher heat-transfer coefficients in a pulsed bed than those attained in a fluidized bed.

e. Small-scale Studies with Irradiated Fuels (A. Chilenskas)

Last Reported: ANL-7457, pp. 122-125 (May 1968).

Additional investigations of irradiated fuels are awaiting equipment modifications being performed in the senior cave facility of the Chemical Engineering Division. A PaR Model 3500 electromechanical manipulator was tested on its bridge and carriage in an operating area outside the cave. Installation, operation; and maintenance procedures for Model $\mathrm{J}$ masterslave manipulators are being evaluated. The PaR Model 3000 manipulator will be tested next.

f. Engineering Design, Analysis and Evaluation (N. M. Levitz)

Last Reported: ANL-7478, p. 116 (July 1968).

A fluoride volatility processing plant for fast breeder reactor fuels (one metric ton of actinides per day) is being considered. The process 
includes a mechanical decladding step (discussed in Sect. II.D.1.a.(i)); in which uranium and plutonium are: fluorinated to the volatile hexafluorides; $\mathrm{PuF}_{6}$ is thermally decomposed to $\mathrm{PuF}_{4} ; \mathrm{PuF}_{4}$ is refluorinated to $\mathrm{PuF}_{6}$; and a $\mathrm{PuF}_{6}-\mathrm{UF}_{6}$ mixture of the desired uranium-to-plutonium ratio is converted to $\mathrm{PuO}_{2}-\mathrm{UO}_{2}$. The composition of the projected fuel feed was presented earlier (see Progress Report for May 1968, ANL-7457, p. 121 ).

(i) Plant Layout. The conceptual plant will have two sections for processing operations. In one section, consisting of a heavily shielded cave and a deep pool, mechanical head-end steps will be performed. The other section, for fluoride volatility process equipment, will be a windowed, $140-\mathrm{ft}$ long, 26-ft wide, $40-\mathrm{ft}$ high air-atmosphere process cell divided into three compartments. Thickness of the shielding for each compartment will be based on the activity of the material to be processed. Installation, operation, and maintenance of equipment will be with master-slave manipulators suspended from an overhead bridge and carriage, through-the-wall manipulators, and a heavy-duty overhead crane. A decontamination cell and a hot shop will be located beneath the process cell. Removal and introduction of equipment, process material, and supplies will be through small transfer locks in the walls and a blister. in the roof.

(ii) Fluorination Reactors. The design of the fluorination reactors is based on criticality considerations. The uranium fluorination reactor and plutonium reactor will have slab configurations, the cross" section of the former having a 4 -in. thickness and 4 -ft width, and the cross section of the latter a 4 -in. thickness and a $2.5-\mathrm{ft}$ width.

(iii) Conversion Reactor. Throughputs and required vessel sizes for the semicontinuous fluid-bed conversion of $\mathrm{PuF}_{6}-\mathrm{UF}_{6}$ to $\mathrm{PuO}_{2}-\mathrm{UO}_{2}$ are being calculated. This fluid-bed conversion process consists of a $1-h r$ main conversion period alternated with a 1 -hr cleanup period, using the same reactor column.

During the main conversion period, when $\mathrm{PuF}_{6}, \mathrm{UF}_{6}, \mathrm{H}_{2} \mathrm{O}$ and $\mathrm{H}_{2}$ are fed at $650^{\circ} \mathrm{C}$, the following reactions may occur:

$$
\begin{aligned}
& \mathrm{PuF}_{6}+\mathrm{H}_{2} \rightarrow \mathrm{PuF}_{4}+2 \mathrm{HF} ; \\
& \mathrm{PuF}_{6}+2 \mathrm{H}_{2} \mathrm{O}+\mathrm{H}_{2} \rightarrow \mathrm{PuO}_{2}+6 \mathrm{HF} ; \\
& \mathrm{UF}_{6}+\mathrm{H}_{2} \rightarrow \mathrm{UF}_{4}+2 \mathrm{HF} ; \\
& 3 \mathrm{UF}_{6}+8 \mathrm{H}_{2} \mathrm{O}+\mathrm{H}_{2} \rightarrow \mathrm{U}_{3} \mathrm{O}_{8}+18 \mathrm{HF} .
\end{aligned}
$$

During the cleanup period, when $\mathrm{H}_{2} \mathrm{O}$ and $\mathrm{H}_{2}$ are fed at $650^{\circ} \mathrm{C}$, the reactions may be:

$$
\begin{aligned}
& \mathrm{PuF}_{4}+2 \mathrm{H}_{2} \mathrm{O} \rightarrow \mathrm{PuO}_{2}+4 \mathrm{HF} \\
& \mathrm{UF}_{4}+2 \mathrm{H}_{2} \mathrm{O} \rightarrow \mathrm{UO}_{2}+4 \mathrm{HF} ; \\
& \mathrm{U}_{3} \mathrm{O}_{8}+2 \mathrm{H}_{2} \rightarrow 3 \mathrm{UO}_{2}+2 \mathrm{H}_{2} \mathrm{O}
\end{aligned}
$$


The off-gases (mainly HF) generated during conversion will be disposed of by reaction with limestone. The capacity of a conversion reactor with $0.375-\mathrm{ft}^{2}$ inside cross-sectional area would be $408.7 \mathrm{~kg}$ per day of $\mathrm{PuO}_{2}-$ $\mathrm{UO}_{2}\left(23 \% \mathrm{PuO}_{2}\right)$.

2. Closed Cycle Processes--Research and Development--Compact Pyrochemical Processes

a. Supporting Chemical Studies (I. Johnson)

Last Reported: ANL-7478, pp. $117-118$ (July 1968).

The thermodynamic properties of the neptunium-cadmium sys tem are being investigated to provide information for the development of separation processes involving neptunium (s.ee Progress Report for June 1968, ANL-7460, p. 113).

Emf data.have been obtained using a galvanic cell of the form: $\mathrm{Np} \mid \mathrm{NpCl}_{3}, \mathrm{KCl}-\mathrm{LiCl}$ (eutectic) $\mid \mathrm{Np}-\mathrm{Cd}$ (two-phase alloy). The emf data, when plotted as a function of the temperature, may be represented by two straight lines. The intersection of these lines at $479^{\circ} \mathrm{C}$ is a peritectic in the $\mathrm{Cd}-\mathrm{Np}$ system, where the $\mathrm{NpCd}_{11}$ intermetallic compound is in equilibrium with the $\mathrm{NpCd}_{6}$ intermetallic compound and a liquid alloy containing approximately $1.7 \mathrm{a} / \mathrm{o}$ neptunium. The enthalpies and entropies of formation of $\mathrm{NpCd}_{11}$ and $\mathrm{NpCd}_{6}$ may be derived from the emf-temperature data obtained with the galvanic cell.

\section{b. Process Engineering Studies (R. D. Pierce)}

Last Repórted: ANL-7478, p. 118 (July 1968).

Highly sensitive mutual-inductance liquid-level probes are being developed to detect and control the levels and interfaces of liquid metals and molten salts in pyróchemical processes (see Progress Report for February.1968, ANL-7427, pp. 123-124).

A probe has been built that is one inch long and has 16 turns of 8-mil platinum wire per inch. The probe has been tested in a 20 -mil thick tantalum well immersed in liquid cadmium at $465^{\circ} \mathrm{C}$, and has produced an excellent output of $\sim 2.25 \mathrm{mV}$./in. of immersion. The probe is now being tested at various temperatures.

c. Experimental Flowsheet Investigations (R. D. Pierce)

Last Reported: ANL-7478, p. 119 (July 1968).

Two experiments (Runs ZD-3 and -4) were performed to study the removal of stainless steel cladding from oxide fuels by dissolution of the cladding in molten zinc (see Progress Report for April 1968, ANL-7445, pp. $120-121$ ). 
Analytical results have been received for samples of the zincstainless. steel supernatant solution discharged after the decladding step in Run ZD-4. These results show that less than $0.01 \%$ of the uranium charge was entrained in the waste decladding solution, which was discharged at $800^{\circ} \mathrm{C}$.

Modifications are being made to the helium glovebox that will contain the salt-transport furnaces in the Plutonium Salt-Transport Facility (see Progress Report for May 1968, ANL-7457, pp. 126-127). Holes are being cut in the base plate of the box to accommodate the water-cooled adapter flanges which support the salt-transport furnaces.

A transfer tunnel that will connect the two large heliumatmosphere gloveboxes is being fabricated. "One of the boxes will contain salt-transport equipment, and the other will contain metal-salt contacting equipment and a'retorting furnace. A transfer lock between the latter box and an attached nitrogen-atmosphere glovebox has been renovated.

The six stainless steel furnace vessels to be used in the facility have been received from the Nuclear Division of Union Carbide, Paducah, Kentucky.

The design of the top flanges of the reaction and receiver vessels is essentially.complete. Design work is continuing on the retorting furnace and on a remote method for raising and lowering transfer tubes between vessels.

\section{d. Liquid Metal-Molten Salt Contactors (R. D. Pierce)}

Last Reported: ANL-7457, pp. 125-126 (May 1968).

A mixer-settler unit is being designed that employs a solidrotor pump (see ANL-7457). The concept has been successfully demonstrated in a clear plastic model using an aqueous-organic system for the fluid phases.

A single-stage mixer-settler with a solid-rotor pump is being designed for processing 3.5-gal batches of liquid metal with a pumping rate of 0 to $1 \mathrm{gpm}$. This size unit is appropriate for use in the Plutonium SaltTransport Facility (see Sect. II.D.2.c) and could handle $\sim 50 \mathrm{~kg} / \mathrm{day}$ of spent fast breeder reactor fuel. The unit will be tested with a liquid $\mathrm{Cu}-\mathrm{Mg} /$ molten salt system at $650^{\circ} \mathrm{C}$. 
3. General Chemistry and Chemical Engineering--Research and

Development

a. Characterization of Nitrogen-bearing. Species in Sodium Systems:

Solubility of Nitrogen in Liquid Sodium (F. A. Cafasso)

(Final report for FY 1968.)

Last Reported: A.NL-7457, p. 128 (May 1968).

The solubility of nitrogen.in liquid sodium was found (see

AN L- 7457) to vary from 12 to 50 parts pertrillion per atmosphere between 450 and $600^{\circ} \mathrm{C}$. The measurements were made by saturating liquid sodium at a preselected temperature with ${ }^{15} \mathrm{~N}$-enriched nitrogen gas at a known pressure, stripping the dissolved nitrogen with helium, trapping the stripped gas, and then determining its quantity and isotopic composition by means of a mass spectrometer.

The use of tracer nitrogen-15 not only permitted the solubility to be measured, but also provided insight into the nature of the solution process. An isotopically unequilibrated mixture $\left(46.8 \mathrm{~mol} \%{ }^{15} \mathrm{~N}_{2}\right.$, $\left.42.8 \mathrm{~mol} \%{ }^{14} \mathrm{~N}_{2}, 10.4 \mathrm{~mol} \%{ }^{14} \mathrm{~N}^{15} \mathrm{~N}\right)$ was used to saturate the sodium; hence the dissolved nitrogen, on exsolution, would be expected to give an equilibrated mixture $\left(27.1 \mathrm{~mol} \%{ }^{15} \mathrm{~N}_{2}, 23.0 \mathrm{~mol} \%{ }^{14} \mathrm{~N}_{2}, 49.9 \mathrm{~mol} \%{ }^{14} \mathrm{~N}^{15} \mathrm{~N}\right)$ if it had dissolved monatomically but to exhibit the same composition as the starting mixture if it had dissolved diatomically. Mass-spectrometric analyses of stripped-gas samples revealed only a small change in isotopic composition (to $46.4 \mathrm{~mol} \%{ }^{15} \mathrm{~N}_{2}, 41.9 \mathrm{~mol} \%{ }^{14} \mathrm{~N}_{2}, 11.7 \mathrm{~mol} \%{ }^{14} \mathrm{~N}^{15} \mathrm{~N}$ ). 'The extent of the isotopic re-equilibration is not consistent with a mechanism involving purely monatomic dissolution of nitrogen. It seems more likely that the observed change was due to catalysis by the heated steel surfaces of the apparatus. Slow exchange between ${ }^{15} \mathrm{~N}_{2}$ and ${ }^{14} \mathrm{~N}_{2}$ over heated iron catalysts is a known phenomenon.* The results therefore appear to be entirely consistent with the as sumption of diatomic solution of molecular nitrogen in sodium.

With this report work on the solubility of nitrogen in liquid sodium is completed.

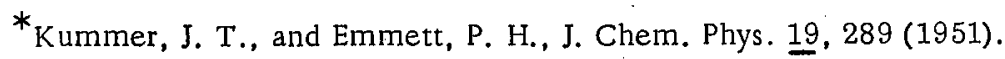


b. Phase Diagram Study of the Ternary System U-Pu-O

(P. E. Blackburn and A. E. Martin)

Last Reported: ANL-7457, p. 129 (May 1968).

Preparations are continuing for a phase study of the U-Pu-O system at high temperatures, especially that portion of the system which is most relevant to fast reactor fuels. This study will be carried out in a plutonium-glovebox facility under development. Some minor changes in the facility and in the planned operating procedures which were recommended by a safety review committee have been completed and approved.

Before closing the glovebox, temperature corrections were obtained for the special optical insert for the glovebox window so that accurate temperatures of charges heated in the tungsten resistance furnace could be taken with an optical pyrometer located outside the glovebox. Corrections also were obtained for other optical components in the light path.

With the glovebox closed, the location and closing of many minor leaks in the glovebox and its various fittings were accomplished. Plutonium materials were then bagged into the facility. The first furnace experiment with plutonium materials as a charge was carried out in July. The two major furnaces in the glovebox: the arc-melting furnace and the tungsten resistance furnace, have operated successfully with plutonium materials as charges. Other operations in the glovebox have also proceeded smoothly.

Samples from the initial exploratory tests on U-Pu-O materials have been submitted for metallographic and $X$-ray diffraction examination, and for chemical analyses. When reports on these examinations and analyses are available, evaluations of the initial tests will be made.

C. Total Effusion of Pu-O and U-Pu-O (P. E. Blackburn and R. K. Edwards)

Last Reported: ANL-7457, p. 129 (May 1968).

The effusion apparatus, previously used to determine the congruently vaporizing composition of urania as a function of temperature, is being coupled to a glovebox so that effusion studies of plutonium-bearing materials may be carried out. A quadrupole mass spectrometer will be installed in the effusion apparatus. Modification of the apparatus to allow installation of the spectrometer is under way. The mass spectrometer has been received. 
A vacuum microbalance will also be installed in the effusion apparatus. The microbalance will be used to determine total effusion rates by allowing vapors effusing from the Knudsen cells to condense on the microbalance weighing mechanism. The microbalance has been received; however, minor modifications will be required in order to allow installation in the effusion apparatus. These modifications are also under way.

\section{PUBLICATIONS}

Review of Low-mass Atom Production in Fast Reactors

Norman D: Dudey ANL-7434 (April 1968)

Electronic Absorption Spectra of Solutions of Sodium Metal in Solid and Liquid Sodium Chloride

D. M. Gruen, M. Krumpelt, and I. Johnson Abstracts of Papers, 156 th Am. Chem. Soc. Mtg., Atlantic City, Sept. 8-13, 1968, ANAL-26

Laboratory Investigations in Support of Fluid-bed Fluoride Volatility Processes. Part XIX. Reaction of Bromine Pentafluoride with Selected Compounds of Uranium and Plutonium.

R. L. Jarry, J. J. Stockbar, and M. J. Steindler ANL-7412 (March 1968)

Resonance Widths and Spacings: Their Averages and Distributions

P. A. Moldauer

Phys. Rev. 171, 1164-1169 (July 20, 1968)

Laboratory Investigations in Support of Fluid-bed Fluoride Volatility Processes. Part XVII. Fluorination of Neptumium(IV) Fluoride and Neptunium(IV) Oxide

L. E. 'Trevorrow, T. J. Gerding, and M. J. Steindler ANL-7385 (April 1968)

Transient Thermal Stresses Associated with Sudden Initiation of Internal Heat Generation in a Segment of a Circular Cylinder

Richard A. Valentin and Daniel, F. Schoeberle ANL-7420 (March 1968)

Argonne Code Center: Benchmark Problem Book. Numerical Determination of the Space, Time, Angle, or Energy Distribution of Particles in an Assembly. ANL-7.416 (February 1968) 


\section{NUCLEAR SAFETY}

A. Reactor Kinetics--Other ReactorKinetics--Research and Development

1. Coolant Dynamics

a. Critical Flow (H. K. Fauske)

Last Reported: ANL-7478, pp. 124-125 (July 1968).

(i) Sodium Tests. Additional data obtained on flashing flow of liquid sodium include axial pressure and temperature profiles. Analyses are in progress to interpret the two-phase frictional and momentum pressure drop components. These are strongly dependent on the velocity ratio, i.e., the ratio of the average vapor velocity to the average liquid velocity.

In order to check the validity of the analyses, the sodium loop has been temporarily shut down to install an emf void meter. Void measurements should lead to an accurate evaluation of the velocity ratio during adiabatic subsonic as well as sonic liquid-sodium-vapor flows, because the appropriate vapor quality can be evaluated from simultaneous measurements of axial temperature and pressure profiles in the boiling zone.

b. Coolant Dynamics (R. M. Singer and R. E. Holtz)

Last Reported: ANL-7478, pp. 125-126 (July 1968).

(i) Sodium Superheat Experiments. Testing of the sodium superheat experiment is continuing with the sandblasted-surface test vessel. Test runs using a helium cover gas are being conducted to determine to what extent the cover gas (dissolved gas content in liquid metal) influences the incipient boiling superheats. All previous superheat tests have employed argon as the cover gas.

Superheat data with the sandblasted surface and the argon cover gas have been analyzed. The data show the same portion of incipient boiling superheat as those obtained with the polished surface for the same pressure-temperature history.

(ii) Coolant Expulsion Experiments. Assembly of the sodium expulsion experiment is nearly complete. The expulsion tube has been welded into the system. The system instrumentation is being checked prior to charging the system with sodium.

(iii)'Transient Experiments. The fabrication and assembly of the Transient Test Loop is continuing. The loop as sembly will be completed when an EM pump is delivered. 
Development and fabrication of instrumentation are continuing. A calorimetric-type flowmeter has been fabricated.

2. Core Structural Safety (C. K. Youngdahl)

Last Reported: ANL-7478, p. $126^{\circ}$ (July 1968).

a. Dynamic Plasticity Analysis of Circular Shells. A general computer program, RINGLOAD, is being written to determine the plasticdeformation history of circular cylindrical shells acted on by impulsive ring loads. The program combines the capabilities of the more specialized programs that were used to produce the results included in previous monthly reports, and requires simpler input information and less preliminary computation by the user. In addition, RINGLOAD may be used to solve a wider variety of problems and yields more detailed output information than was possible with the preliminary programs.

When completed, RINGLOAD will cover both Phase-1 and Phase-2 types of deformation patterns, and will treat pulse shapes that have either instantaneous jumps or pass gradually through the yield load. The time interval at which output is desired may be specified, as well as the axial positions at which deformation are calculated. In order to compare results for various pulses more easily, an option is provided for automatic scaling of the problem variables and parameters by the appropriate powers of the impulse associated with the pulse shape.

Assorted subroutines are used with RINGLOAD. The subroutine PULSEINF receives input information on the pulse shape and returns various calculated pulse parameters, such as pulse duration, total impulse, impulse after yielding begins, time at which yielding begins, mean time of pulse, and locations and values of relative maxima of pulse. The last are needed because Phase-2 deformation takes place in the vicinity of pulse maxima. The subroutine PULSEFUN provides the main program with the value of the pulse and its slope as a function of time. The ANL-library subroutine DIFSUB is used to perform integration steps for the system of nonlinear differential equations associated with the Phase-1 deformation, while the subroutine DIFFUN provides the righthand sides of these differential equations as a function of time and load. The programs RINGGLOAD, DIFSUB, and DIFFUN apply for any type of pulse, whereas PULSEINF and PULSEFUN have been written for loads which are prescribed point by point, such as by being read from a transducer pressure graph. Other versions of PULSEINF and PULSEFUN will be written for some simple analytical shapes, e.g., a decaying exponential.

The main program and subroutines have been completed for the Phase-1 type of deformation, and some calculations were made for comparison with earlier results. The previous conclusion that the impulse 
and mean time are the important characteristics of a pulse in determining the final shell deformation still appears valid. The calculation of a Phase- 2 deformation is being programmed.

\section{Fuel Meltdown Studies with TREAT (C. E. Dickerman)}

a. Meltdown Studies with Ceramic Fuels

Last Reported: ANL-7478, p. 127 (July 1968).

(i) Mark-II Loop Calibration Run with $\mathrm{UO}_{2}$ Pin. Radiochemical measurements have been completed for $93 \%$ enriched uranium foils and $13 \%$ enriched $\mathrm{UO}_{2}$ oxide pellets from a sample pin, run inside a Mark-II TREAT loop, in a calibration run to measure the ratio between sample power and TREAT power. Foils were banded to the surface of the stainless steelclad pin to provide a check on pellet data and on the circumferential variation in surface neutron flux. The pellets, of course, represent a direct measurement of sample fissions. The sample was a mockup of the fuel pin to be used in the initial "checkout" transient with the loop (see Progress Report for April 1968, ANL-7445, p. 130). Integrated reactor power for the run was $40 \mathrm{MW}-\mathrm{sec}$ (as determined by a linear operating instrument).

Four pellets were analyzed, one from the top of the fuel stack, one from the bottom, and two from the central portion. Results for radiochemistry of ${ }^{99} \mathrm{Mo}$ and ${ }^{140} \mathrm{Ba}$

TABLE III.A.1. Pellet Radiochemical Data

\begin{tabular}{|c|c|c|c|}
\hline \multirow[b]{2}{*}{ Position } & & \multicolumn{2}{|c|}{$\begin{array}{c}\text { Fissions }\left(\times 10^{-12}\right) / \\
\mathrm{g} \text { of } \mathrm{UO}_{2}\end{array}$} \\
\hline & & ${ }^{99} \mathrm{Mo}$ & ${ }^{140} \mathrm{Ba}$ \\
\hline Top & & 4.81 & 5.05 \\
\hline Center (upper) & & 4.84 & 5.03 \\
\hline Center (lower) & & 4.91 & 5.10 \\
\hline Bottom & & 4.97 & 5.12 \\
\hline & Avg & 4.88 & 5.08 \\
\hline
\end{tabular}

fission products are given in. Table III.A.1. From these data it was concluded that the two fission products gave consistent. results and that a value of $4.98 \times 10^{12}$ fissions/ $\mathrm{g}$ of $\mathrm{UO}_{2}$, or a calibration value of $1.25 \times 10^{11}$ fissions $/ g \mathrm{UO}_{2}-\mathrm{MW}-\mathrm{sec}$, should be used for the "checkout" experiment. By means of the conversion factor $2.77 \times 10^{-11}$ joules/ fission,* a calibration of $3.45 \mathrm{~J} /$ g. $\mathrm{UO}_{2}-\mathrm{MW}-\mathrm{sec}$ was obtained. This

value is $\sim 25 \%$ lower than the provisional value used in preliminary test specifications and safety analyses, but is quite adequate for experimental needs. The two sets of pellet data indicate a small $(\sim 2 \%)$ increase in sample power from the top to bottom. A similar power increase was found for the foils. Eight foils were along the fuel: 5 in a vertical line, at top, $5 \mathrm{~cm}$ below top, center, $5 \mathrm{~cm}$ from bottom, and bottom; and three additional at the center, $90^{\circ}$ from each other along the circumference of

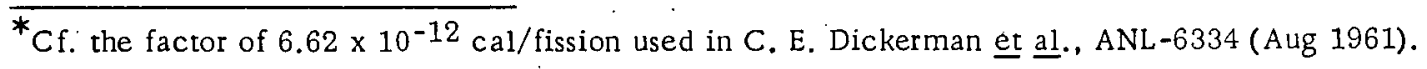


the cladding. A weighed average of the foil data gave a calibration value $1 \%$ lower than that from the pellets, in comparison with a transport-theory calculation that the surface-to-average sample power ratio is 1.11 . Because of possible experimental uncertainties and the local foil-induced perturbations of neutron flux, the foil data are considered to substantiate the pellet-based average calibration factor of 3.45 .

For the measurements, the loop was run: in a slotted core loading like that planned for the "checkout" transient. The difference in. foil activation between the north and south sides of the slot was less than $1 \%$; however, the foil adjacent to the return leg of the recirculating loop gave results about $5 \%$ lower than the average of the other three foils at that position.

The outputs from the reactor transient power instruments were recorded during the calibration run and used to obtain transient power calibration factors, so that the data reported in the actual Mark-II loop transient experiment will be consistent with the calibration run.

The loop used in the calibration run has been returned to Illinois for outfitting. The loop pump used in the run has been transferred to the shops for replacement of the original pump tube (used in pump testing.) with one of the high-pressure tubes for actual experimental service.

b. Development of Experimental Methods

Last Reported: ANL-7478, pp. 127-128 (July 1968).

(i) Holddown Device for Use in Mark-II Integral Sodium TREAT Experiments. During the experimental use of the Mark-II Integral Sodium Loop in the TREAT facility, the failure of ceramic-fuel elements within the loop can be sufficiently violent as to expel the sodium coolant upward from the test section at very high velocities. In analyses of maximum hypothetical accidents, it was calculated that the slug of liquid sodium moving with such velocity, on striking the top closure of the loop, could, in theory, transmit enough kinetic energy to the approximately $100 \mathrm{~kg}$ of loop to lift it some $5 \mathrm{ft}$ above the reactor grid plate. In addition to the downward rebound energy of the sodium slug, the fall under gravity of the loop from this height would probably damage both loop and reactor core seriously. The ejection of the loop, of course, corresponds to a rod-ejection reactivity accident.

By increasing the effective mass of the loop, the effect of the sodium impact against the top of the device can be reduced.: This has been accomplished by rigidly coupling the top of the integral:loop to a $22,700-\mathrm{kg}$ load consisting of the rotating plug and cover shield blocks of 
the reactor, using a high-load holddown. The holddown consists of a heavywalled, tubular steel column placed in direct line with the test section and closure tube of the loop, between the closure hood of the loop and the underside of the rotating plug. The bottom of the column rests on the hood, with a split column transmitting compressive force through the hood to the closure flange of the loop. The top of the holddown is an extended, heavily reinforced pad which is clamped across the slot in the rotating plug. The effective length of the holddown is adjusted by means of a threaded, locking internal plug in the top pad.

The elongation of the loop enclosure by thermal expansion as the facility is brought to experimental temperatures is compensated for by the incorporation in the holddown column of a shock transmitter. This consists of a limited-orifice, spring-loaded dashpot, in which the fluid is a polysiloxane, popularly known as "sili-putty." A highly viscous fluid under conditions of long-term, low-force loading, the puttylike material has some of the properties of a solid when loaded by impact or shock, exhibiting sufficient elastic modulus literally to bounce, and a considerable shear strength. Under heavy impact, the putty fractures in a pseudocrystalline fashion, instead of deforming. In the holddown dashpot, the putty is fully constrained within a massively strong cylinder against a heavy piston; the slow force of thermal expansion will cause it to flow slowly through the small piston orifices into a reservoir, but the mass of putty becomes rigid during the application of impact or shock forces. During thermal contraction of the loop enclosure, the heavy piston spring will return the piston to the withdrawn position, and the putty will flow back into the piston chamber of the cylinder under gravity.

4. Materials Behavior and Energy Transfer

a. Pressure Generation due to Violent Meltdown (R. O. Ivins)

Last Reported: ANL-7457, pp. 135-136 (May 1968).

A program of TREAT experiments designed to study the pressure generated during the meltdown of stainless steel-clad, $\mathrm{UO}_{2}$-core fuel rods contained within a sodium-filled piston autoclave (see Fig. IV.A.1, ANL-7457, p. 136) is in progress. These experiments should provide a better understanding of the mechanics of fuel-rod breakup during a nuclear excursion.

The first experiment with the piston-autoclave assembly began recently. After the first transient, preliminary data indicated a negligible pressure rise within the autoclave and a rise in the sodium temperature of only $\sim 100^{\circ} \mathrm{C}$. (Information on the energy input of the transient is not yet available.). Subsequent neutron radiography showed no change in the internal geometry of the autoclave and fuel. 
A second, more energetic transient was therefore made. Preliminary results also indicated relatively little pressure and temperature change. If neutron radiographs again show no internal changes, a third transient will be made. Present plans call for continuing in this manner until fuel failure occurs; at this time the autoclave will be disassembled.

5. 1000-MWe Safety Studies

a. Contract Management, Review and Evaluation (L. W. Fromm)*
Last Reported: ANL-7478, pp. 45-47 (July 1968).

All safety work included in the current 1000-MWe Follow-on Studies as Task $V$ has been completed. Results will be included in the individual contractors,' Task-II and -III reports.

ANL evaluations of contractors' proposals for the 1000-MWe LMFBR Plant Safety Analysis studies have been completed. Questions regarding the work scope and further implementation of the studies must be resolved as must the cost and time schedule for the studies.

\section{B. TREAT Operations}

\section{Reactor Operations (J. F. Boland)}

Last Reported: ANL-7478, pp. 132-133 (July 1968).

A series of seven temperature-limited transients were run with a dummy experimental capsule in the reactor to obtain data on the operating characteristics of the reactor with fuel temperatures above $400^{\circ} \mathrm{C}$. Four transients were run using a core which contained a viewing slot, and three with a core without a viewing slot, because these two core configurations are:the ones used for the majority of experiments. Figure III.B.l shows

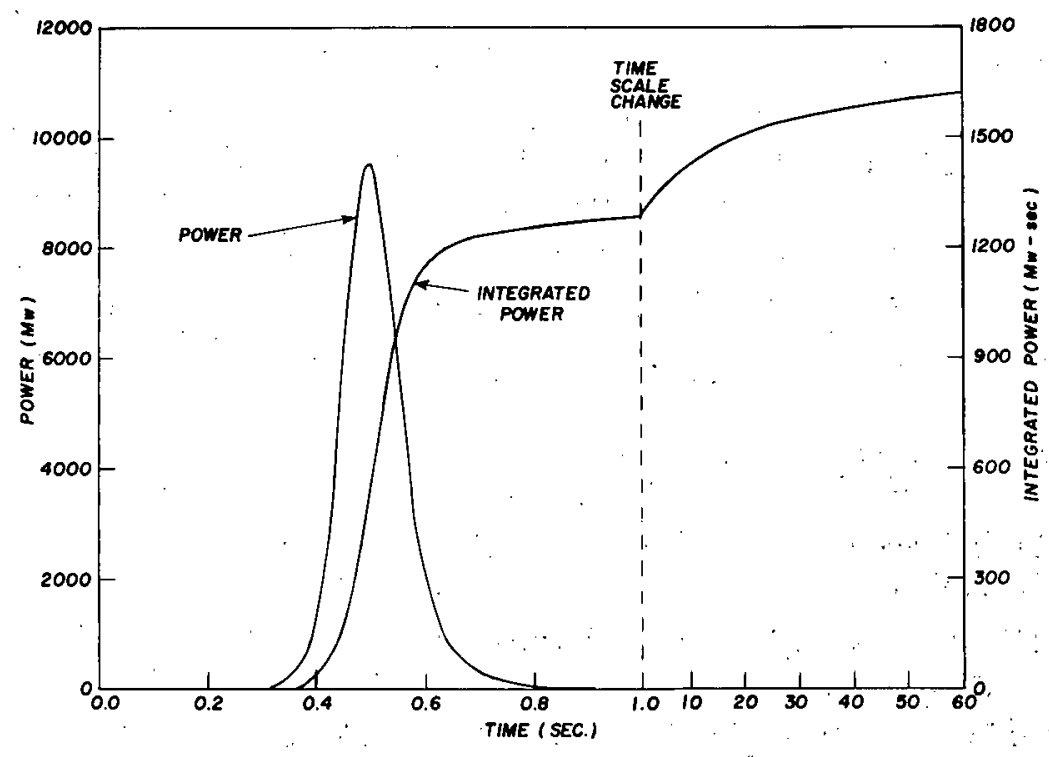

* See also Sect. I.D.1.
Fig. III.B.1

Power and Energy Release from TREAT Transient Initiated by $4.05 \% \triangle \mathrm{k}$ Reactivity Addition 
the reactor-power and energy-release data recorded during a transient initiated with a reactivity addition of $4.05 \%$ in the core without a viewing slot. The maximum fuel temperature recorded during this transient was $480^{\circ} \mathrm{C}$.

In order to reach the new fuel-temperature operating limit of $600^{\circ} \mathrm{C}$, the reactivity and reactor-period operating limits now in effect must be revised. Further experiments in this series will not be conducted until these revisions are made in the operating limits.

A preirradiated $\mathrm{UO}_{2}$ fuel sample (experiment FCR-C5B) was irradiated for GE.

Neutron radiographs were made of experimental capsules from EBR-II Subassembly XO31, melt-wire temperature indicators from two EBR-II blanket subas semblies; TREAT experiment GE-FCR-C5B, and TREAT experiment CEN-S2.

Experiment CEN-S2 was subjected to two transient irradiations. Neutron radiographs were made following each transient. Transient data and the neutron radiographs obtained following the second transient are being examined to determine if useful data can be obtained from additional transient irradiations of this capsule. The piston autoclave is being used for this series of experiments to investigate sodium expansion and pressure-generation phenomena associated with transient heating of a cluster of stainless steel-clad $\mathrm{UO}_{2}$ fuel rods in sodium (see Progress Report for May 1968, ANL-7457, p. 135, and Progress Report for November 1967, ANL-7399, p. 166).

2. Development of Automatic Power Level Control System (J. F. Boland)

Last Reported: ANL-7478, p. 133 (July 1968).

The specifications for the hydraulic control-rod drives have been completed and are undergoing internal review prior to submission to vendors.

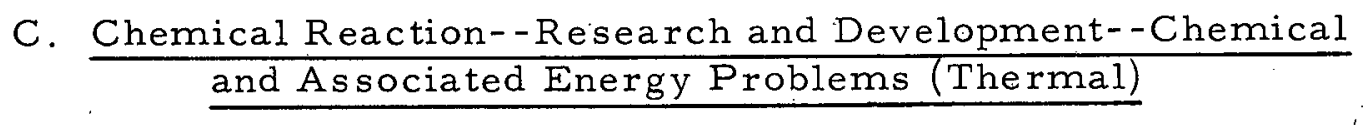

1. Analysis of Excursion Accidents (J. J. Barghusen)

Last Reported: ANL-7457, pp. 144-146 (May 1968).

In the continuing in-pile study of the characteristics of fuel failure, three additional TREAT photographic experiments have been performed with Zircaloy-clad fuel rods containing vibrationally compacted $\mathrm{UO}_{2}$ 
( $5 \%$ enriched) particles. These specimens were nearly identical in composition and dimensions to the vibrationally compacted $\mathrm{UO}_{2}$ fuel rods previously tested in TREAT (experiments CEN-233T to $-237 \mathrm{~T}$ in Progress Reports for November 1967, ANL-7399, pp. 169-171, and February 1968, ANL-7427, pp. 146-147).

A summary of the results of three recent experiments (CEN-243T, $-244 \mathrm{~T}$, and $-245 \mathrm{~T})$ is presented in Table III.C.1. Fission-energy inputs of 243,257 , and $344 \mathrm{cal} / \mathrm{g} \mathrm{UO}_{2}$, respectively, were recorded for the three experiments. The fuel rod from run CEN-243T (68-msec period) failed at the end of the transient owing to rupture of the cladding at the bottom of the fuel rod. The rupture appeared as a small hole in a blister; the remainder of the rod was essentially unblemished at the end of the transient.

TABLE III.C.1. Results from TREAT Meltdown Experiments with Zircaloy-clad $\mathrm{UO}_{2}$ Fuel Rods Submerged in Water $\left(3000 \mathrm{~g} \mathrm{H}_{2} \mathrm{O}\right.$ coolant $)$

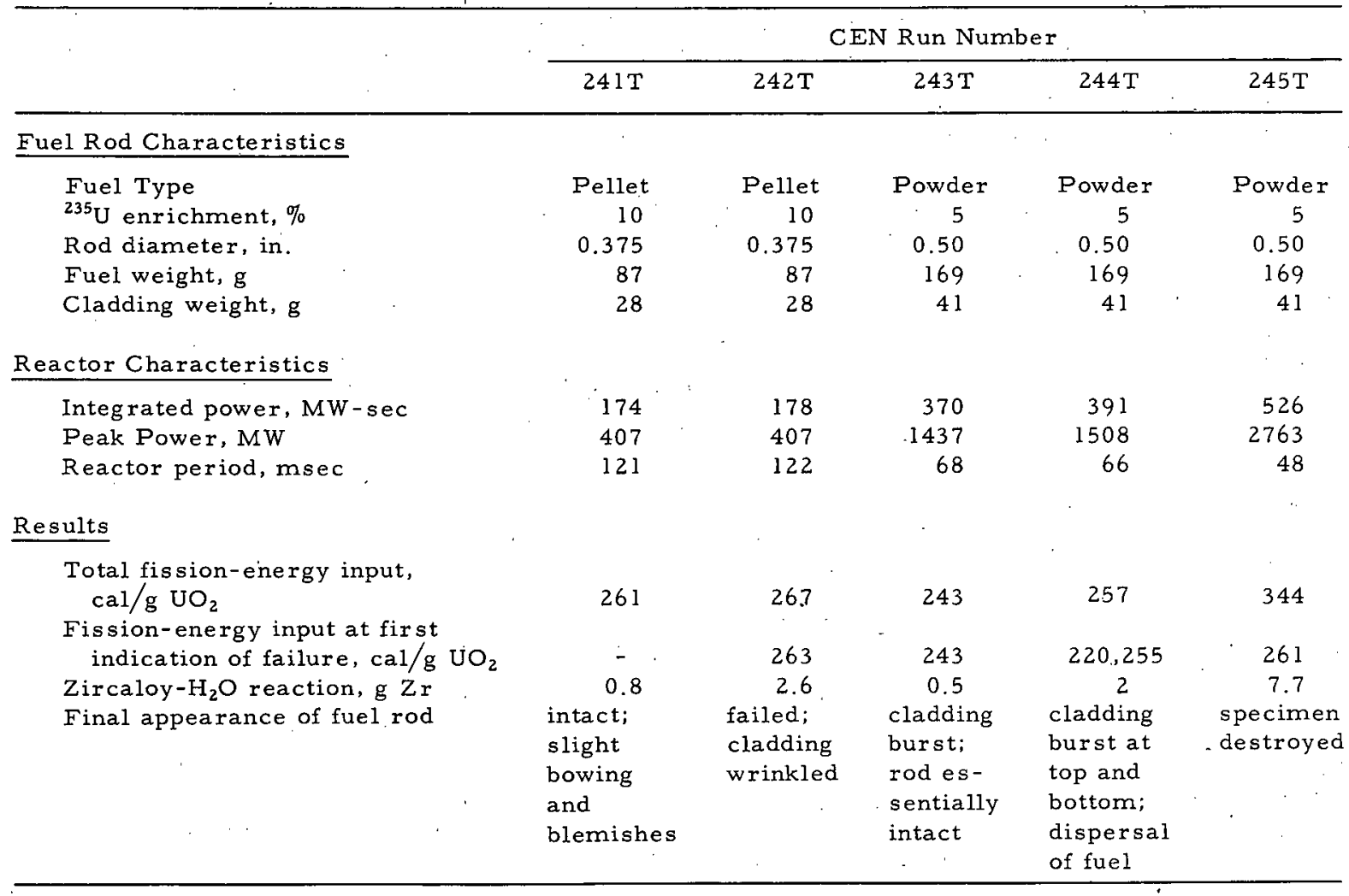

In run CEN-244T, two discrete failures were observed on the highspeed motion-picture record of the event, one at the bottom of the fuel rod at $220 \mathrm{cal} / \mathrm{g} \mathrm{UO}_{2}$, and one at the top of the rod at $255 \mathrm{cal} / \mathrm{g} \mathrm{UO}$. The latter event involved the larger hole in the cladding and was associated with the dispersal of a small quantity of $\mathrm{UO}_{2}$ into the coolant. In both cases, cladding failure was probably the result of high internal pressure and intimate contact of the cladding with molten $\mathrm{UO}_{2}$ rather than failure by extensive metal-water reaction. 
The fuel-rod specimen for run CEN-245T failed during the transient at a fission-energy input of $261 \mathrm{cal} / \mathrm{g} \mathrm{UO}_{2}$. The specimen after the transient showed that considerable dispersion of oxide fuel accompanied the failure. The cladding was broken into three major pieces, and the entire internal surface and portions of the external surface of the cladding were coated with fused $\mathrm{UO}_{2}$. The quantity of hydrogen evolved during the test was equivalent to that produced by reaction of $7.7 \mathrm{~g}$ of zirconium with water.

In addition to the above experiments, two tests (CEN-241T and $-242 \mathrm{~T}$ ) were performed to establish the failure threshold of $3 / 8$-in.-dia pellet-type fuel specimens at a reactor transient period of $12 \overline{\mathrm{I}} \mathrm{msec}$. These experiments are also summarized in Table III.C.1. They involved transients at fission-energy inputs of 261 and $267 \mathrm{cal} / \mathrm{g} \mathrm{UO}_{2}$, respectively. The fuel rod from the test $(\mathrm{CEN}-241 \mathrm{~T})$ at the lower energy level was intact after the transient and was slightly bowed. The fuel rod from the test (CEN-242T) at the higher energy level failed at the top of the rod near the end of the transient at an energy of $263 \mathrm{cal} / \mathrm{g} \mathrm{UO}_{2}$ owing to embrittlement of metal by metal-water reaction and interaction with $\mathrm{UO}_{2}$. The cladding was badly wrinkled over the entire rod, particularly at the location of the failure.

All experiments with Zircaloy-2-clad, $\mathrm{UO}_{2}$-core (both vibrationally compacted and sintered pellet) fuel rods are currently being correlated; the results will be presented in a later report.

\section{PUBLICATIONS}

Transient Combined Conduction-Radiation in an Optically Thick SemiInfinite Medium

R. P. Heinisch and R. Viskanta*

AIAA Journal 6, 1409-141l (July 1968)

Violently Sprayed Sodium-Air Reaction in an Enclosed Volume

T. S. Krolikowski, L. Leibowitz, R. O. Ivins and S. K. Stynes**

Abstracts of Papers, 156th Am. Chem. Soc. Mtg., Atlantic City, Sept. 8-13, 1968, NUCL-123

Effects of Metal-Water Reactions on Reactor Loss-of-Coolant Accidents

J. C. Hesson, R. O. Ivins and R. E. Wilson

Abstracts of Papers, 156th Am. Chem. Soc. Mtg., Atlantic City, Sept. 8-13, 1968, NUCL-122

The Development of Pumps for Use in Fast-reactor-safety Integral-loop Experiments

L. E. Robinson and R. D. Carison

ANL-7369. (April 1968)

Film Boiling from a Sphere

L. C. Witte

Ind: Eng. Chem. Fundamentals $\underline{7}(3), 517-518$ (August 1968) Letter

\footnotetext{
* Purdue University.

** Wayne State University.
} 
Form AEC-426

Rev. $6 / 68$

AECM 3201
U. S. ATOMIC ENERGY COMMISSION

RECOMMENDATION FOR DISPOSITION OF INFCRMATION PRODUCT

(Washington-designated contractors use Form AEC-427)

\section{- See Instructions on Reverse Side -}

\begin{tabular}{l|l}
\hline $\begin{array}{c}\text { 1. AEC Report No. } \\
\text { ANL-7487 }\end{array}$ & $\begin{array}{l}\text { 2. TItle } \\
\text { REACTOR DEVELOPMENT PROGRAM PROGRESS REPORT } \\
\text { August } 1968\end{array}$ \\
\hline
\end{tabular}

Xa. Scientific and technical report.

$\square$ b. Conference paper (if this box is checked, items 5, 6, and 7. below do not apply.) Title of conference

Date of conference

Exact location

Sponsoring organization

$\square$ c. Other (Specify)

\section{Copies Transmitted: (Check one or more applicable boxes)}

X a. Copies being transmitted for standard distribution by AIC - DTI.

Db. Copies being transmitted for special distribution by AEC - DTI, per attached Iist.

$\square$ c. A single reproducible copy being transmitted to AEC - DTI.

\section{Recommended Distribution: (Check one)}

Xa. Normal handling: no restraint on distribution except as may be required by the security classification and patent clearance status.

Db. Normal handling in the U.S., but there should be no foreign distribution.

Dc. Make available only to U.S. Government agencies and their contractors.

$\square$ d. Make available only within AEC and to AEC contractors.

$\square$. Make available only within AEC.

$\square$ f. Make available only to those listed in item 10., below.

g. Make available only as spécifically approved by the responsible program division.

\section{Recommended Announcement:}

Q. Normal procedure may be followed.

$\square$ b. Recommend following announcement limitations:

\section{Reason for Restrictions Recommended in 5. or 6. above:}

\section{$\frac{1}{\left.8 ; \text { Patent Clearance: (Check } a_{\text {. or }} b_{0}\right)}$ \\ Q $a$. AEC patent clearance has been granted by responsible AEC patent group. \\ Ub. Report has been sent to responsible AEC patent group for clearance.}

9. Defense Information: (For classified information product only.

$\square$ a. does

Report

Db. does not

contain defense information other than restricted data.

10. Addicional information or remarks.

-

11. Submitted by:

Alvin Glassner

Name and position (Please print or type)

Chief Editor

Organization Technical Publications Department

Argonne National Laboratory

Signature

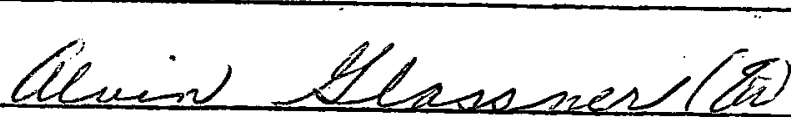

Date

September 26,1968 
